\title{
LOW CYCLE FATIGUE BEHAVIOR OF CONCRETE WITH RECYCLED CONCRETE AGGREGATES
}

\author{
A Thesis \\ presented to \\ the Faculty of California Polytechnic State University, \\ San Luis Obispo
}

In Partial Fulfillment

of the Requirements for the Degree

Master of Science in Civil and Environmental Engineering

by

Paul Mark Gordon

June 2011 
(C) 2011

Paul Mark Gordon

ALL RIGHTS RESERVED

ii 


\section{Committee Membership}

TITLE:

AUTHOR:

DATE SUBMITTED:

COMMITTEE CHAIR:

COMMITTEE MEMBER:

COMMITTEE MEMBER:
Low Cycle Fatigue Behavior of Concrete with

Recycled Concrete Aggregates

Paul Mark Gordon

June 17, 2011

Daniel C. Jansen, Associate Professor

Charles Chadwell, Assistant Professor

Bing Qu, Assistant Professor 


\section{Abstract}

Low Cycle Fatigue Behavior of Concrete with Recycled Concrete Aggregates Paul Mark Gordon

A comparison of concrete containing recycled concrete coarse aggregates and natural coarse aggregates subjected to high strain, low cycle compressive fatigue is presented. Using a strain based feedback control loop, concrete cylinders are compressed at $15 \mu \varepsilon / \mathrm{s}$ to a specified strain then unloaded to zero stress for 10 cycles. After cycling, all samples are loaded to a strain of 0.008 . Direct concrete material variables are the water to cement $(\mathrm{w} / \mathrm{c})$ ratio, taken as $0.60,0.45$, and 0.39 , and percent coarse recycled concrete aggregate content, varied from 0 to $100 \%$. The primary testing variable is the specified unloading strain. Unloading strains include $60,75,90,100$, and 120 percent of the strain at peak stress. Ten batches of concrete were made, generating a total of 224 samples for testing. Findings confirm previous research showing a reduction in strength with increasing recycled concrete coarse aggregate content, an equivalent concrete with only $25 \%$ replacement of natural coarse aggregates and an equivalent strength concrete with a decrease in the $\mathrm{w} / \mathrm{c}$ ratio and $100 \%$ recycled concrete coarse aggregates. Fatigue testing indicates that each cycle's maximum stress remains unchanged, but the stiffness degrades more rapidly with increasing recycled aggregate content and a constant $w / c$ ratio.

Keywords: compressive strength; elastic modulus; energy dissipation; fatigue; low cycle fatigue; recycled concrete; sustainability; stiffness; stress strain; 


\section{Acknowledgements}

This thesis would not have been possible without the generous donation of commercially produced recycled concrete coarse aggregates by Lehigh Hansen. The natural aggregates, cement and facilities needed for testing were provided by California Polytechnic State University, San Luis Obispo.

I would like to thank my advisor, Daniel Jansen, whose encouragement, guidance and support from initial ideas to the conclusion of this thesis have provided anchorage and a sounding board for the many evolutions of this project. You have given me an appreciation for the depth of knowledge required to truly understand materials in engineering and have shown me that concrete can be and is so much more than just a strength specified in a design.

Special thanks to Civil Engineering graduate students Brett Schoppe, Jeff Blanchette and the many other students who helped with concrete production and testing. Overall, the guidance provided by faculty at California Polytechnic State University, San Luis Obispo and the assistance provided by staff were invaluable in the completion of this thesis. 


\section{Table of Contents}

List of Tables .................................................................................................... viii

List of Figures........................................................................................................................ix

CHAPTER $1 \quad$ Introduction ............................................................................................

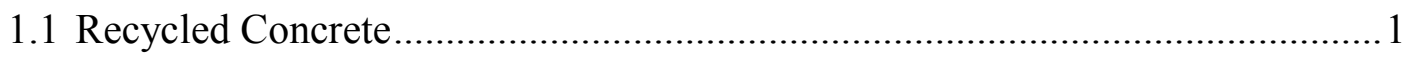

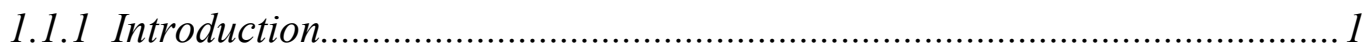

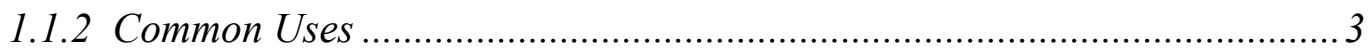

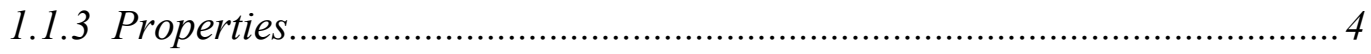

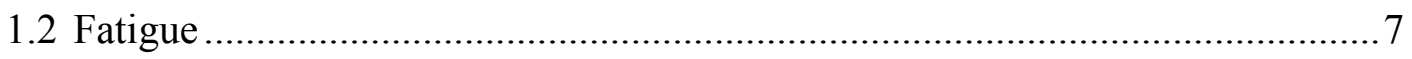

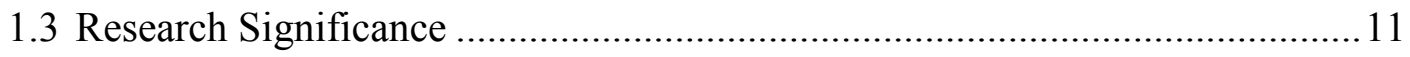

CHAPTER 2 Experimental Investigation........................................................12

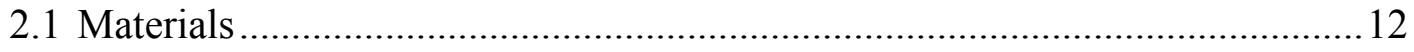

2.2 Specimens

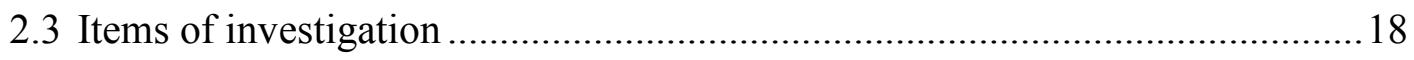

2.3.1 Stress Controlled Compression.............................................................. 19

2.3.2 Strain Controlled Compression ...........................................................20

CHAPTER 3 Analysis and Results.......................................................................26

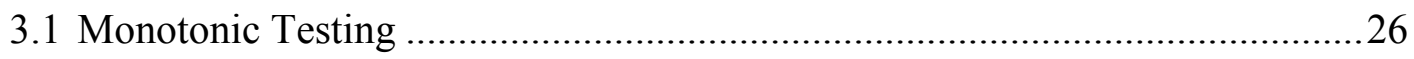

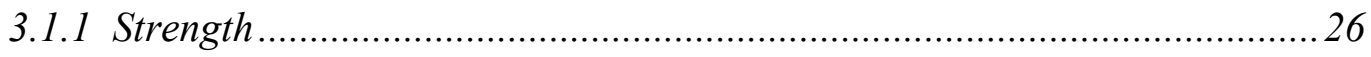




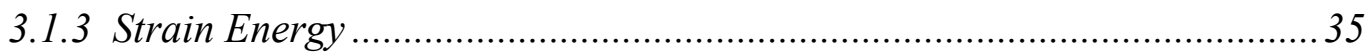

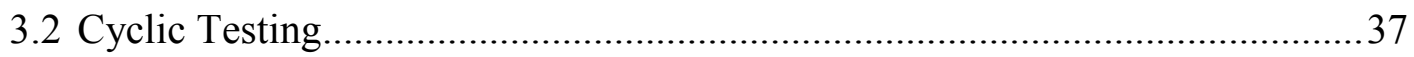

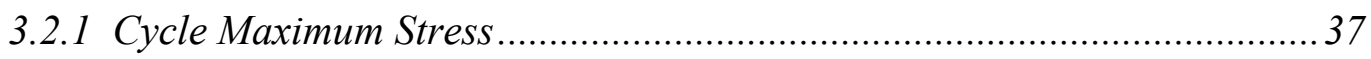

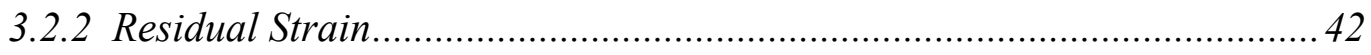

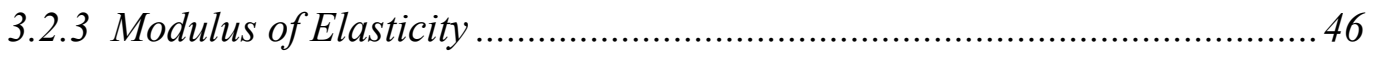

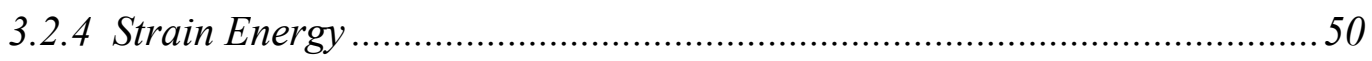

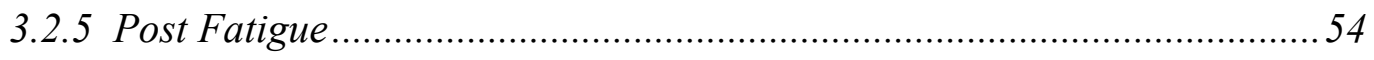

CHAPTER 4 Conclusions...............................................................................58

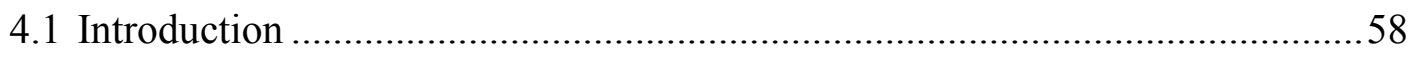

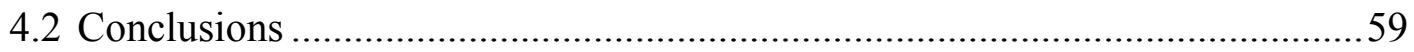

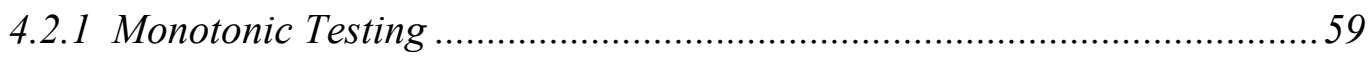

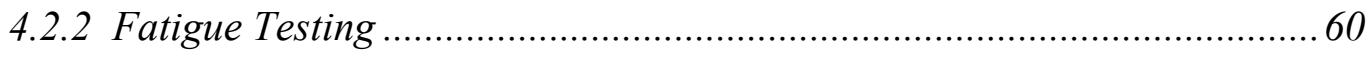

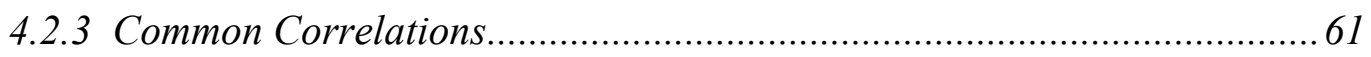

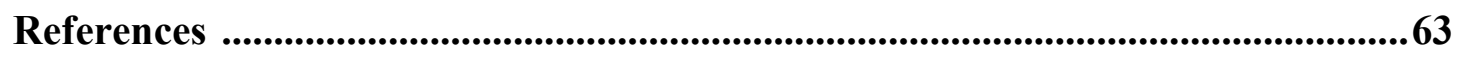

Appendix A Notation ........................................................................................66

Appendix B Residual Mortar Content..................................................................69

Appendix C Stiffness Degradation .........................................................................70

Appendix D Batch Records .................................................................................... 73 


\section{List of Tables}

Table 2.1 - Aggregate properties ............................................................................ 14

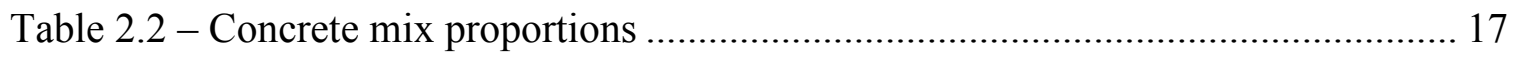

Table 3.1 - Mechanical properties of hardened concrete ............................................ 26

Table 3.2 - Dissipated strain energy from monotonic loading ..................................... 52

Table 3.3 - Stresses at strains of 0.005 and 0.008 from monotonic testing..................... 55

Table B 1 - Residual mortar content - raw data.................................................... 69 


\section{List of Figures}

Figure 1.1 - Fatigue loading: (A) fixed stress (Otter and Naaman 1988), (B) fixed strain and (C) incremental strain (Maher and Darwin 1989)................................ 9

Figure 2.1 - (A) recycled concrete, (B) crushed granite and (C) fine aggregate.............. 13

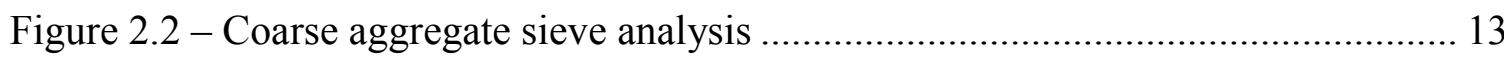

Figure 2.3 - Test machine setup ........................................................................... 19

Figure 2.4 - Stress strain terminology: (A) monotonic testing and (B) cyclic testing ..... 21

Figure 2.5 - Strain controlled compression test setup ………........................................ 22

Figure 2.6 - Strains measured with LVDTs and extensometers..................................... 23

Figure 2.7 - Stress strain curves from cyclic and monotonic testing $(0.60-100)$............. 25

Figure 3.1 - Concrete compressive strength with different aggregate replacements ....... 27

Figure 3.2 - Concrete compressive strength variation as a function of $w / c$ ratio............. 29

Figure 3.3 - Concrete compressive strength from stress controlled loading, $\mathrm{f}_{\mathrm{c}}$, and

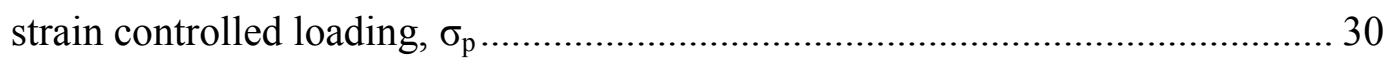

Figure 3.4 - The influence of the density on concrete's compressive strength ................. 31

Figure 3.5 - Concrete's elastic modulus with different aggregate replacements ............. 33

Figure 3.6 - Strain energy calculation from monotonic testing..................................... 35

Figure 3.7 - Strain energy variation with ultimate stress from monotonic testing........... 36

Figure 3.8 - Percent change in max cycle stresses with curve fit $(0.39-100) \ldots \ldots \ldots \ldots \ldots \ldots . . . .38$

Figure $3.9-b$ coefficient variation with changing w/c ratio: (A) natural aggregate and (B) recycled concrete aggregate. 
Figure $3.10-b$ coefficient variation with changing recycled aggregate content

Figure 3.11 - Residual strains of concrete with the same w/c ratio

Figure 3.12 - Residual strains of concrete with changing w/c ratio (all aggregate replacements) 45

Figure 3.13 - Percent change in each cycle's stiffness with curve fit $(0.45-50)$ 47

Figure 3.14 - Variation of the $a$ coefficient with respect to the $b$ coefficient 48

Figure 3.15 - Behavior of the $a$ coefficient for concrete with 0 and $25 \%$ recycled concrete aggregates 49

Figure 3.16 - Energy dissipation in one cycle..... 51

Figure 3.17 - Dissipated strain energy due to cycling: (A) natural aggregate, (B) 50\% recycled concrete and (C) 100\% recycled concrete. 53

Figure 3.18 - Post cycling dissipated strain energy 56

Figure 3.19 - Stresses at strains of 0.005 and 0.008 for 0,50 , and $100 \%$ recycled aggregate replacements

Figure C 1 - Comparison of stiffness degradation with varying w/c ratio: (A) natural aggregate and (B) recycled concrete aggregate 70

Figure C 2 - Comparison of stiffness degradation with changing recycled concrete aggregate content. The w/c ratio remains the same within each graph. 71

Figure C 3 - Stiffness degradation for concretes with the same strength but different aggregates. 


\subsection{Recycled Concrete}

\subsubsection{Introduction}

In 2009, the U.S. Geological Survey's (USGS) Minerals Yearbook estimates that 1.17 billion metric tons of crushed stone was produced for use as an aggregate in the United States (Willett 2009). In that same year, the USGS estimates that 49 states produced 13 million metric tons of recycled concrete aggregates, only $1.1 \%$ of the total crushed stone production (Willett 2009). While comprising only a small fraction of the total crushed stone production, recycled concrete aggregate production in 2009 saw a 225\% increase from the 2003 estimate of four million metric tons (Sandler 2003; Willett 2009). In 2003 the estimated contribution of waste concrete to the construction and demolition waste stream was 181 million metric tons (Sandler 2003). With only a small fraction of the available waste concrete being recycled and a large demand for crushed stone as an aggregate, waste concrete remains a relatively untapped resource for use as an aggregate in new construction. Increased usage of waste concrete as a construction material will help to sustain the current concrete construction industry and will enable more responsible utilization of natural aggregate resources today and in the future. 
Along with preserving natural aggregate resources, recycling waste concrete conserves limited urban landfill space and reduces costs associated with the disposal of waste concrete (Hansen 1986; Hansen 1992; Tabsh and Abdelfatah 2009; Zega et al. 2009). Frondistou-Yannas (as cited in Hansen 1992) proposes that economics may eventually be a driving force for the usage of recycled concrete aggregates, particularly as the availability of natural aggregates and dumping sites in some areas decrease. While economics may be a large motivation for using recycled concrete aggregates in the future, today, governments worldwide are reducing their dependence on principal resources with policies aimed at growing recycling and material recovery (Hansen 1992). Even with government incentives, the use of recycled concrete in new applications will be restricted without increased efforts to create a better awareness of the limitations associated with its use and the establishment of clear specifications for its safe and responsible implementation into society (Rao et al. 2007).

Using waste concrete as an aggregate in structural concrete increases the recycled concrete aggregate's value. At present, recycled concrete is commonly used as base course and drainage rock, and, to stay competitive, manufacturers charge a price appropriate for these low value applications, approximately $\$ 5$ per ton. Many times the recycled aggregate sold at this price has a much higher quality than the aggregate typically used in these applications. Increasing the use of recycled concrete aggregates in new concrete creates a demand for higher quality waste concrete products and provides incentives for the recycling of concrete waste which, when appropriately used in structural applications, could be sold at a higher price, approximately $\$ 20$ per ton. 
When recycled coarse aggregates are used in a new concrete, some economic deterrents may arise. With increasing recycled coarse aggregate content, a batch's cement portion is often increased to make up for deficiencies in strength often seen with the use of recycled concrete aggregates. Since cement is the most expensive constituent in concrete, the cost of concrete made with recycled aggregates may be inherently higher than that of most natural aggregate concretes.

\subsubsection{Common Uses}

Waste concrete is used in a broad range of applications. Hardened concrete, with no stipulations as to its performance, has the potential for use in any application where natural stone is currently used. The Construction Materials Recycling Association has identified many of the major markets where waste concrete has been effectively utilized.

The primary markets for recycled concrete come from the crushing of waste concrete into an aggregate. This recycled concrete aggregate is often used as an untreated sub-base or base course which provides a foundation for highway pavements. Another common use of recycled concrete aggregate is as pipe bedding. Recycled concrete aggregates are often used in applications such as pipe bedding and highway base courses because they provide some economic benefit, are readily available and are accepted as performing adequately for those purposes. Landscaping is another application where waste concrete has been used with good success. This may take to form of erosion control, block walls, architectural features, walkways, among other things. (Construction Materials Recycling Association 2011) 
Apart from use as a loose aggregate, recycled concrete aggregates can be used in ready mix concrete. The production of recycled concrete aggregate for use in new concrete, a higher level application, is more difficult than the production of aggregate for lower level applications because the aggregate must be of a higher quality, suitable for its use in the new concrete. This involves a greater level of quality control, rejecting extraneous materials in the aggregate such as wood, sheetrock and asphalt.

In order for recycled concrete aggregates to be used in structural concrete, the waste concrete source should be controlled, as the properties of the original concrete have been shown to affect the new concrete's properties. Ideally, recycled concrete aggregates for use in structural concrete would come from a large source of waste concrete, such as airport runways, where there is a lasting supply and consistent waste concrete properties. Recycled aggregates should also be initially tested in new concrete to determine the strength and quality of concrete achievable from the established source. This is already done with natural aggregates from a new source. Recycled concrete aggregates come from small, highly variable sources, so quality control presents a daunting challenge.

\subsubsection{Properties}

When recycled concrete aggregates replace natural aggregates in new concrete, the concrete will be identified as recycled aggregate concrete for all replacements. In the past, a great deal of work has been done to determine the properties of recycled concrete aggregates and recycled aggregate concrete. The impact of using recycled concrete aggregates on the fresh and hardened properties of concrete follows distinct trends seen in the extensive research involving recycled concrete aggregates. 
It is well established in the literature that aggregates obtained from crushed concrete have higher water absorption capacities, lower bulk specific gravities (Limbachiya et al. 2000; Tavakoli and Soroushian 1996; Topçu and Guncan 1995) and higher losses associated with durability tests such as Los Angeles abrasion and sulfate soundness when compared to commonly used natural aggregates (Hansen and Narud 1983; Sagoe-Crentsil et al. 2001; Tabsh and Abdelfatah 2009; Topçu and Sengel 2004). The differences in aggregate properties are primarily the result of residual mortar attached to the original natural aggregates after crushing (Hansen and Narud 1983; Hansen 1992; Yang et al. 2008; Shayan and Xu 2003). The residual mortar fraction of recycled concrete aggregates has been reported to range from $20-40 \%$ by volume or weight, depending on the size fraction investigated, and the attached residual mortar tends to increase as the aggregate particle size decreases (Abdelgadir et al. 2007; Hansen et al. 1983; Topçu and Sengel 2004).

The fresh and hardened properties of recycled aggregate concrete are also altered by recycled concrete aggregates. It has been shown that the workability of recycled aggregate concrete is reduced due to the high absorption capacity, rough texture and angularity of recycled concrete aggregates (Anderson et al. 2009; Topçu and Guncan 1995). This angularity and roughness, often seen in laboratory produced aggregates, is significantly reduced when the aggregates are commercially produced (Sagoe-Crentsil et al. 2001).

Hardened recycled aggregate concrete often has a lower compressive strength than natural aggregate concrete, dropping as much as $50 \%$ but more commonly $5-10 \%$ (as cited in Hansen 1992). Other research has repeatedly shown up to a $25 \%$ decrease in 
compressive strength of concrete containing natural sand and recycled concrete coarse aggregates (Anderson et al. 2009; Etexeberria et al. 2007; Katz, 2003; Tabsh and Abdelfatah 2009). The elastic modulus of new concrete also typically decreases with the inclusion of recycled concrete aggregates (Anderson et al. 2009; Katz 2003; Yang et al. 2008).

Wide variability is found in the physical properties reported for recycled aggregate concrete. This is due to the large influence that the w/c ratio and natural aggregate of recycled concrete aggregate's source concrete has on the mechanical properties of recycled aggregate concrete (Ajdukiewicz and Kliszczewicz 2002; Hansen and Narud 1983; Tavakoli and Soroushian 1996; Zega et al., 2009). Ajdukiewicz and Kliszczewicz (2002) and Tavakoli and Soroushian (1996) have shown that it is possible to obtain recycled aggregate concrete with a higher strength than a natural aggregate concrete. The greater strength was caused by a low w/c ratio in the recycled concrete aggregate's source concrete compared to the w/c ratio in the new concrete. This shows that a high strength source concrete can give a higher strength recycled aggregate concrete when compared with concrete having the same w/c ratio.

Equivalent strength and a more comparable elastic modulus in concrete made with recycled concrete aggregates can be obtained by decreasing the new concrete's w/c ratio (Hansen and Narud 1983; Limbachiya et al. 2000). The required decrease in w/c ratio depends on the properties of the recycled concrete aggregate's source concrete. While this is an effective way to achieve higher quality recycled aggregate concrete, it diminishes some of the economic benefits associated with the use of recycled concrete aggregates (Etxeberria et al. 2007). 
As an alternative to $100 \%$ replacement of natural aggregates, a concrete can be made with only replacing a fraction of the natural aggregates. Concrete made with natural sand and up to a $30 \%$ replacement of the natural coarse aggregates with recycled concrete aggregates exhibits the same mechanical properties as those found in natural aggregate concrete made with the same w/c ratio (Etxeberria et al. 2007; Koulouris et al. 2004; Limbachiya et al. 2000).

\subsection{Fatigue}

In general, fatigue is the process of permanent, progressive internal structural damage induced by repeated loading (Hsu 1981). Each successive load applied to the structure acts on a damaged or altered material structure, and the result of this damage accumulation is the degradation of material properties, such as strength and elastic modulus, and reduced performance of the structure (Milenkovic and Pluis 2000). Structures experience a wide array of fatigue loadings depending on their location and function. Hsu (1981) divided theses loadings into three categories consisting of superhigh $\left(10^{6}\right.$ to $500 \times 10^{6}$ cycles $)$, high $\left(10^{3}\right.$ to $10^{6}$ cycles $)$ and low cycle ( 1 to 1000 cycles) fatigue. Super high cycle fatigue is typically the result of mass rapid transit systems, machine vibrations or sea waves. High cycle fatigue loading often comes from automobile traffic on bridges and pavements, railway traffic on bridges and concrete ties, or planes on airport pavements (Hsu 1981). Low cycle fatigue is more commonly the result of seismic loading which often induces high stresses and strains in a structural material (Lee and Barr 2004). 
Cyclic loadings to a specified stress, specified strain or with incremental strains are three common methods of compressive fatigue testing. An example of each can be seen in Figure 1.1. Loading to a specified stress, seen in Figure $1.1 \mathrm{~A}$, is the most common of the three loading types and typically models high cycle fatigue from automobile traffic. Fixed stress cycling usually deals with stresses that are substantially lower than the concrete material's peak stress. The resulting data is given in an S-N curve or Wohler diagram where the number of cycles to failure is plotted with respect to the maximum stress at cycling. Fatigue loading to a fixed strain, seen in Figure 1.1 B, is less common and has been used to observe concrete damage with cyclic loading in the post peak region of the stress strain curve. Fixed strain loading is typically done to model low cycle fatigue, and little or no investigation has been done past about 40 cycles. Cyclic loading with incremental strains, seen in Figure 1.1 C, also can be used to look at fatigue damage at strains greater than the strain at peak stress but is different from fixed strain testing in that only one loading cycle is completed at each specified strain.

Since a typical reinforced concrete member resists loading through a moment couple consisting of concrete which takes compression and steel rebar which takes tension, typical fatigue failure of structural concrete members occurs due to compressive fatigue in the concrete or tensile fatigue in the rebar (Hsu 1981). Because of this, early reinforced concrete fatigue testing focused on the compressive fatigue of concrete and the tensile fatigue of steel. Flexural fatigue testing, dealing with the modulus of rupture, became more prevalent with the increased use of unreinforced concrete in highways where concrete must take compression and tension (Lee and Barr 2004). Most flexural fatigue testing focused on the high-cycle, low stress behavior of concrete. 

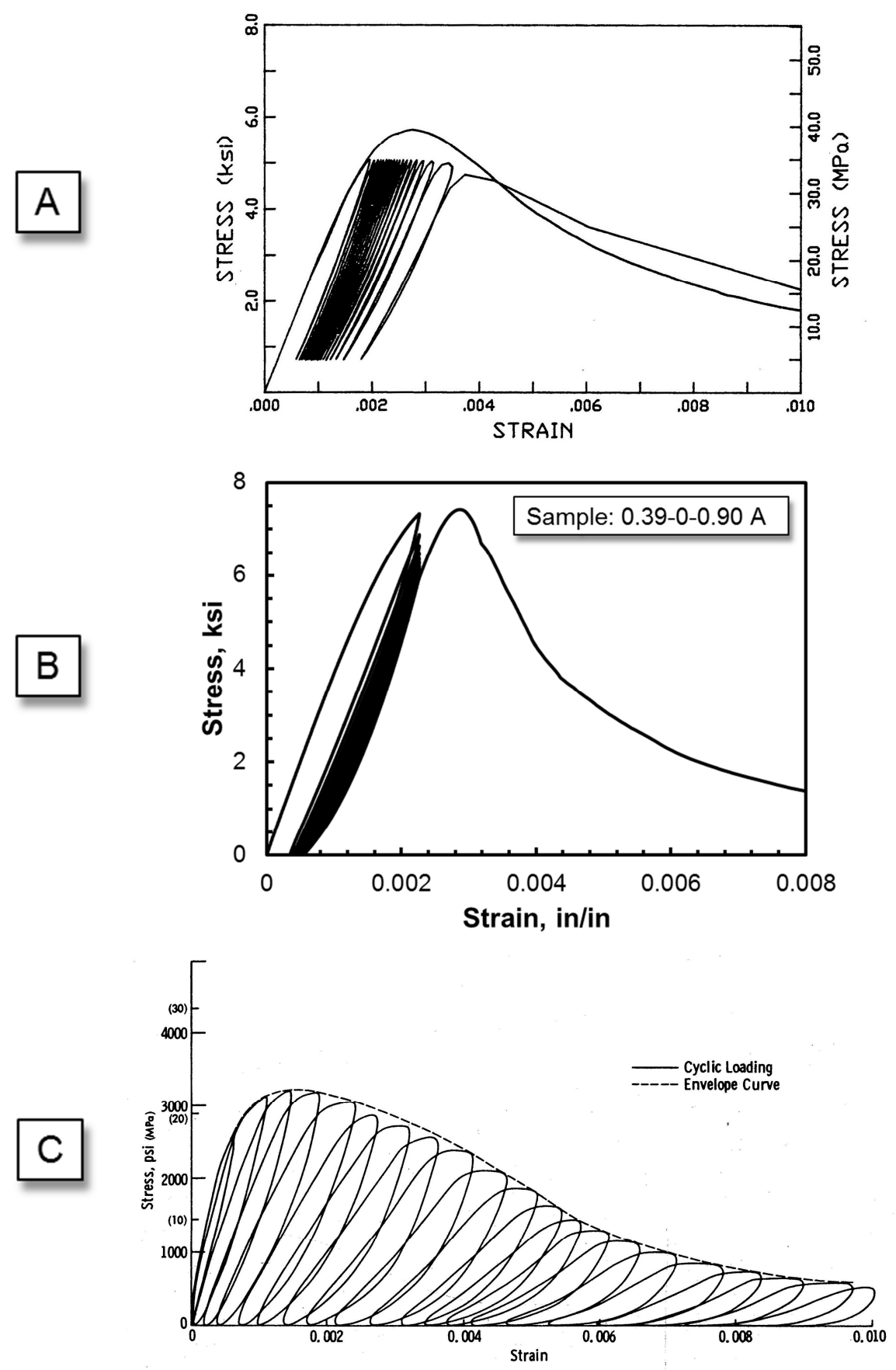

Figure 1.1 - Fatigue loading: (A) fixed stress (Otter and Naaman 1988), (B) fixed strain and (C) incremental strain (Maher and Darwin 1989).

When structures are subjected to an earthquake, they experience few cycles, and the structural materials may experience much higher stresses and strains than are 
typically seen with standard cyclic loading. Low cycle fatigue testing is meant to investigate the damage done to a material by inducing these high stresses and strains.

To observe the behavior of concrete subjected to these high strains, cyclic testing of plain and fiber reinforced concrete samples is often done under displacement control (Maher and Darwin 1989; Mu et al. 2004; Otter and Naaman 1988; Sinha et al. 1964). This allows testing of the specimen in the post peak region of the stress strain curve and has shown that fatigue of concrete subjected to pre and post-peak cyclic loading can be bound by the monotonic stress strain curve with what is termed the envelope curve when dealing with fatigue loading (Mu et al. 2004; Otter and Naaman 1988).

The envelope curve was found to define failure of concrete under fixed stress and fixed strain cyclic loading and is typically reached through the accumulation of residual strains from repeated loading to a fixed stress without the concrete ever reaching its maximum compressive stress (Otter and Naaman 1988). Alternatively, Maher and Darwin (1989) and Sinha et al. found that an envelope curve, created through cyclic loading with incremental strains, does not correspond with the monotonic stress strain curve. Maher and Darwin (1989) proved that the envelope curve even varies between different loading schemes in a cementitious material and suggested that this may be due to creep from the varying periods of time concrete is held under load with different fatigue testing programs.

Concrete cyclically loaded to a specified strain, seen in Figure 1.1 B, will never reach the monotonic stress strain curve with continued cyclic loading and should not experience failure traditionally seen with loading to a specified stress. The peak stress of each cycle with loading to a specified strain decreases. This is primarily due to a 
reduction in the concrete's stiffness and an increase in its residual strain. Accumulation of damage decreases with each successive cycle leading to what could be a shakedown limit. A shakedown limit in fatigue testing occurs in a material when there is no increase in residual strain with continued loading (Sinha et al. 1964). With cyclic loading to specified strains, a shakedown limit was not found by Maher and Darwin (1989) with testing up to 42 cycles to a strain of 0.004 . It was found that decreases in the concrete's stiffness stabilized with continued cycling, but the strength and strain continued to degrade. This degradation was determined to be a result of time dependent deformations or creep in the concrete (Maher and Darwin 1989).

\subsection{Research Significance}

In recent years an increased effort has been directed toward demonstrating that the recycling of concrete can produce quality aggregates suitable for re-use in structural grade concrete. This study presents the effect of low cycle, high strain fatigue on the strength, stiffness and energy dissipation of concrete made with recycled concrete aggregates. Knowing how recycled aggregate concrete performs when subjected to cyclic loading at high stresses and strains, many times seen with earthquakes, is vital to integration of these aggregates into structural design. This work presents an original view of the performance of recycled aggregate concrete subjected to these extreme loadings and helps to form a more complete understanding of the appropriate uses and limitations of recycled concrete aggregates used in structural applications. 


\section{CHAPTER 2 Experimental Investigation}

\subsection{Materials}

All concrete was produced with ASTM type II/V ordinary portland cement. Crushed granite was used as the natural coarse aggregate, and recycled coarse aggregates came from crushed concrete that was commercially produced by Lehigh Hansen, located in San Diego California. In the literature, fine recycled concrete aggregate has been found to significantly decrease the workability of fresh concrete and considerably reduces the strength and elastic modulus of concrete (Ajdukiewicz and Kliszczewicz 2002; Shayan and $\mathrm{Xu}$ 2003; Yang et al. 2008). Shayan and $\mathrm{Xu}$ (2003) proposed the restriction of fine recycled concrete aggregates in new concrete to $50 \%$ of the fine aggregate fraction in order to obtain a better concrete. Yang et al. (2008) found that concrete with $100 \%$ coarse and fine recycled aggregates experienced a $60-80 \%$ reduction in its compressive strength, but only a $20-40 \%$ reduction in strength with just course recycled aggregate replacement. 


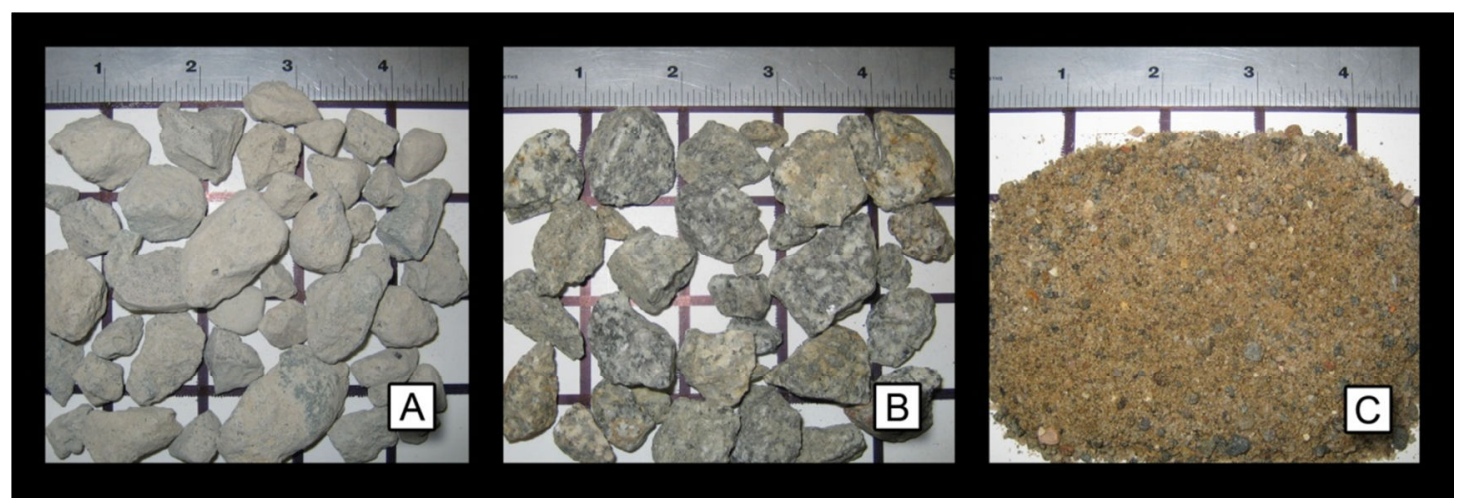

Figure 2.1 - (A) recycled concrete, (B) crushed granite and (C) fine aggregate

Due to increased variability and reduced compressive strength seen with using fine recycled concrete aggregates, sand was used as the fine aggregate for both the natural aggregate and the recycled aggregate concretes. Figure 2.1 shows the three different types of aggregates used and the composite nature of recycled concrete coarse aggregate. The recycled concrete coarse aggregates and the crushed granite coarse aggregates had very similar gradations, seen in Figure 2.2, adequately fitting to ASTM C33 (2007) size 56 gradation limits.

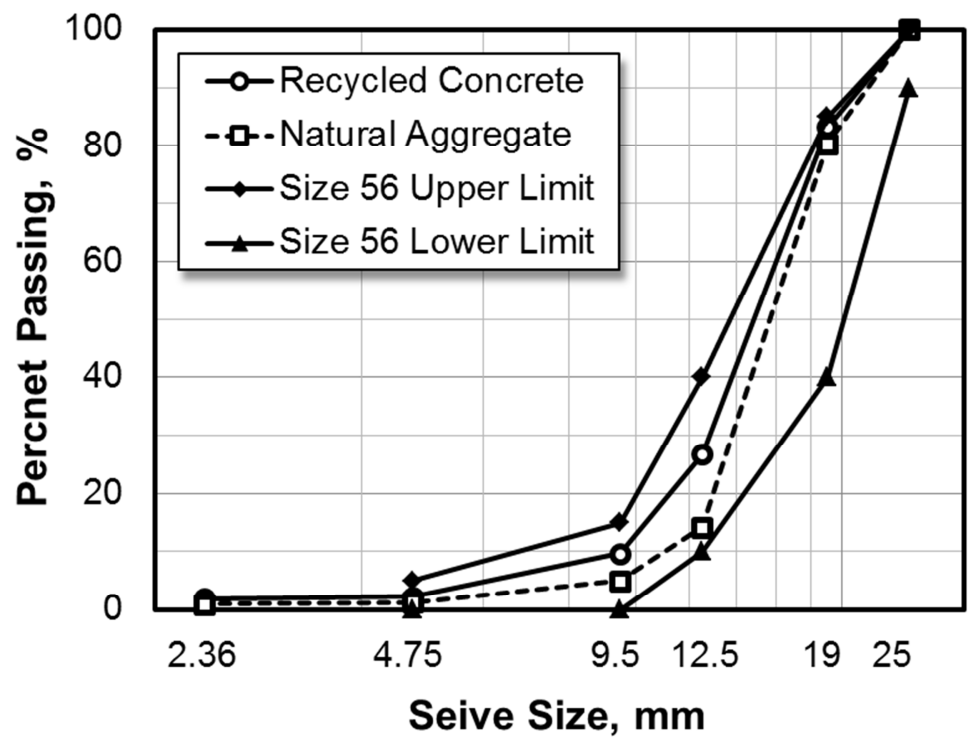

Figure 2.2 - Coarse aggregate sieve analysis 
Previous research shows that recycled concrete aggregates have a much higher absorption capacity, from 5-10\%, and lower specific gravity, ranging from 2.1-2.4, than natural aggregates due to the presence of air voids in the residual mortar attached to the original natural aggregates after crushing (Hansen 1992). As seen in Table 2.1, the crushed granite coarse aggregates had an absorption capacity of $1.4 \%$, and the recycled concrete coarse aggregates had an absorption capacity of $4.9 \%$. When compared to absorption capacities commonly found in literature, the recycle concrete coarse aggregate's relatively low absorption capacity indicates that the source concrete had a low air void content in its mortar and a dense natural aggregate. The recycled concrete coarse aggregate also had a relatively high specific gravity compared to those found in the literature. This is another indication of the high quality and dense nature of these recycled concrete aggregates compared to those found in literature.

\section{Table 2.1 - Aggregate properties}

\begin{tabular}{lcccc}
\hline \hline \multicolumn{1}{c}{ Aggregate } & $\begin{array}{c}\text { Nominal Size } \\
\text { (ASTM C33) }\end{array}$ & $\begin{array}{c}\text { Specific } \\
\text { Gravity }\end{array}$ & $\begin{array}{c}\text { Absorption, } \\
\text { \% }\end{array}$ & $\begin{array}{c}\text { Residual } \\
\text { Mortar, \% }\end{array}$ \\
\hline \hline Crushed Granite & 1" to 3/8" & 2.61 & 1.4 & - \\
\hline Recycled Concrete & 1" to 3/8" & 2.47 & 4.9 & $33.9 \pm 1.4$ \\
\hline Fine Aggregate & - & 2.56 & 2.2 & - \\
\hline \hline $1 "=2.54 \mathrm{~cm}$ & & & &
\end{tabular}

The cement paste attached to the original natural aggregates in recycled concrete aggregate is called residual mortar. Many different methods have been used to determine the residual mortar content of recycled concrete aggregates. Methods that report the mortar content by volume typically involve a visual determination of the residual mortar percentage. Hansen and Narud (1983) found the residual mortar content by cutting cubes 
into slices and using the linear traverse method in a similar manner to the method described in ASTM C597 (2007). Visual determination of residual mortar content was also done by Abdelgadir et al. (2010). A close correlation was found between image analysis and the test method used in this study which involves the removal of the recycled aggregate's residual mortar (Abdelgadir et al. 2010).

Test methods that report the residual mortar content by mass typically involve the removal of the attached mortar. One such method, originally proposed by Kasami et al., uses a hydrochloric acid solution to disintegrate the residual mortar (as cited in Yang et al. 2008). A hydrochloric acid solution has also been used in a Japanese investigation to determine the residual mortar content (as cited in Hansen 1986) as well as by Zega et al. (2009). Another method of residual mortar removal, used by Sánchez and Gutiérrez (2008), involves heating recycled concrete aggregates to $932^{\circ} \mathrm{F}\left(500^{\circ} \mathrm{C}\right)$ then rapidly cooling them in water. This rapid cooling induces cracks in the mortar and allows for its removal.

The method used in this study was proposed by Abdelgadir et al. (2010) and involves submersion of the recycled concrete aggregate in a sodium sulfate solution for 24 hours then exposing the aggregates and solution to five freeze thaw cycles. The aggregates are then drained and washed on a \#4 sieve. The residual mortar content is calculated by the following expression:

$$
R M C=\frac{\left(W_{R C A}-W_{O V A}\right)}{W_{R C A}}
$$


where $\mathrm{RMC}$ is the residual mortar content as a percent, $\mathrm{W}_{\mathrm{RCA}}$ is the weight of the recycled coarse aggregate prior to removal of the residual mortar and $\mathrm{W}_{\text {OVA }}$ is the weight of the original aggregates after the residual mortar has been removed. All aggregates were weighed in the oven dry state. Following the above procedure, six samples were tested, seen in Appendix B Table B1, and an average residual mortar content of $33.9 \%$, seen in Table 2.1, was determined for the complete gradation of coarse aggregates. This falls into the range of residual mortar contents found in literature, typically $20-40 \%$ (Abdelgadir et al. 2007).

\subsection{Specimens}

Three w/c ratios, consisting of $0.60,0.45$, and 0.39 , and five natural aggregate replacements of $0,25,50,75$ and $100 \%$ by volume were varied between batches of concrete. Ten concrete batches were made with a total of 224 concrete samples created for testing. Batch designations, seen in Table 2.2, describe each concrete mix's w/c ratio and the percent of recycled concrete coarse aggregates, by volume, which replaced natural coarse aggregates. For example, the batch designated $0.45-50$ has a w/c ratio of 0.45 and a recycled concrete coarse aggregate content of $50 \%$ by volume. The volume fraction of coarse aggregates and water was held constant across all batches. To change a batch's w/c ratio, the cement content was altered in a similar manner to that done by Koulouris et al. (2004). This would cause a change in the total mortar volume but was compensated for by altering the fine aggregate portion in the mix design.

Due to the high absorption capacity of recycled concrete aggregates, it is essential to determine their moisture content and adjust the concrete mix's water content to ensure 
accurate free water in the concrete's mortar (Etxeberria et al. 2007; Hansen 1992; Rakshvir and Barai 2006). To control the moisture content of all aggregates, they were sampled one day prior to batching to determine their moisture content and placed in sealed buckets. Each batch's water content was adjusted before batching to account for aggregate moisture content.

Table 2.2 - Concrete mix proportions

\begin{tabular}{|c|c|c|c|c|c|c|c|c|}
\hline \multirow{2}{*}{$\begin{array}{c}\text { Water/ } \\
\text { Cement } \\
\text { Ratio }\end{array}$} & \multirow{2}{*}{$\begin{array}{c}\text { Recycled } \\
\text { Concrete, } \\
\%\end{array}$} & \multirow{2}{*}{$\begin{array}{c}\text { Batch } \\
\text { Designation, } \\
\text { w/c-\%RCA }\end{array}$} & \multirow{2}{*}{$\begin{array}{c}\text { Air } \\
\text { Content, } \\
\% \\
\end{array}$} & \multicolumn{5}{|c|}{ SSD Weights, lb/yd ${ }^{3}$} \\
\hline & & & & Cement & Water & $\begin{array}{c}\text { Fine } \\
\text { Aggregate }\end{array}$ & $\begin{array}{l}\text { Crushed } \\
\text { Granite }\end{array}$ & $\begin{array}{l}\text { Recycled } \\
\text { Concrete }\end{array}$ \\
\hline \multirow{2}{*}{0.39} & 0 & $0.39-0$ & 1.3 & 833 & 325 & 1147 & 1634 & 0 \\
\hline & 100 & $0.39-100$ & 1.3 & 832 & 325 & 1147 & 0 & 1545 \\
\hline \multirow{5}{*}{0.45} & 0 & $0.45-0$ & 1.9 & 717 & 323 & 1230 & 1623 & 0 \\
\hline & 25 & $0.45-25$ & 1.0 & 724 & 326 & 1241 & 1229 & 388 \\
\hline & 50 & $0.45-50$ & 2.4 & 713 & 321 & 1224 & 808 & 764 \\
\hline & 75 & $0.45-75$ & 1.5 & 720 & 324 & 1236 & 408 & 1157 \\
\hline & 100 & $0.45-100$ & 1.7 & 718 & 323 & 1232 & 0 & 1539 \\
\hline \multirow{3}{*}{0.60} & 0 & $0.60-0$ & 3.0 & 532 & 319 & 1361 & 1606 & 0 \\
\hline & 50 & $0.60-50$ & 1.3 & 541 & 325 & 1384 & 817 & 773 \\
\hline & 100 & $0.60-100$ & 1.6 & 539 & 324 & 1380 & 0 & 1541 \\
\hline
\end{tabular}

$1 \mathrm{lb} / \mathrm{yd}^{3}=5.818 \mathrm{~N} / \mathrm{m}^{3}$

Concrete was mixed in a nine cubic foot polyethylene drum-type mixer. All aggregates were initially mixed with half of the required water, and the aggregate-water mixture was allowed to soak for 10 minutes prior to addition of the remaining batch components. The cement and remaining water were then added and mixed. To obtain a target slump of six to eight inches, an ASTM C494 (2007) compliant polymeric superplasticizer was added. After achieving the desired slump, the unit weight of the fresh concrete was determined in accordance with ASTM C143 (2007). Concrete was 
then placed in $4 \times 8$ inch $(102 \times 203 \mathrm{~mm})$ plastic cylinder molds and compacted using a rod and mallet following ASTM C192 (2007) specifications for consolidation of concrete. Finished cylinders were covered with a plastic sheet to reduce surface evaporation while curing in the molds.

After $24 \pm 8$ hours, samples were removed from the molds and placed in a moist curing room until testing. Before testing, the average diameter and length of all cylinders was determined with a caliper, and the unit weight of each cylinder was calculated using each sample's buoyant and dry weight. All samples were capped not more than a week before testing with a high strength sulfur compound following specifications in ASTM C617 (2007). A sulfur capping compound was used due to its ability to give consistent results with high strength concrete $\left(\mathrm{f}_{\mathrm{c}}>10,000\right.$ psi $(70 \mathrm{MPa})$ ) (Carrasquillo and Carrasquillo 1987). Even though high strength concrete was not tested, sulfur capping gave us the option to test higher strength concrete while keeping the capping type consistent between batches.

\subsection{Items of investigation}

The concrete's compressive strength was determined with both stress and strain controlled testing. Investigations pertaining to the effect of recycled aggregate replacement on the fatigue of concrete explored changes in the maximum stress of each cycle, initial residual strain, elastic modulus or stiffness of each cycle, total energy dissipated as a result of cycling and post fatigue loading behavior. Testing occurred at 28 days \pm 20 hours in accordance with ASTM C39 (2007). All samples were tested with a 110 kip $(500 \mathrm{KN})$ servo-hydraulic test machine. A series 505 Silentflo hydraulic power 
unit provided the hydraulic pressure for testing. This unit was controlled by a personal computer which was interfaced with a Flextest SE control unit. The test frame had an overall stiffness of $4200 \mathrm{kip} / \mathrm{in}(740 \mathrm{KN} / \mathrm{mm})$, and computer programs executed all testing protocols. The test machine setup can be seen in Figure 2.3.

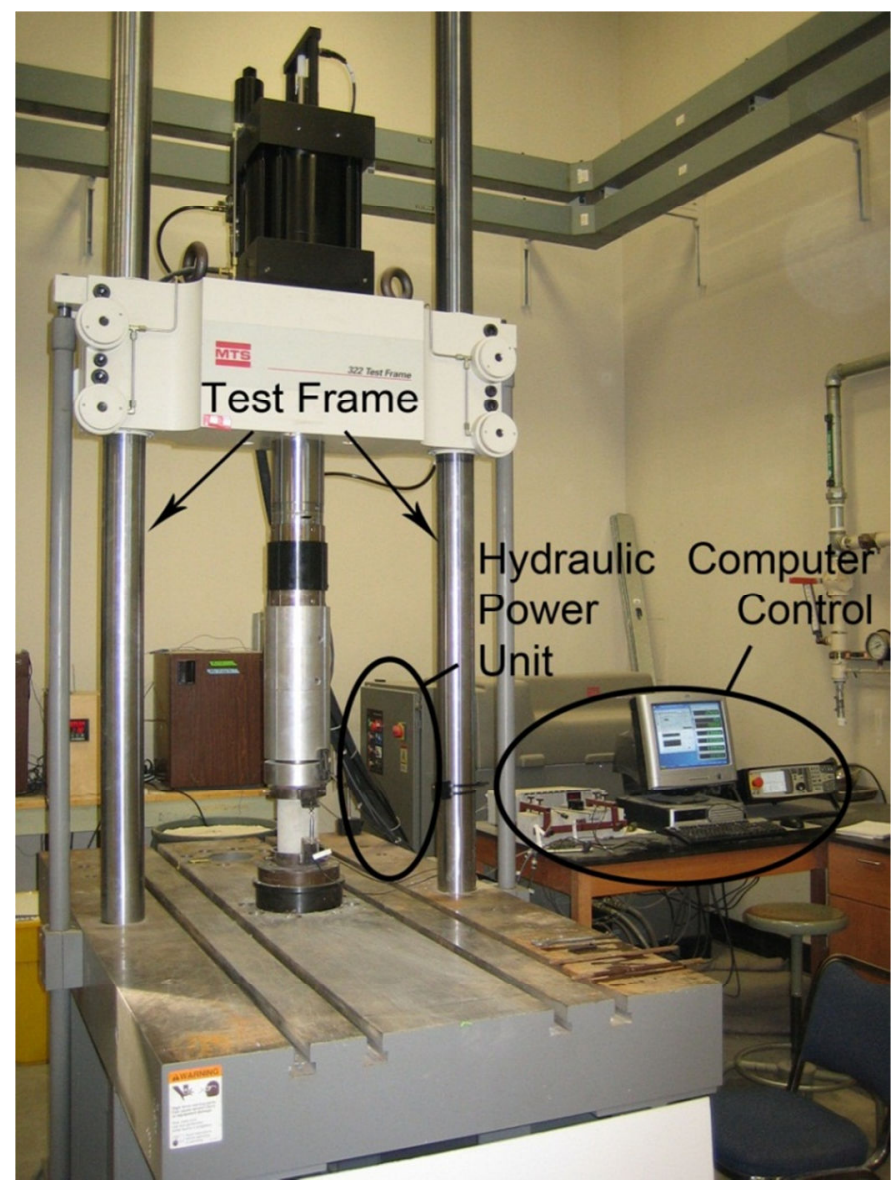

Figure 2.3 - Test machine setup

\subsubsection{Stress Controlled Compression}

Concrete cylinders were tested under stress control to determine the concrete's compressive strength, $\mathrm{f}_{\mathrm{c}}$. This was a monotonic test following specifications in ASTM C39 (2007) where cylinders were loaded at a constant rate of $36 \mathrm{psi} / \mathrm{s}$ (248 $\mathrm{kPa} / \mathrm{s})$. Damp 
cylinders were centered under the test machine's upper platen, seen in Figure 2.5, and manually loaded to $\sim 100 \mathrm{lbs}$. A computer program, created for the stress controlled test, loaded specimens until failure, which was defined as the concrete's inability to carry increasing load. The maximum compressive force held by each cylinder was recorded and divided by that cylinder's cross sectional area to determine the concrete's compressive strength, $\mathrm{f}_{\mathrm{c}}$.

\subsubsection{Strain Controlled Compression}

Strain controlled compression testing was used for both monotonic and cyclic investigations. Figure 2.4 shows stress strain curves from a typical monotonic test and a fatigue test where the concrete was cycled to a specified strain in the post peak region of the stress strain curve. In Figure 2.4 A, a concrete cylinder's monotonic stress strain curve is seen. The modulus of elasticity for this type of loading is defined as E, calculated as the chord modulus between points a and $b$. The maximum concrete stress is defined as $\sigma_{\mathrm{p}}$ and its corresponding strain as $\varepsilon_{\mathrm{p}}$, seen as point $\mathrm{c}$.

In Figure 2.4 B, a cyclic test sample's stress strain curve is seen. The unloading strain is labeled $\varepsilon_{\mathrm{c}}$, and the maximum stress reached in each cycle is defined as $\sigma_{\mathrm{i}}$ where $\mathrm{i}$ is the cycle number. At initiation of cycling, the concrete's stress is termed $\sigma_{0}$, seen as point $\mathrm{d}$, and all cycles after that are consecutively numbered 1-10 with $\sigma_{10}$ being the maximum stress in the $10^{\text {th }}$ cycle. For cyclic testing, the elastic modulus of the initial loading branch is termed $\mathrm{E}_{0}$, and the stiffness of the loading branches in subsequent cycles is labeled $E_{i}$ where $i$ is the cycle number. These were also estimated by a chord modulus between two points, represented by a and b or e and f in Figure $2.4 \mathrm{~B}$. 

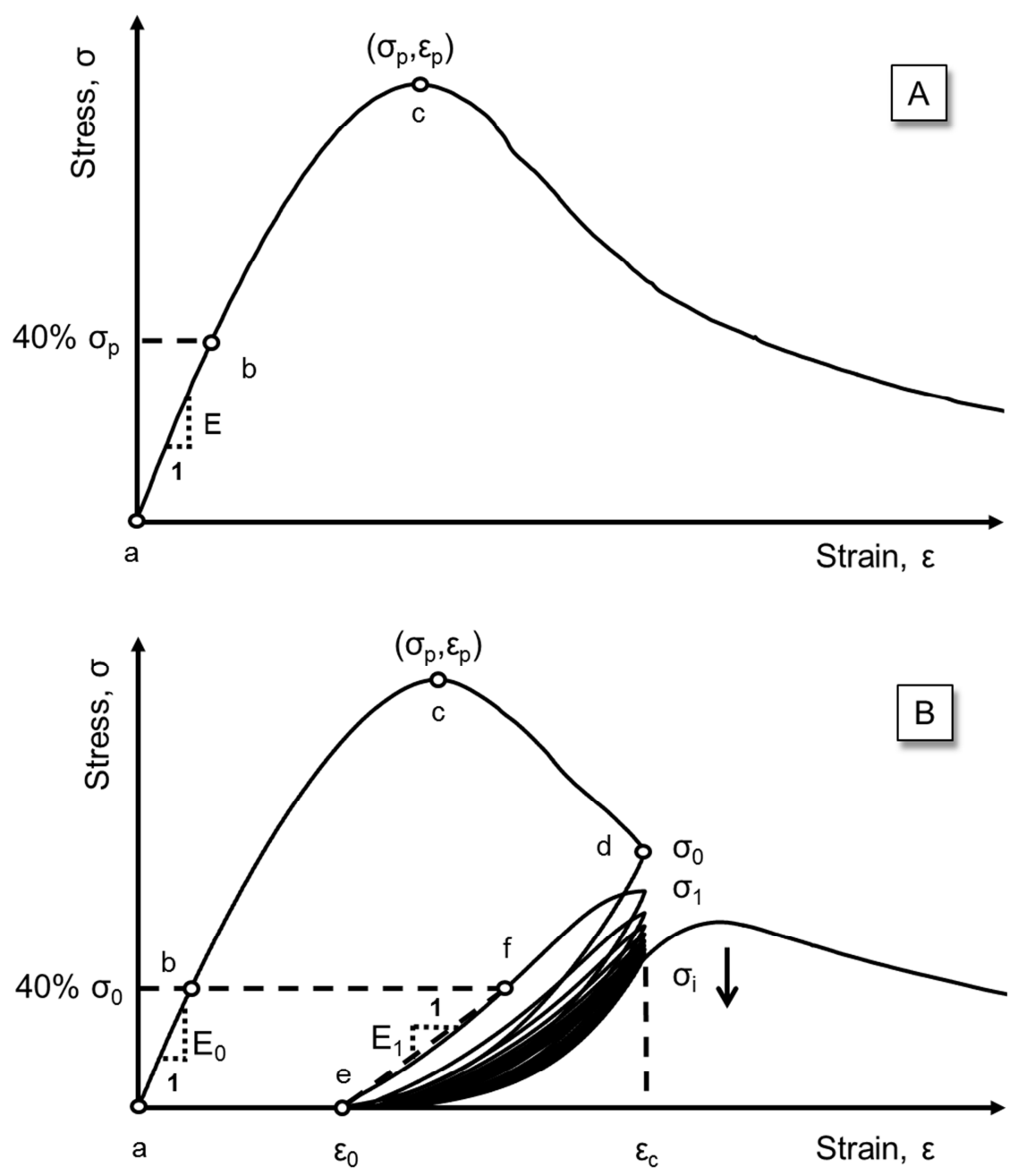

Figure 2.4 - Stress strain terminology: (A) monotonic testing and (B) cyclic testing

A strain loading rate of $15 \mu \varepsilon / \mathrm{s}$ was chosen to give a similar stress loading rate while in the concrete's elastic range as that seen in the stress controlled compression test. This strain rate is in the static loading region defined as strain rates between $55-1 \mu \varepsilon / \mathrm{s}$ where very little change in concrete strength is seen with changes in strain loading rate (Bischoff and Perry 1991). Above this static loading region, an increase in the compressive loading strain rate has been shown to cause a small but steady increase in the measured strength of concrete up until about $60 \mathrm{\varepsilon} / \mathrm{s}$ where a more significant increase 
is seen (Ross et al. 1994). Bischoff and Perry (1991) compiled work by many different authors and also a found a drastic increase in the compressive strength when the loading strain rate reached about $60 \mathrm{\varepsilon} / \mathrm{s}$.

Cylinder displacement was measured and controlled by the average reading of two \pm 0.1 inch linear variable differential transformers (LVDTs), diametrically opposed to one another. Figure 2.5 shows a typical strain controlled test setup with a steel ring attached at the top and bottom of the concrete specimen holding the two LVDT's. Two four inch extensometers, also seen in Figure 2.5, were placed on some samples at ninety degrees to each LVDT and were used to verify the accuracy of the LVDT displacement measurements.

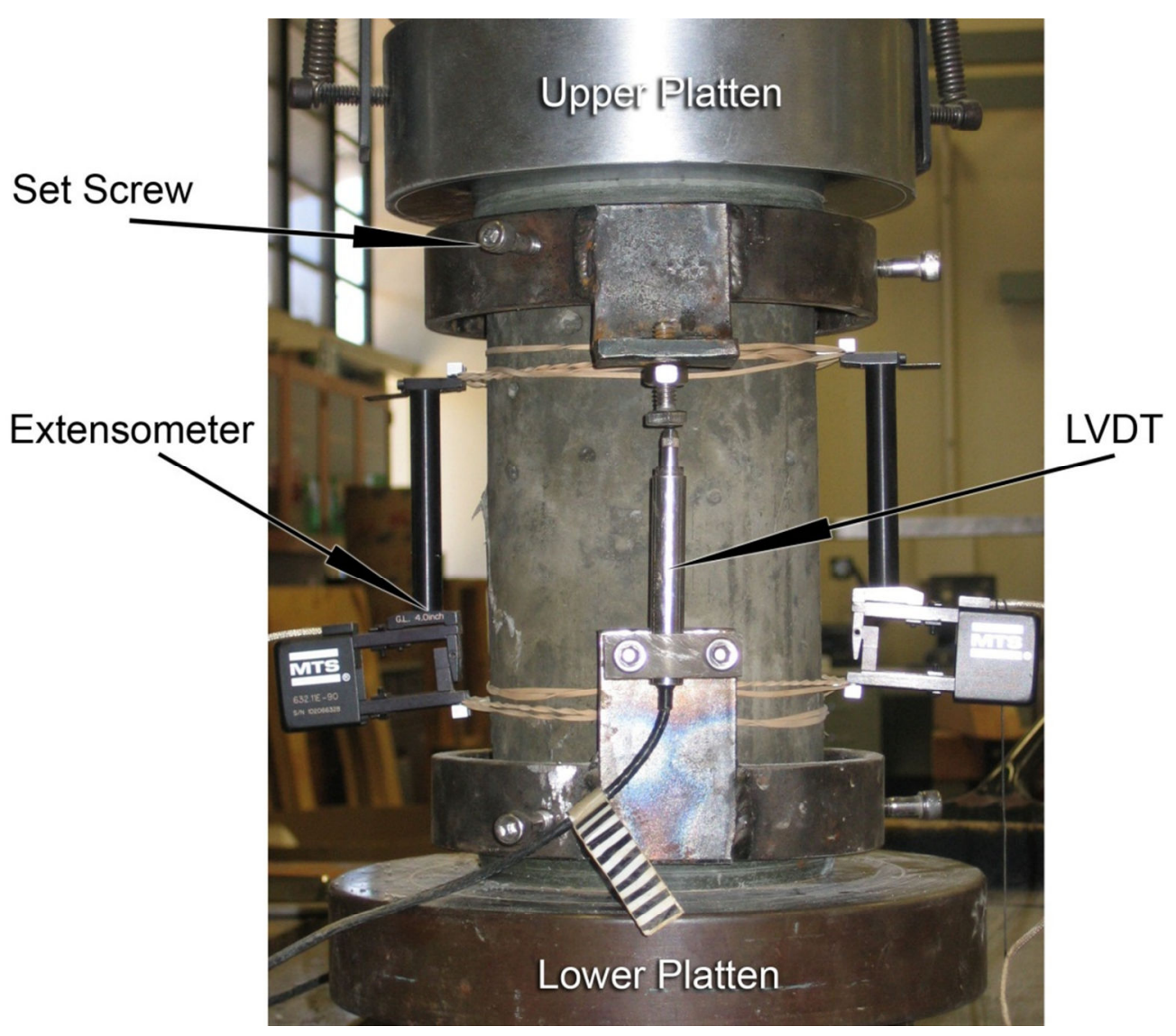

Figure 2.5 - Strain controlled compression test setup 
The monotonic stress strain curve for sample 0.60-50-SSC A is shown in Figure 2.6. A comparison of the strains calculated with displacements measured with LVDTs and extensometers reveals a discrepancy between the measurements. Extensometer strains consistently measured slightly higher than LVDT strains, particularly once damage began to occur in the concrete. This is likely explained by the localized failure of concrete proposed by Jansen and Shah (1997) and Mu et al. (2004).

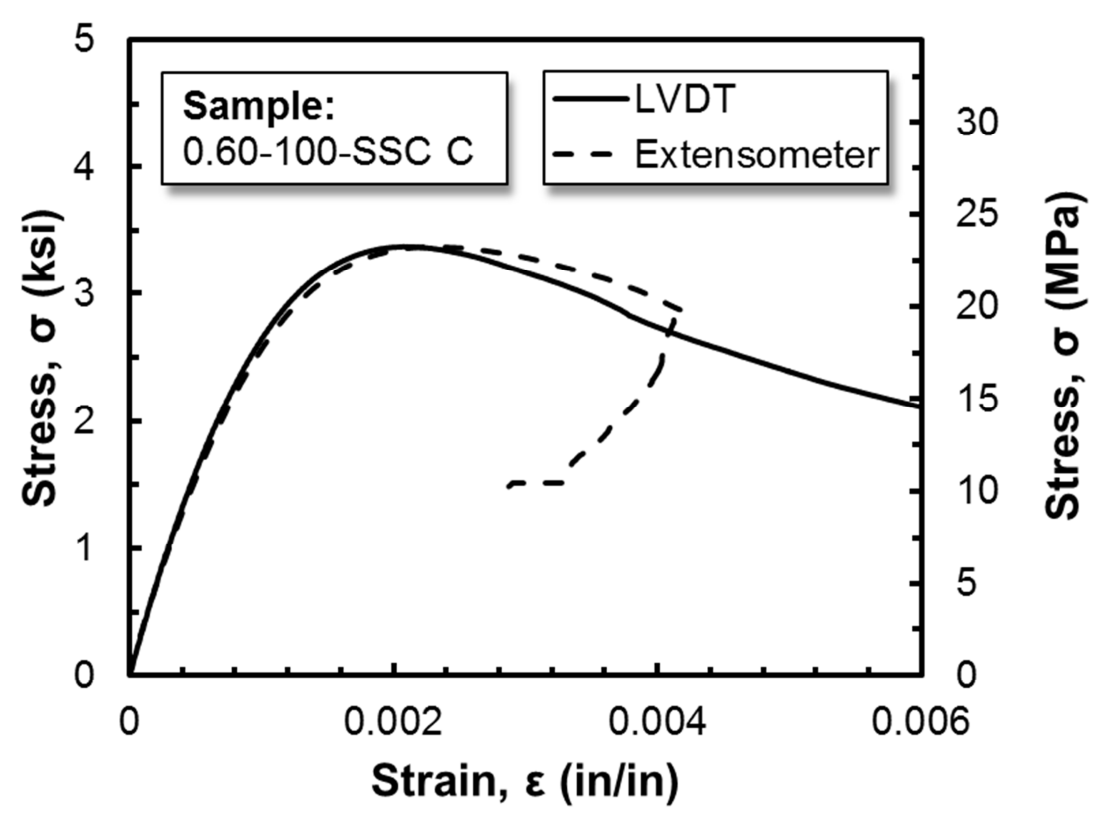

Figure 2.6 - Strains measured with LVDTs and extensometers

Strains measured in a sample are the average of those seen over the distance bracketed by a displacement measurement device. The gauge length of the LVDT measurement device was approximately 1.5 times the length of the extensometers and both were centered at the midpoint of a test specimen. If the concrete's damage was localized and both displacement measurement devices bracket this damage zone, then the 
device with a smaller gauge length would record larger average strains for the same test specimen. Extensometers lost contact with the concrete specimen as the testing progressed into to post-peak region, seen in Figure 2.6, so the LVDT setup was used for actuator control and strain calculations.

For each concrete batch, three strain controlled monotonic samples and three fatigue specimens, cycled to an unloading strain of 0.003 , were initially tested. From these tests, six peak stresses $\left(\sigma_{\mathrm{p}}\right)$ and their corresponding strains $\left(\varepsilon_{\mathrm{p}}\right)$ were established. The remaining unloading strains were calculated by multiplying the average strain at peak stress by a predetermined factor. This multiplication gave the unloading strain as a fraction of the strain at peak stress. Typical factors used to establish cycling strains were $0.6,0.75,0.9,1.0$, and 1.2. Factors less than one remained the same for all concrete batches, but factors greater than one did not stay the same. The 1.2 factor was calculated to be half way between 1.0 and the factor associated with a strain of 0.003 . This factor varied between 1.15 and 1.3 during testing. All post peak factors were adjusted after testing to reflect the actual strain at peak stress for the sample tested.

Three cylinders were tested at each unloading strain associated with the factors greater than or equal to 1.0, and two samples were tested for each of the remaining strains associated with factors less than one. A larger number of samples were tested in the post peak region because increased scatter was seen in the data collected from cycling to unloading strains in this region. Each fatigue cylinder was subjected to a total of 10 cycles to its specified unloading strain and then displaced to a final strain of 0.008 which was defined as failure. Figure 2.7 contains representative graphs for strain controlled cyclic and monotonic testing from the $0.60-100$ batch of concrete. 

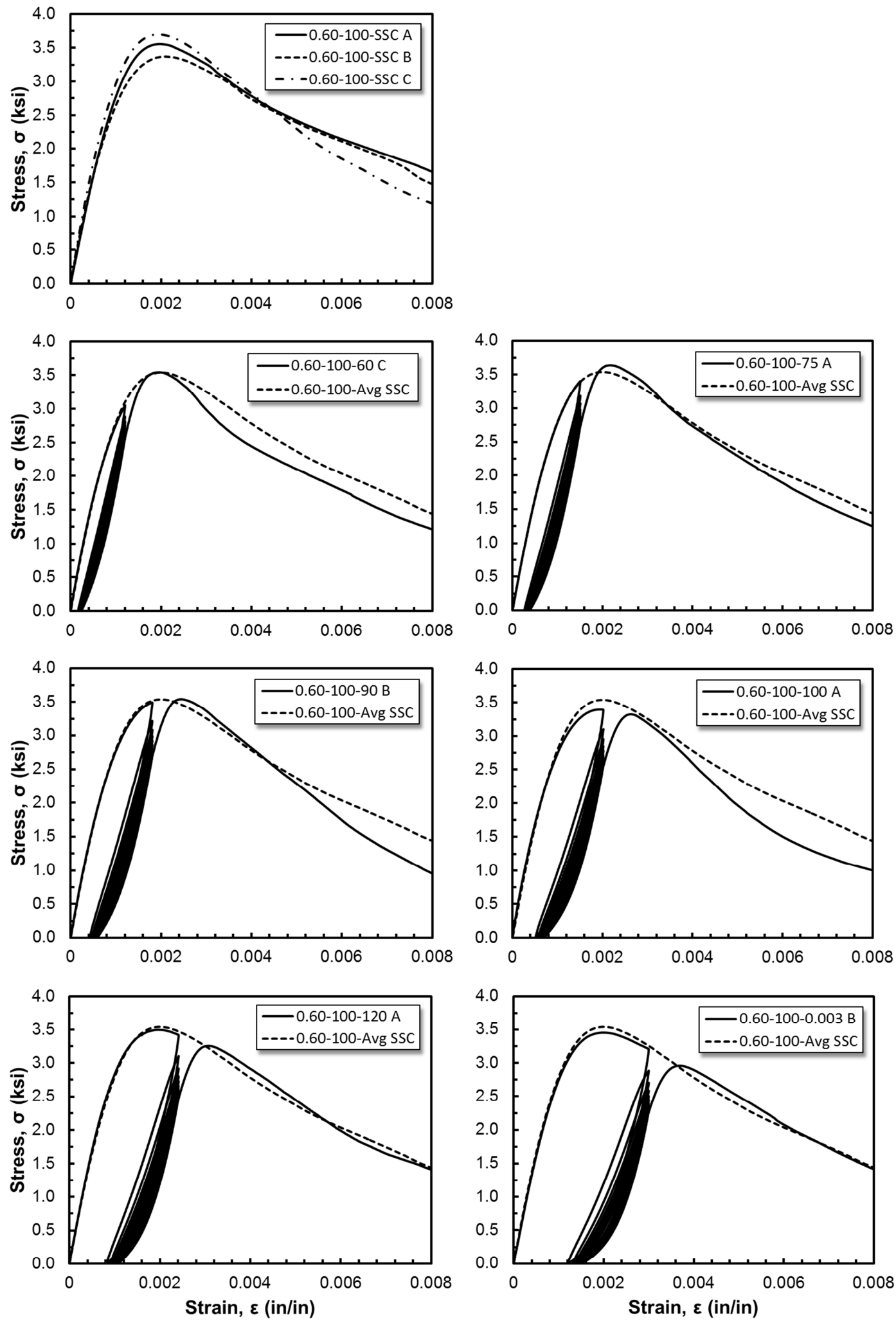

Figure 2.7 - Stress strain curves from cyclic and monotonic testing (0.60-100) 


\section{CHAPTER 3}

\section{Analysis and Results}

\subsection{Monotonic Testing}

\subsubsection{Strength}

The compressive strength of concrete, shown in Table 3.1, decreases with increasing recycled aggregate content when all other variables are constant. A $7-15 \%$ decrease in strength is seen for batches with $100 \%$ recycled concrete aggregate content. The reduction in strength is also shown graphically in Figure 3.1.

Table 3.1 - Mechanical properties of hardened concrete

\begin{tabular}{|c|c|c|c|c|c|c|c|}
\hline \multirow{2}{*}{$\begin{array}{c}\text { Water/ } \\
\text { Cement } \\
\text { Ratio }\end{array}$} & \multirow{2}{*}{$\begin{array}{c}\text { Recycled } \\
\text { Concrete, } \\
\% \\
\end{array}$} & \multicolumn{2}{|c|}{$\begin{array}{l}\text { Compressive } \\
\text { Strength, ksi }\end{array}$} & \multicolumn{2}{|c|}{ Strain at Peak Stress } & \multicolumn{2}{|c|}{$\begin{array}{c}\text { Elastic Modulus, } \\
\text { ksi }\end{array}$} \\
\hline & & $f^{\prime} c$ & STDV & $\varepsilon$, in/in & STDV, $\mu \varepsilon$ & $\mathbf{E}$ & STDV \\
\hline \multirow{2}{*}{0.39} & 0 & 7.25 & 0.28 & 0.00249 & 106 & 3861 & 119 \\
\hline & 100 & 6.45 & 0.13 & 0.00209 & 56 & 4252 & 122 \\
\hline \multirow{5}{*}{0.45} & 0 & 6.35 & 0.15 & 0.00228 & 96 & 3702 & 96 \\
\hline & 25 & 6.26 & 0.18 & 0.00218 & 94 & 3749 & 160 \\
\hline & 50 & 5.66 & 0.17 & 0.00215 & 93 & 3637 & 126 \\
\hline & 75 & 5.45 & 0.15 & 0.00204 & 59 & 3831 & 119 \\
\hline & 100 & 5.42 & 0.20 & 0.00201 & 111 & 4018 & 126 \\
\hline \multirow{3}{*}{0.6} & 0 & 4.21 & 0.07 & 0.00204 & 90 & 3286 & 94 \\
\hline & 50 & 4.16 & 0.25 & 0.00213 & 90 & 3215 & 135 \\
\hline & 100 & 3.91 & 0.09 & 0.00199 & 64 & 3353 & 152 \\
\hline
\end{tabular}

$1 \mathrm{ksi}=6.895 \mathrm{MPa}$ 
This strength loss correlates well with the typical 5-25\% strength loss found in literature when only coarse recycled concrete aggregates replace natural aggregates in new concrete (Anderson et al. 2009; Etexeberria et al. 2007; Katz 2003; Tabsh and Abdelfatah 2009). The loss of concrete strength may result from an increase in interfacial transition zones within the recycled aggregates and an increase in air voids coming from the residual mortar. These flaws create planes of weakness and stress concentrations in the concrete composite which initiate cracking and lead to an early failure of the specimen.

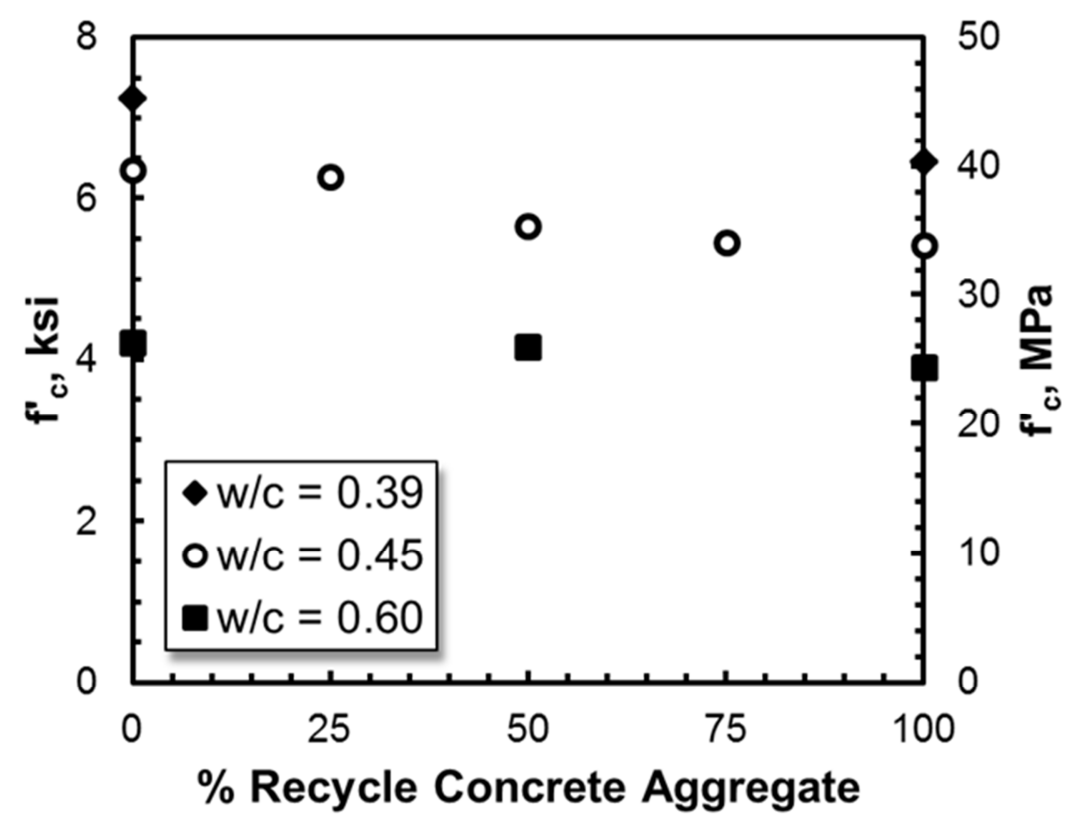

Figure 3.1 - Concrete compressive strength with different aggregate replacements

In Figure 3.2, the compressive strengths of batches containing zero and $100 \%$ recycled concrete coarse aggregates are plotted with respect to their w/c ratio. The 
strengths at these aggregate replacements are described mathematically using a least squares fit with the following expression termed Abrams law:

$$
f^{\prime}{ }_{c}=\frac{A}{B^{w / c}}
$$

where $\mathrm{f}_{\mathrm{c}}$ is the concrete's average compressive strength from stress controlled testing, $\mathrm{A}$ and B are constants specific to the data and w/c is the concrete's w/c ratio (Abrams 1927). Mindess et al. (2003) states that the variation of B primarily results from changes in the cement type. The variation in A was assumed to come from changes in the concrete's coarse aggregate. Following this theory, A was altered between concrete batches with different coarse aggregate contents and B was held constant for all batches. The compressive strength of concrete with crushed granite coarse aggregates and with recycled concrete coarse aggregates can be determined with equations $3.2 \mathrm{a}$ and $3.2 \mathrm{~b}$ respectively:

$$
\begin{gathered}
{f^{\prime}}^{\prime}=\frac{19.26}{12.15^{w / c}} \\
{f^{\prime}}^{\prime}=\frac{17.00}{12.15^{w / c}}
\end{gathered}
$$

Seen in Figure 3.2, the compressive strength of the $0.39-100$ batch of concrete is the same as the $0.45-0$ batch. Research suggests that concrete containing $100 \%$ recycled 
concrete coarse aggregates can be comparable to natural aggregate concrete by changing the w/c ratio (Hansen and Narud 1983; Limbachiya et al. 2000). As seen in Figure 3.2, an equivalent compressive strength for natural and recycled aggregate concrete can be achieved by altering the w/c ratio and can be accurately predicted using Equation 3.1, originally proposed by Abrams (1927).

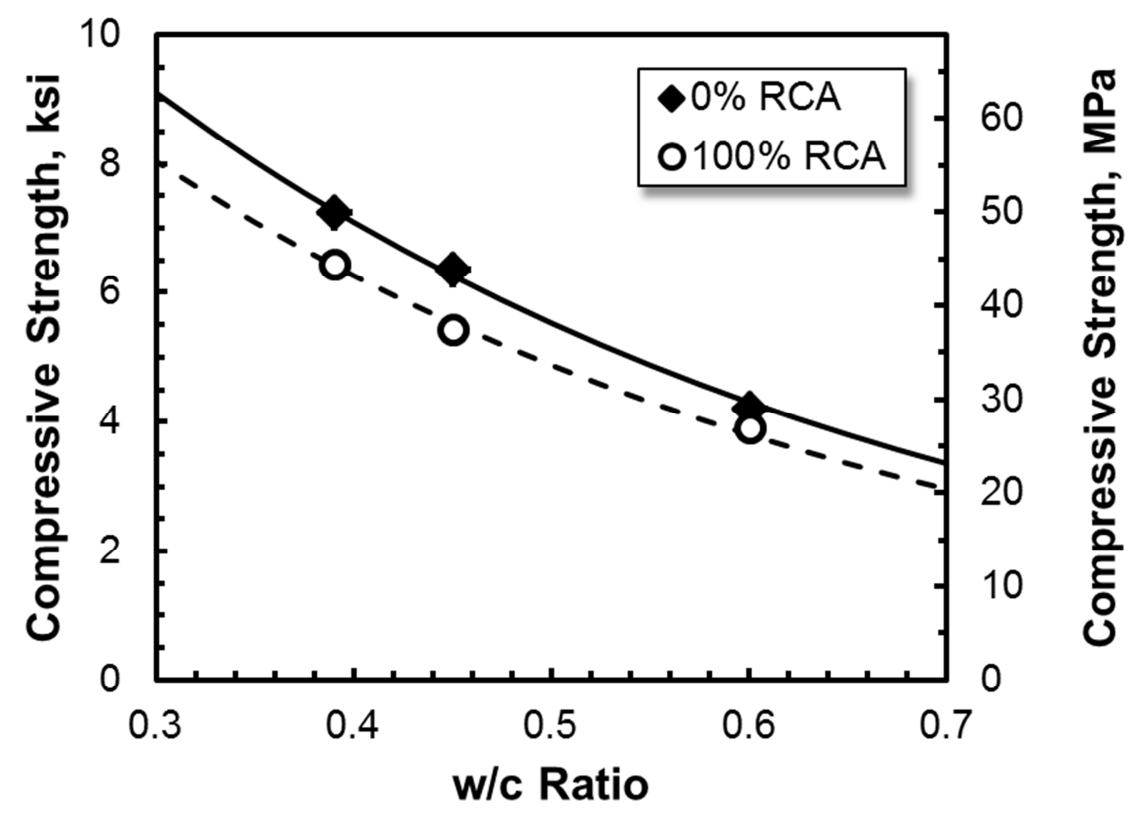

Figure 3.2 - Concrete compressive strength variation as a function of w/c ratio

Concrete samples under stress controlled loading exhibited higher peak strengths than those under strain controlled loading. This is likely due to the increased time concrete samples were exposed to high stresses in the strain controlled test. Figure 3.3 plots concrete's average strain controlled maximum stress with respect to that found in the stress controlled test and shows that differences in strength between testing methods is relatively constant no matter the concrete's maximum stress. The recycled aggregate 
content and w/c ratio do not seem to affect the difference in strength measured by the two testing methods, but, instead, this is purely a function of the loading stress and strain rates.

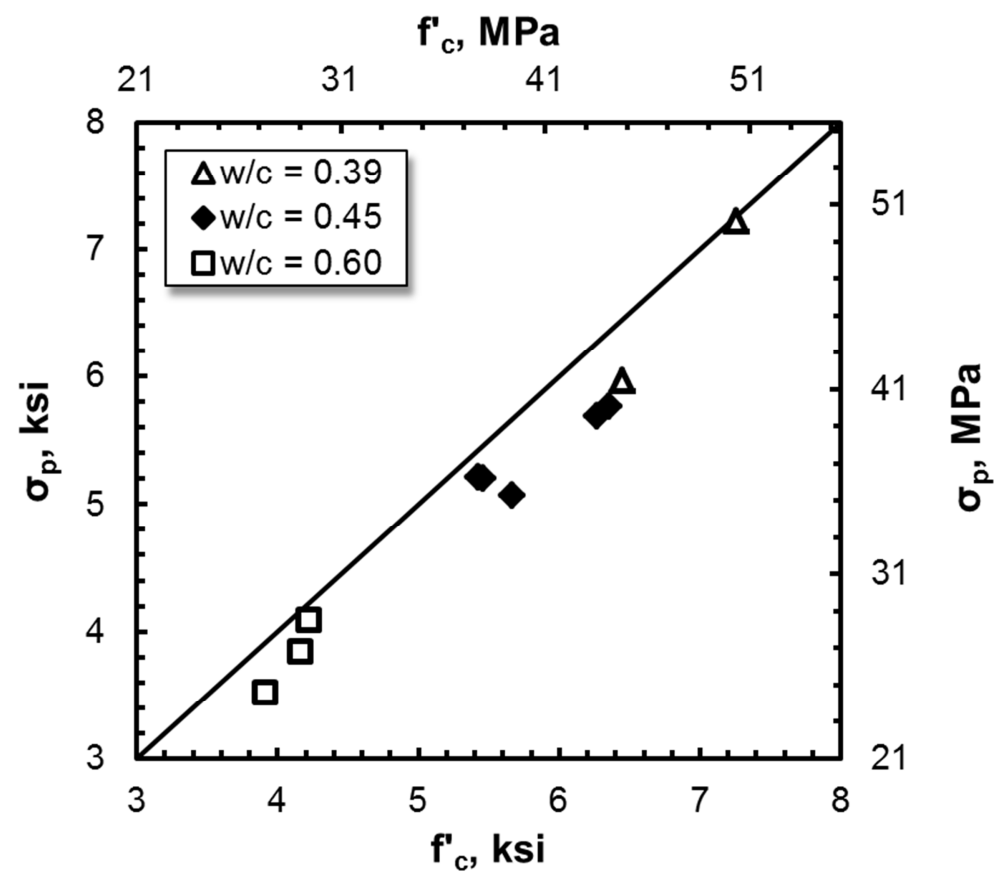

Figure 3.3 - Concrete compressive strength from stress controlled loading, $f_{c}$, and strain controlled loading, $\sigma_{\mathrm{p}}$

In this study, an increase in density resulted in an increase in strength with constant coarse aggregate content. The density increase in this type of scenario is due to a decrease in the $\mathrm{w} / \mathrm{c}$ ratio. When the $\mathrm{w} / \mathrm{c}$ ratio was decreased, the cement content was increased, and since the mortar content was held constant, an equivalent volume of sand was removed from the mix design. Seen in Table 2.1, sand has a lower specific gravity than cement, so there is a net increase in the concrete's density. Figure 3.4 shows this change in strength with changing concrete density for 0 and $100 \%$ recycled concrete aggregate replacements, and, as Topçu (1997) found, the density of hardened recycled aggregate concrete 
decreased with an increase in recycled aggregate content. Seen in this graph, the recycled concrete aggregate is less dense than crushed granite aggregate, also seen in Table 2.1.

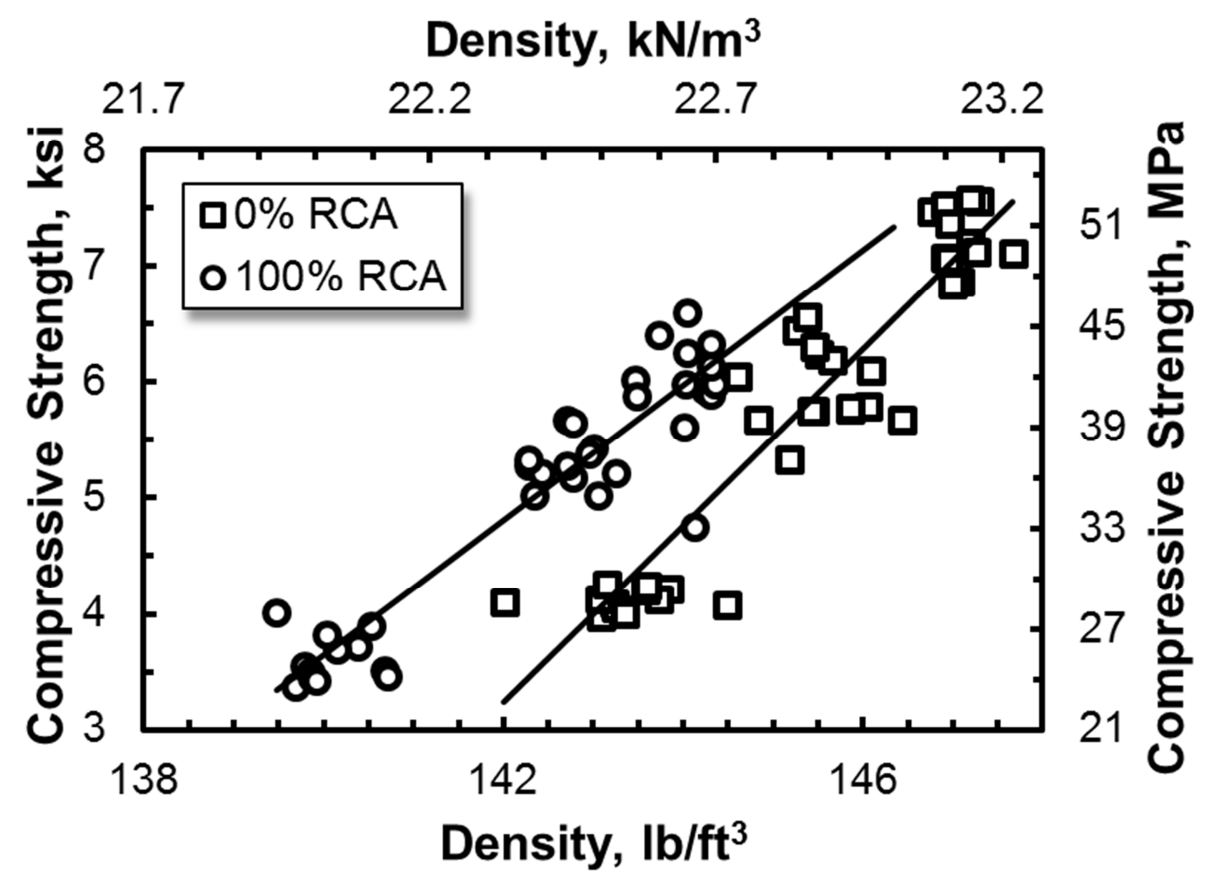

Figure 3.4 - The influence of the density on concrete's compressive strength

As concrete's strength increases, recycled aggregate concrete and natural aggregate concrete densities seem to converge for concrete of equivalent strength. This is caused the large increase in cement required to achieve the same increase in w/c ratio at a low w/c ratio. For example, a batch of concrete containing $100 \mathrm{lbs}$. (445 N) of water, with a $\mathrm{w} / \mathrm{c}$ ratio of 0.5 , requires $22.2 \mathrm{lbs} .(98.8 \mathrm{~N})$ of cement powder to obtain a w/c ratio of 0.45 , a w/c ratio decrease of 0.05 . A batch of concrete, with the same water content and a w/c ratio of 0.35 , requires $47.7 \mathrm{lbs}$. $(212 \mathrm{~N})$ of cement to decrease the $\mathrm{w} / \mathrm{c}$ ratio to 0.3 , also a $\mathrm{w} / \mathrm{c}$ ratio decrease of 0.05 .

The required decrease in w/c ratio, in the recycled aggregate concrete, to achieve an equivalent strength concrete between the recycled and natural aggregate concrete was 
calculated to be 0.05 . This is true only for the aggregates and mixture proportions used in this study. Algebraic manipulation of Equation $3.2 \mathrm{a}$ and $\mathrm{b}$ shows that the single value of 0.05 required to give similar strengths between the natural and recycled aggregate concrete for all w/c ratios results from holding B in Equation 3.1 constant between batches with different aggregate contents.

In general, the strain at peak stress decreases with increasing recycled aggregate content. This is seen in Table 3.1, and does not follow the typical trend seen in the literature. Xiao et al. (2004) found that with increasing recycled aggregate content the strain at peak stress increased as much as $20 \%$. An increase has also been found by Ruhl and Atkinson and was attributed to a decrease in the elastic modulus (as cited in Xiao et al. 2004). Belén et al. (2009) found a similar increase in the strain at peak stress with increasing recycled aggregate content. All these authors used recycled aggregates with the same natural aggregate as that used in the control concrete, and all experienced a reduction in concrete's elastic modulus with increasing recycled aggregate content.

\subsubsection{Modulus of Elasticity}

The concrete's modulus of elasticity was estimated as the slope between two points on the strain controlled monotonic stress strain curve, shown as points $a$ and $b$ in Figure 2.4 A. The method used follows the calculation of the chord modulus of elasticity described in ASTM C469 (2007). The elastic modulus was calculated with the following equation:

$$
E=\frac{\left(\sigma_{2}-\sigma_{1}\right)}{\left(\varepsilon_{2}-0.000050\right)}
$$


where $\mathrm{E}$ is the modulus of elasticity, $\sigma_{2}$ is $40 \%$ of the max stress achieved in the sample tested, $\sigma_{1}$ is the stress corresponding to a strain, $\varepsilon_{1}$, of $50 \mu$, and $\varepsilon_{2}$ is the strain corresponding to the stress $\sigma_{2}$.

In contrast to common findings in literature, the elastic modulus of recycled aggregate concrete increased with an increase in the recycled concrete aggregate content and a constant $\mathrm{w} / \mathrm{c}$ ratio. This can be seen in Table 2.1 and is graphically displayed in Figure 3.5. Previous research suggests that recycled concrete aggregates cause a new concrete's elastic modulus to decrease (Anderson et al. 2009; Katz 2003; Yang et al. 2008). Xiao et al. (2004) showed a 45\% decrease in concrete's elastic modulus with $100 \%$ recycled aggregate content. This is a large decrease, and more typical reductions are $10-33 \%$ (Anderson et al. 2009).

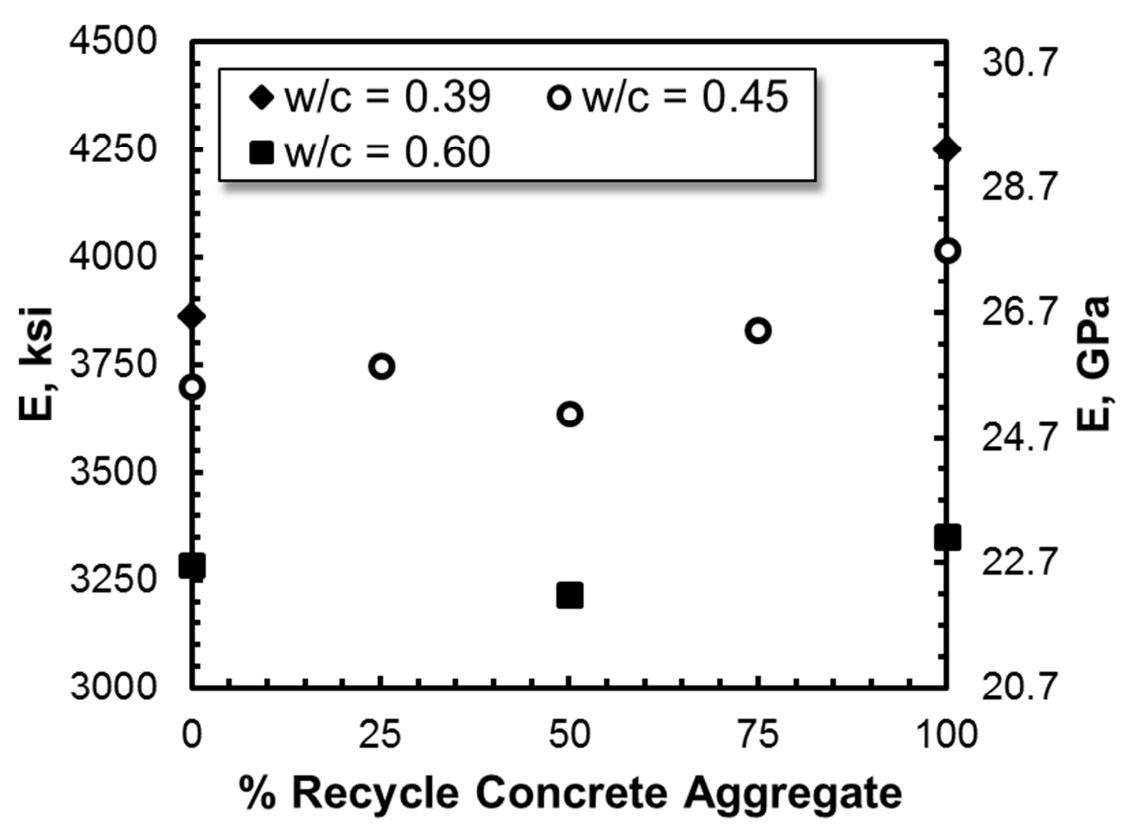

Figure 3.5 - Concrete's elastic modulus with different aggregate replacements 
The elastic modulus of concrete is heavily dependent on the stiffness and volume fraction of its mortar and coarse aggregates. Most research with recycled aggregate concrete involves the use of crushing hardened concrete made with the same natural aggregates as the control concrete. Due to the residual mortar attached to recycled concrete aggregates, there is a net increase in the total mortar content of the recycled aggregate concrete. Aggregates are typically stiffer than mortar at the common w/c ratios investigated, so a decrease in the natural aggregate volume fraction causes a decrease in the new concrete's elastic modulus.

The recycled aggregate used in this study was commercially produced using waste concrete from an unknown source. The elastic modulus of $100 \%$ recycled aggregate concrete using these aggregates was $2-10 \%$ higher than that of the concrete containing crushed granite coarse aggregates. A visual inspection of the recycled aggregates showed that the majority of the recycled concrete aggregate's natural aggregate was river rock. Zega et al. (2009) concluded that the natural aggregates of the recycled aggregate's source concrete have a large influence on the properties of recycled aggregate concrete, possibly greater than the source concrete's w/c ratio. These findings indicate that recycled aggregate concrete can have an equivalent or greater elastic modulus than a natural aggregate concrete depending on the relative stiffness of the natural aggregate from the recycled concrete aggregate's source concrete and the natural aggregates used in the reference concrete. 


\subsubsection{Strain Energy}

It is important to have an understanding of a materials toughness or ability to resist damage when loaded. The strain energy of a concrete cylinder, calculated by summing area under the stress strain curve, provides a measure of a material's toughness (Maher and Darwin 1989; Topçu and Guncan 1995). Strain energy was calculated by integrating a sample's stress with respect to strain out to a strain of 0.008 using the trapezoidal rule. This is seen in Figure 3.6 as the shaded area under the stress strain curve. Energy recovery due to unloading of the sample at a strain of 0.008 was not included in the calculation of strain energy.

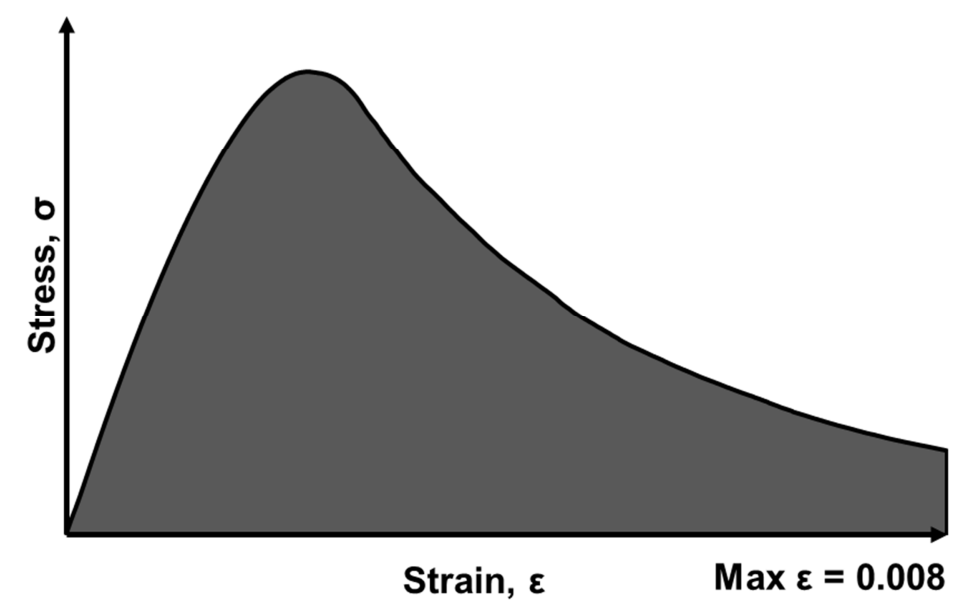

Figure 3.6 - Strain energy calculation from monotonic testing

With increasing recycled aggregate content and a constant $\mathrm{w} / \mathrm{c}$ ratio, the strain energy dissipated during monotonic testing decreased. Topçu and Guncan (1995) also found a decrease in the energy dissipated with monotonic loading of concrete samples containing recycled concrete aggregates. The dissipated strain energy was plotted with 
respect to the peak stress of the concrete sample and can be seen in Figure 3.7. This figure shows that the change in dissipated energy with recycled concrete aggregate content is primarily due to a change in the concrete's strength, not a change in aggregates. The $0.45-75$ batch of concrete exhibited a low energy dissipation capacity, seen in Table 3.2 , due to a drop in the post peak branch of the stress strain curve for the three samples tested. With a larger number of test samples, the average energy dissipated may have been more consistent with the other batches. In Figure 3.7 the $0.45-75$ energy dissipation can be seen as the three triangles in the middle of the graph below the linear fit.

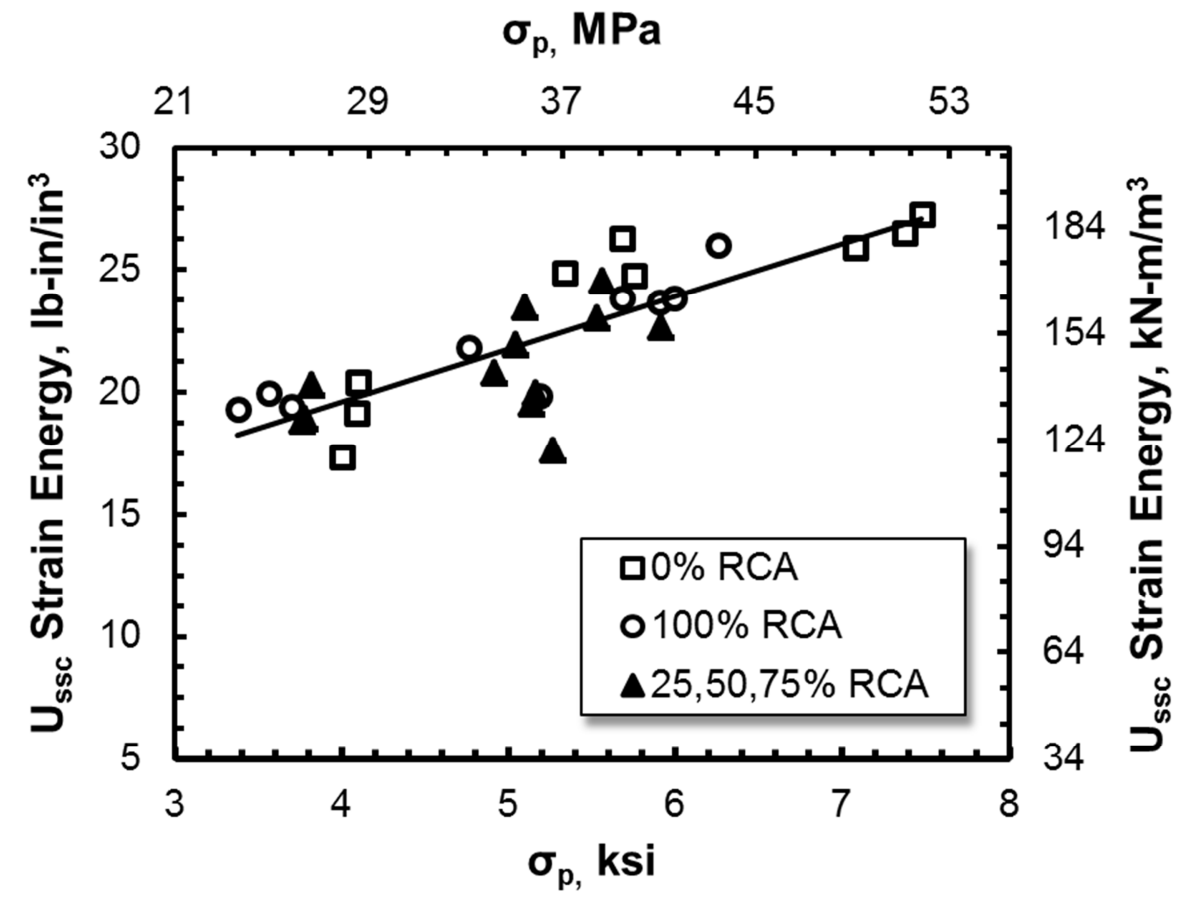

Figure 3.7 - Strain energy variation with ultimate stress from monotonic testing 


\subsection{Cyclic Testing}

Investigation of the low cycle compressive fatigue of concrete cylinders focused on changes in the maximum stress of each cycle, residual strain after initial unloading, stiffness of each cycle and energy dissipated as a result of cycling. These properties have a large impact on a structure's performance. In stress based fatigue testing, residual strains have been used to predict the fatigue life of a concrete element in compression (Otter and Naaman 1988). A structure's integrity heavily relies on concrete's ability to retain its load carrying capacity and stiffness when subjected to cyclic loading. Paskova and Meyer (1997) showed that energy dissipation is also a good measure of damage and tends to be more reliable than residual strain damage models. Chung et al. (1989) also found that the energy dissipated during loading, as a fraction of the total energy dissipation capacity, gives a good measure of a materials residual strength, stiffness and capacity to resist further loading. The investigation of these properties is meant to give a picture of the expected performance of recycled aggregate with respect to natural aggregate concrete when exposed to high stress and strain cyclic loading in a structure.

\subsubsection{Cycle Maximum Stress}

\subsubsection{Analysis}

The degradation of each cycle's maximum stress represents a reduction in the ability of concrete to perform one of its most important roles in a structure. When cyclically loaded to fixed strains, the maximum stress in each cycle primarily degrades as a result of stiffness degradation and residual strain accumulation. Figure 3.8 shows the normalized peak cycle stresses for the unloading strain ratios, $\varepsilon_{\mathrm{c}} / \varepsilon_{\mathrm{p}}$, used during the 
testing of the $0.39-100$ batch of concrete. Each curve represents one sample tested in fatigue with its unloading strain ratio displayed to the right of each curve.

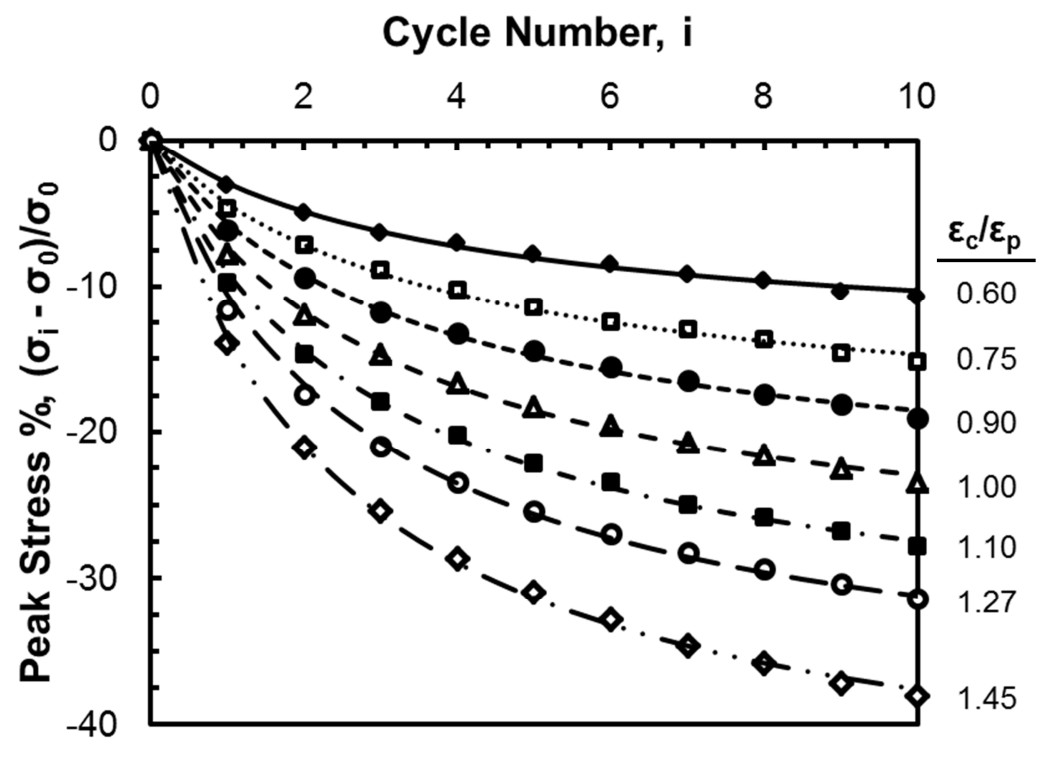

Figure 3.8 - Percent change in max cycle stresses with curve fit (0.39-100)

Normalization allowed a comparison of the change in maximum cycle stresses between concrete with different strengths and aggregates. To accomplish this, each cycle's peak stress was analyzed in terms of a percent change from the stress when cycling began, $\sigma_{0}$. This percent change can be seen in Figure 3.8 and is fit with the following equation:

$$
\frac{\left(\sigma_{\mathrm{i}}-\sigma_{0}\right)}{\sigma_{0}} * 100=\frac{-\boldsymbol{b} i}{(-0.0404 \boldsymbol{b}+4.38+i)}
$$

In Equation 3.4, $\boldsymbol{b}$ is varied for each sample tested, and all constants were calculated using a least squares fit of the normalized maximum cycle stresses from all concrete batches simultaneously. An increase in $\boldsymbol{b}$ reflects a greater percent reduction in the 
maximum stress of each cycle, graphically seen as a drop of the curve in Figure 3.8. Analysis of $\boldsymbol{b}^{\text {'s }}$ variation is the primary tool used to evaluate the change in the maximum stress of each cycle.

\subsubsection{Results}

The maximum stress in each cycle decreased as a result of cyclic loading to a specified strain. To quantify and compare this decrease in strength, Figure 3.9 and Figure 3.10 plot the $\boldsymbol{b}$ coefficient from Equation 3.4 with respect to the unloading strain ratio, $\varepsilon_{\mathrm{c}} / \varepsilon_{\mathrm{p}}$. Each data point represents one concrete cylinder fatigue test. As $\boldsymbol{b}$ increases, a greater reduction is seen in each cycle's maximum stress as a percent of $\sigma_{0}$.

Results indicate that the degradation of the maximum stress in each cycle increases as the unloading strain used in fatigue testing increases. Figure 3.9 compares the $\boldsymbol{b}$ coefficients from concrete containing the same aggregate but with changing w/c ratios. Seen in Figure 3.9 A, as the w/c ratio decreases in the natural aggregate concrete, less percent degradation occurs during pre-peak cycling and greater percent degradation occurs during post-peak cycling. This same trend applies to recycled aggregate concrete, seen in Figure 3.9 B. When cycling occurred at an unloading strain of 1.0, the strain at peak concrete stress, the percent degradation remained the same for all aggregate replacements and $\mathrm{w} / \mathrm{c}$ ratios.

Zhou et al. (1995) proposed that the difference in stiffness between the aggregates and mortar in concrete causes stress concentrations that initiate cracking. The increased difference between the moduli of the aggregates and mortar in higher w/c ratio concrete and the weaker matrix may be initiating cracks earlier than in the lower w/c ratio concrete and contributing to its greater percent reduction in pre-peak load carrying capacity. The 
increased post-peak percent loss of load carrying capacity in concrete with lower w/c ratios may be due to the brittle behavior of low w/c ratio concrete once cracks have initiated. It has been found that, as the w/c ratio decreases, cementitious materials behave in an increasingly brittle manner and exhibit a reduced fatigue life when cycled to a specified stress (Milenkovic and Pluis 2000). This correlates well with the increased strength degradation seen in concretes with a low w/c ratio that are cyclically loaded in the post peak region of the stress strain curve.
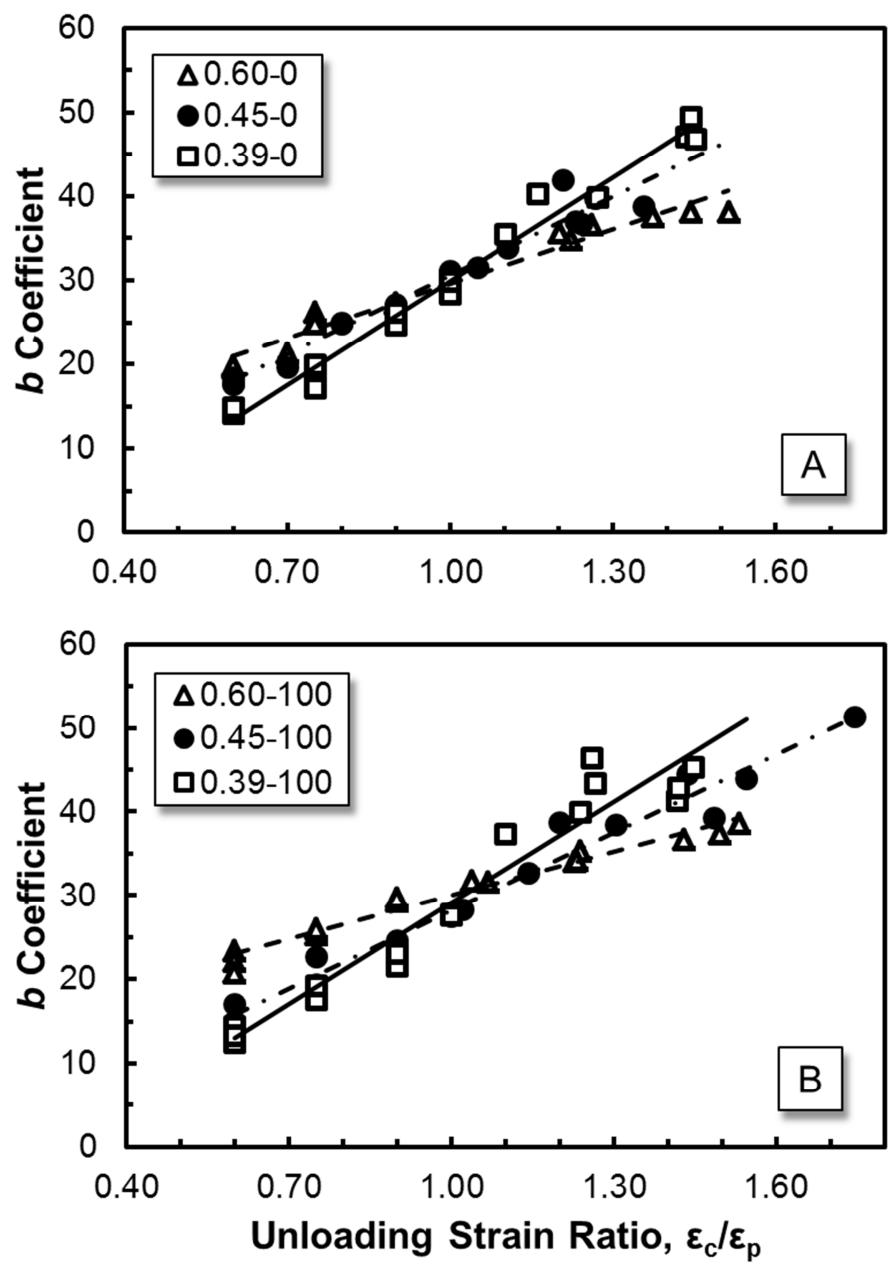

Figure 3.9 $-b$ coefficient variation with changing w/c ratio: (A) natural aggregate and $(B)$ recycled concrete aggregate 

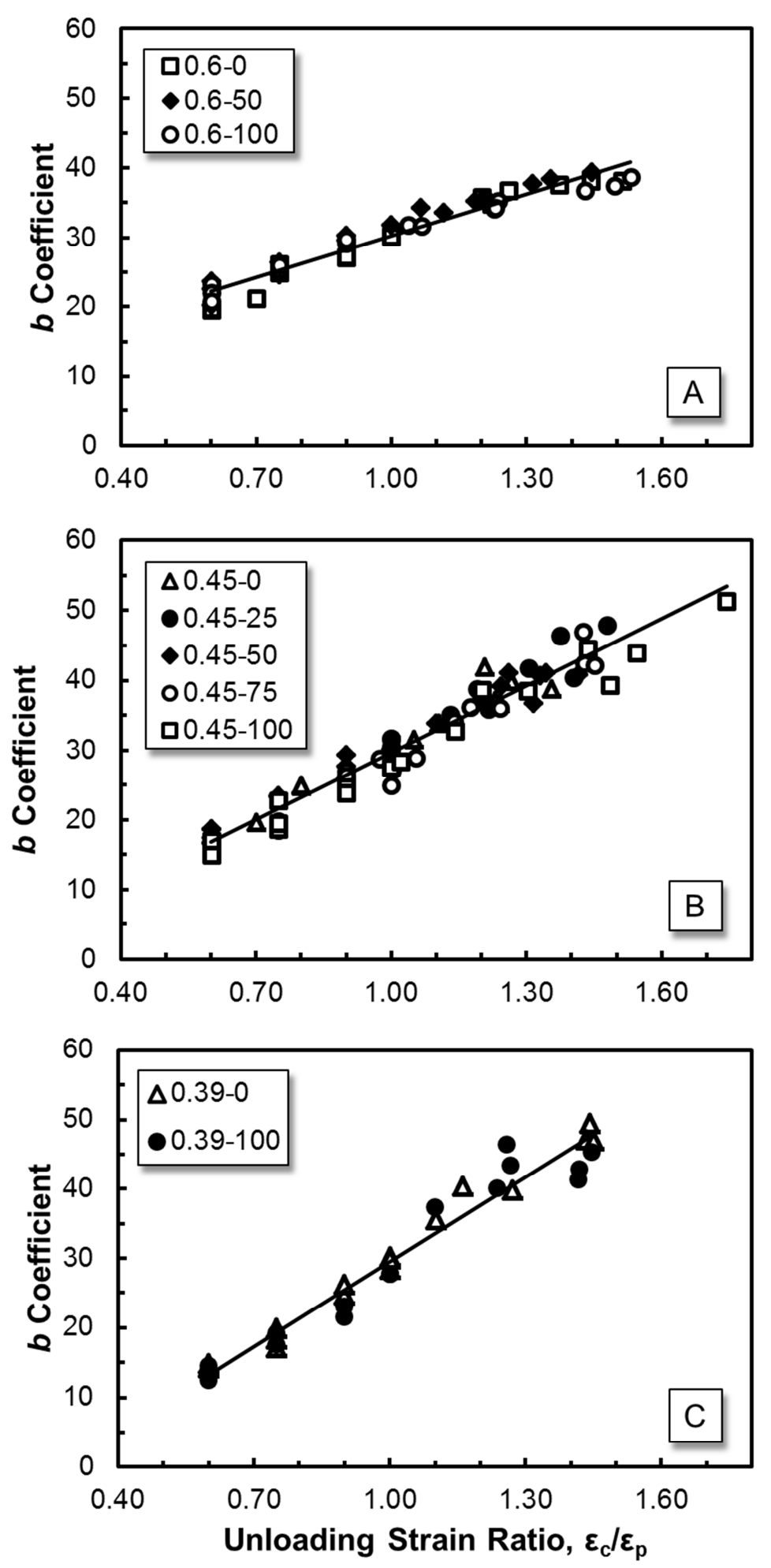

Figure 3.10 - b coefficient variation with changing recycled aggregate content 
While Figure 3.9 shows that the cycle percent maximum stress of concrete subjected to fixed strain cycling changes with the w/c ratio, Figure 3.10 shows that this degradation of concrete does not vary with changes in the recycled concrete coarse aggregate content. The w/c ratio is varied between the plots in Figure 3.10, but within each plot the percentage of recycled concrete coarse aggregate changes. The data suggests that the percent reduction of each cycle's maximum stress only varies with changes in concrete's w/c ratio and not the concrete's recycled coarse aggregate content.

The percent change in peak cycle stress can be predicted by a combination of Equation 3.4 and Equation 3.5. Seen in Equation 3.5, the variables required to predict the $\boldsymbol{b}$ coefficient are the concrete's w/c ratio and a well-defined stress strain curve. After calculation of $\boldsymbol{b}$, it can be inserted into Equation 3.4, and the percent change in maximum cycle stress or the peak stress for each cycle can be found. This is only applicable up to 10 cycles as further testing and a different curve fit would be required for a greater number of cycles.

$$
\boldsymbol{b}=\left(-95.24 \frac{w}{c}+76.6\right) \frac{\varepsilon_{c}}{\varepsilon_{p}}+98.91 \frac{w}{c}-48.57
$$

\subsubsection{Residual Strain}

In this study, residual strain is the accumulation of permanent displacements resulting from compressive loading. The initial residual strain, $\varepsilon_{0}$, point e in Figure $2.4 \mathrm{~B}$, is defined as the strain at zero stress after initial unloading from $\sigma_{0}$, seen as point $d$ in Figure 2.4 B. To compare the initial residual strain between concrete batches, it was 
normalized by the strain at peak stress, $\varepsilon_{0} / \varepsilon_{\mathrm{p}}$, and plotted against the strain at cycling, also normalized by the strain at peak concrete stress, giving the unloading strain ratio, $\varepsilon_{\mathrm{c}} / \varepsilon_{\mathrm{p}}$. Otter and Naaman (1988) analyzed the residual strains of concrete in a similar manner, but these residual strains were derived from loading with incremental strains instead of fixed strain cycling. Since only $\varepsilon_{o}$ is analyzed, the plastic strain data presented here can be compared to other data with loading to and from the envelope curve (Otter and Naaman 1988). Maher and Darwin (1989) also analyzed residual strains but did not normalize the residual or unloading strains.

The normalized residual strain at initiation of the first cycle can be seen plotted against the normalized cycling strains in Figure 3.11 and Figure 3.12. From these plots, it is seen that concrete experiences displacement recovery when unloaded up to a strain of 0.003 . The amount of recovery is related to the vertical distance between the data and the reference line shown, which has a slope of one and intersects the origin.

For all samples, the rate of initial residual strain accumulation decreases with increasing cycling strains. This rate is related to the tangent modulus of the curves seen in Figure 3.11 and Figure 3.12. Maher and Darwin (1989) observed a similar trend for mortar specimens and found that with high cycling strains $\left(\varepsilon_{\mathrm{c}}>0.004\right)$ the rate of residual strain accumulation becomes linear with a slope of one but still offset from the reference line. In this region, an increase in cycling strain causes an identical increase in residual strain. This one to one correlation was attributed to an incremental sliding along previously created internal cracks in the concrete rather than the creation of new cracks (Maher and Darwin 1989). 

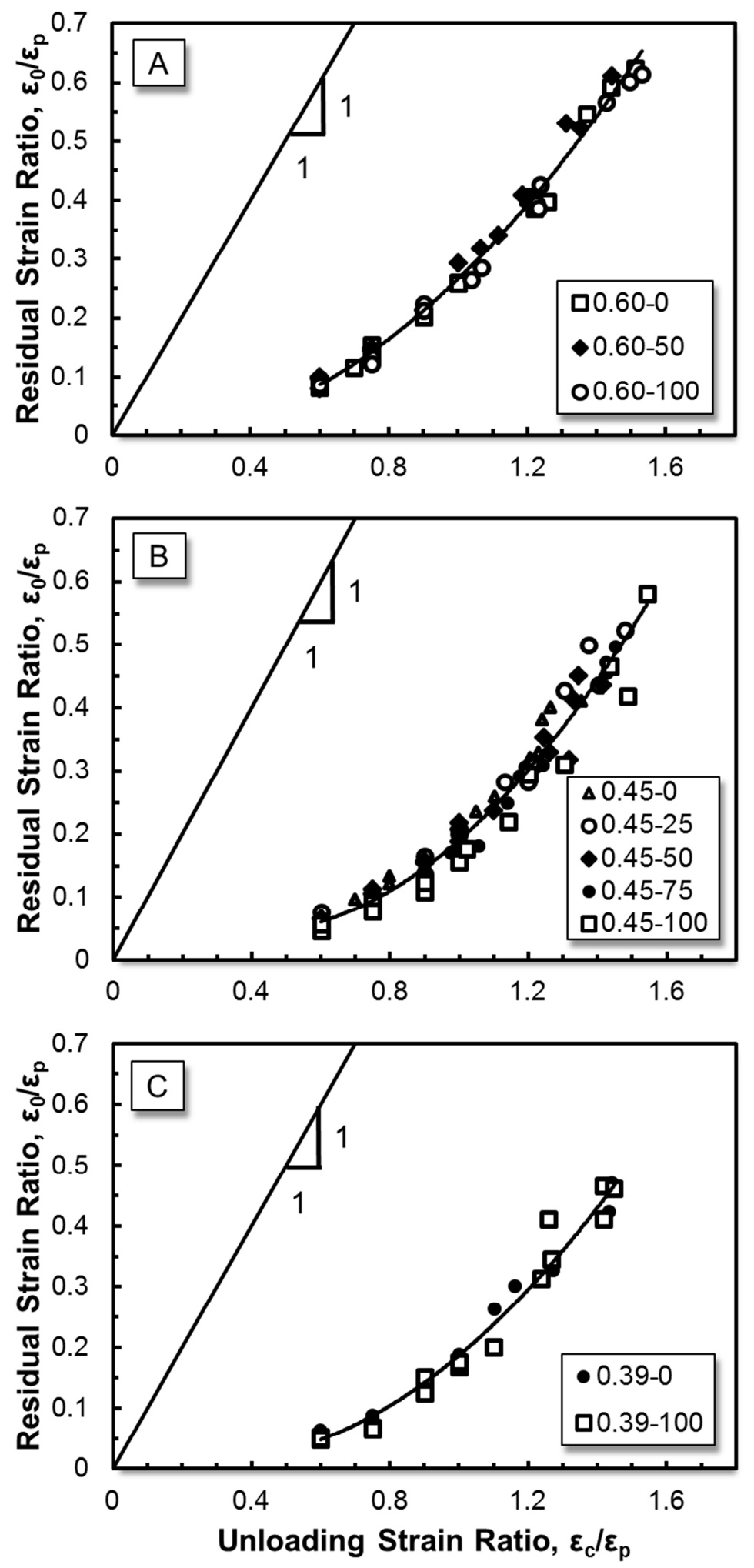

Figure 3.11 - Residual strains of concrete with the same w/c ratio 
The accumulation of residual strains does not change with increasing recycled concrete aggregate content for the unloading strains tested. This can be seen in Figure 3.11 and indicates that a fatigue failure criteria based on residual strains may predict an equivalent failure between recycled aggregate concrete and natural aggregate concrete. Each graph in Figure 3.11 has a constant w/c ratio but changing recycled aggregate content. The consistent behavior of the residual strain of concrete with changing recycled aggregate content reinforces the concept that strength reductions in concrete subjected to fixed strain cycling is strongly tied to its residual strain behavior.

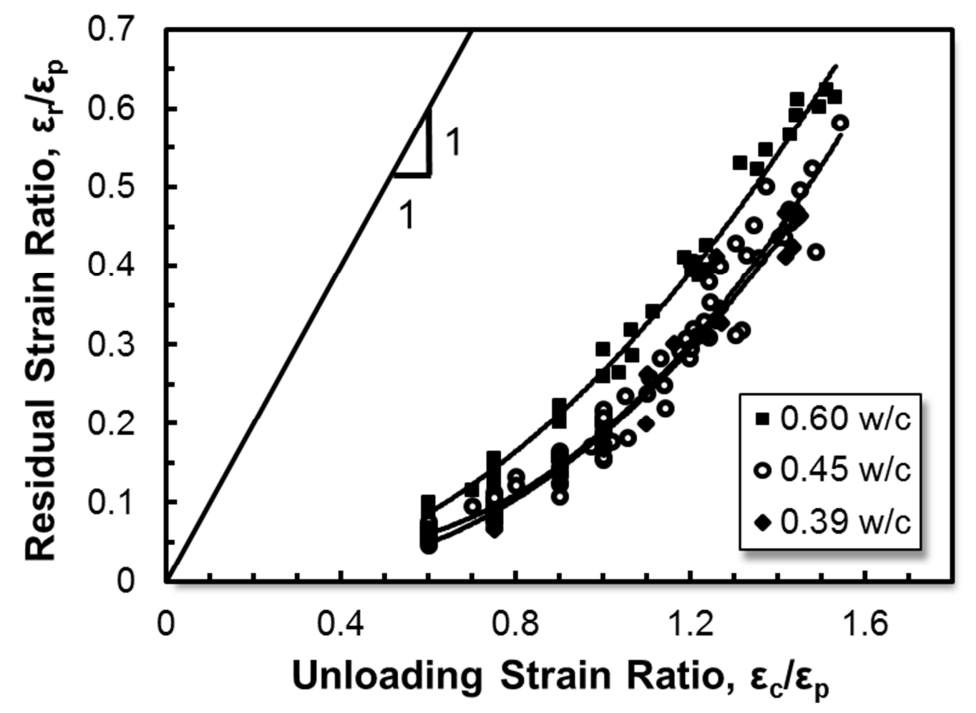

Figure 3.12 - Residual strains of concrete with changing w/c ratio (all aggregate replacements)

While no change in residual strain accumulation is seen with changing aggregate contents, a change can be seen between different w/c ratios. Figure 3.12 shows each w/c ratio plotted separately with all percent aggregate replacements. There is a significant difference in residual strain accumulation between the $0.60 \mathrm{w} / \mathrm{c}$ ratio concrete and the other $\mathrm{w} / \mathrm{c}$ ratios, but the 0.45 and $0.39 \mathrm{w} / \mathrm{c}$ ratios appear to be virtually identical. This is 
likely due to the relatively small $\mathrm{w} / \mathrm{c}$ ratio change between the 0.39 and $0.45 \mathrm{w} / \mathrm{c}$ ratios compared to the 0.45 and $0.60 \mathrm{w} / \mathrm{c}$ ratios. Between the 0.60 and $0.45 \mathrm{w} / \mathrm{c}$ ratios there is a constant increase in the residual strain accumulation across all cycling strains for the higher $\mathrm{w} / \mathrm{c}$ ratio.

\subsubsection{Modulus of Elasticity}

\subsubsection{Analysis}

The change in stiffness of each cycle's loading branch during fatigue testing was estimated by establishing the slope of a line between two points along each loading branch using an altered version of Equation 3.3. The upper stress strain coordinate was taken as $40 \%$ of $\sigma_{0}$ and its corresponding strain, seen as $\sigma_{2}$ and $\varepsilon_{2}$ in Equation 3.3. Representative upper stress strain coordinates are seen as points $\mathrm{b}$ and $\mathrm{f}$ in Figure $2.4 \mathrm{~B}$. The lower stress strain point was taken at a strain of $50 \mu$ from each loading branch's point of zero stress, defined as $\varepsilon_{1}$ where $\varepsilon_{1}$ takes the place of 0.000050 in Equation 3.3, and the corresponding stress at $\varepsilon_{1}$, defined as $\sigma_{1}$ in Equation 3.3. Figure 3.13 shows a representative set of curves describing the stiffness degradation of samples subjected to fatigue testing from the $0.45-50$ batch of concrete. Each curve represents one sample cyclically loaded to an unloading strain ratio shown to the right of Figure 3.13.

Normalization of the stiffness degradation enabled a comparison of the change in stiffness as a result of fatigue loading for concrete with different $w / c$ ratios and aggregate contents. Each cycle's stiffness, $E_{i}$, was evaluated as a percent change from the initial loading branch's stiffness, $\mathrm{E}_{0}$. This percent change is seen in Figure 3.13, and Equation 3.6 was used to mathematically describe it. 


$$
\frac{\left(\mathrm{E}_{\mathrm{i}}-\mathrm{E}_{0}\right)}{\mathrm{E}_{0}} * 100=\frac{-a i}{(-0.0108 a+0.8448+i)}
$$

In Equation $3.6 \boldsymbol{a}$ was varied for each sample tested, and all constants were identified through a least squares fit of all concrete batches simultaneously. Like the $\boldsymbol{b}$ coefficient, which describes changes in the maximum stress of each cycle, an increase in the $\boldsymbol{a}$ coefficient reflects an increase in the stiffness degradation as a percent of the initial elastic modulus or a lowering of the curve seen in Figure 3.13.

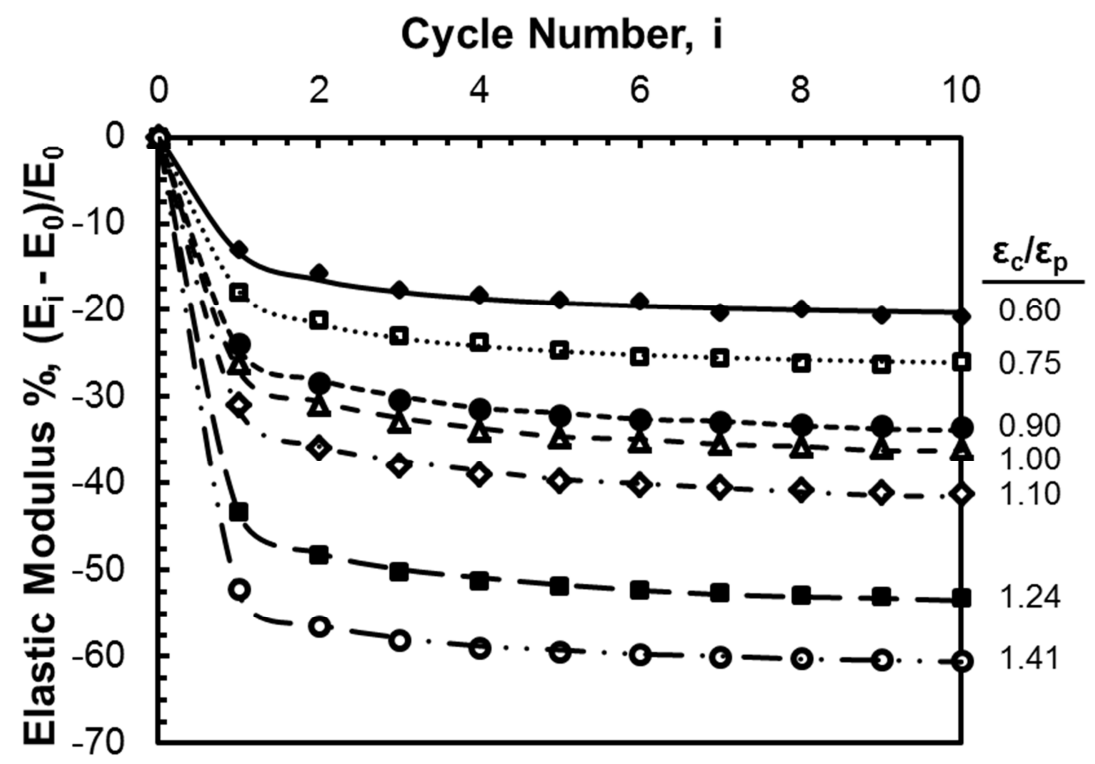

Figure 3.13 - Percent change in each cycle's stiffness with curve fit (0.45-50)

\subsubsection{Results}

The elastic modulus of concrete's initial loading curve increased with the replacement of crushed granite coarse aggregates with recycled concrete coarse 
aggregates, shown in Section 3.1.2. In a similar manner to the decrease in the maximum stress of each cycle, the stiffness of concrete reduced when cycled in compression to specified unloading strains. This decrease is quantified and described by the $\boldsymbol{a}$ coefficient from Equation 3.6.

Figure 3.14 plots $\boldsymbol{a}$ with respect to $\boldsymbol{b}$ from the cycle maximum stress analysis. Since $\boldsymbol{a}$ follows a linear trend as a function of $\boldsymbol{b}$, it can be concluded that as the w/c ratio changes, similar changes occur in the stiffness degradation as occurred in each cycles maximum stress. Concrete's stiffness, as a percent of $\mathrm{E}_{0}$, experiences a larger decrease as the w/c ratio increases when cycled at strains below about $118 \%$ of the strain at peak stress. Above this strain, cyclic loading causes slightly less percent reduction in the stiffness as the $\mathrm{w} / \mathrm{c}$ ratio increases. Instead of coinciding at $100 \%$ of the strain at concrete's peak stress like the strength degradation, the stiffness degradation coincides at about $118 \%$ of the strain at peak stress for all samples with the same aggregate.

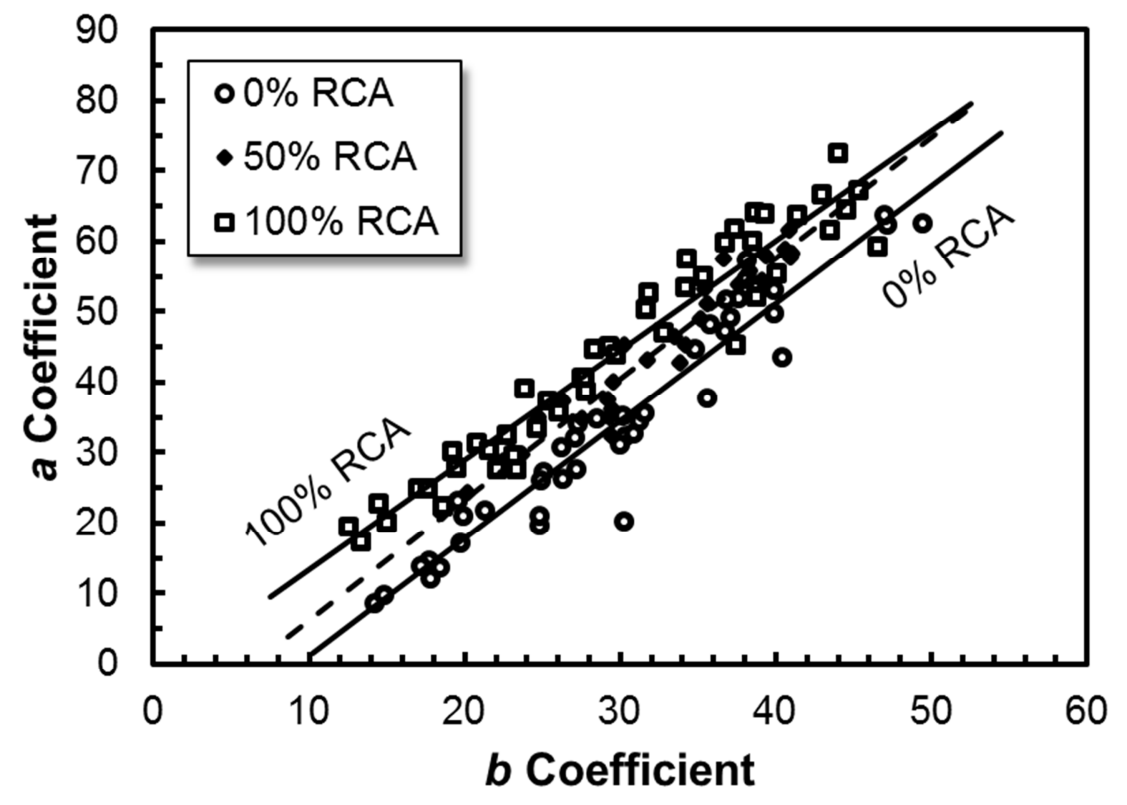

Figure 3.14 - Variation of the $a$ coefficient with respect to the $b$ coefficient 
There is an increase in the stiffness degradation due to the use of recycled concrete aggregates. Figure 3.14 shows an increase in $\boldsymbol{a}$ with the usage of 50\% and $100 \%$ recycled concrete aggregates. This increase, with respect to $\boldsymbol{b}$, appears to only be due to the percent aggregate replacement and not the w/c ratio of the concrete.

While the increased stiffness degradation is unfavorable for recycled aggregate concrete with high replacements of natural aggregate, Figure 3.15 shows that when only $25 \%$ of the natural aggregates are replaced with recycled concrete aggregates in a 0.45 w/c ratio concrete, no change is seen in the stiffness degradation. Graphs showing the $\boldsymbol{a}$ coefficient plotted with respect to the unloading strain ratio, $\varepsilon_{\mathrm{c}} / \varepsilon_{\mathrm{p}}$, for all w/c ratios and aggregate replacements are presented in Appendix $\mathrm{C}$ and should be referenced for further explanation of the stiffness degradation.

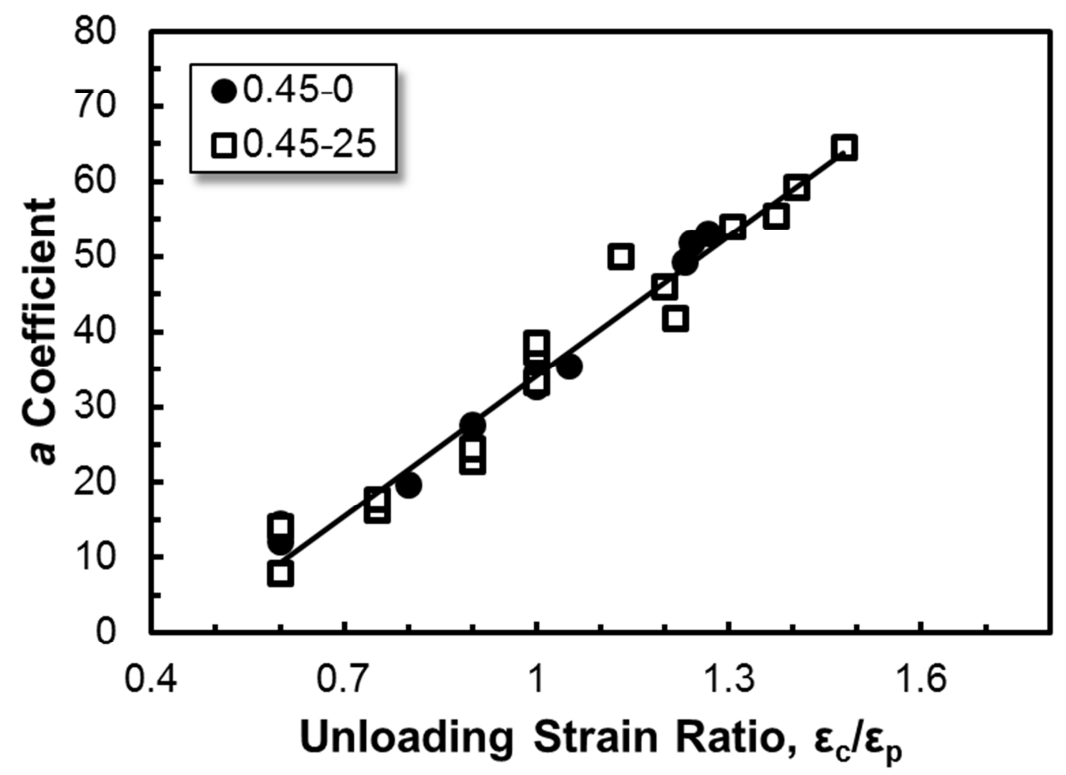

Figure 3.15 - Behavior of the $a$ coefficient for concrete with 0 and $25 \%$ recycled concrete aggregates 
The stiffness degradation as a result of cycling can be predicted using Equation 3.6 and Equation 3.7. Equation 3.7 calculates the $\boldsymbol{a}$ coefficient as a function of $\boldsymbol{b}$, and, since the change in $\boldsymbol{a}$ is dependent on the concrete's w/c ratio and coarse aggregate, the prediction proposed only describes the behavior of the aggregates used in the study. Results would likely vary with concrete containing different natural or recycled coarse aggregates. Once $\boldsymbol{a}$ is calculated, it can be inserted into Equation 3.6, and the stiffness can be calculated for concrete up to 10 cycles at a fixed strain.

$$
\boldsymbol{a}=[0.0011(\% R C A)+1.6677] \boldsymbol{b}+0.1319(\% R C A)-15.494
$$

\subsubsection{Strain Energy}

Each cycle's strain energy was calculated by adding the area under its loading branch and subtracting the area under its unloading branch. The area under both the loading and unloading branches is considered input energy to the system. The area under the unloading branch is referred to as recovered energy, and the resulting energy dissipated during one cycle is the hysteretic area enclosed by the loading and unloading curves, seen in Figure 3.16.

The total strain energy dissipated in a concrete cylinder subjected to fatigue loading $\left(\mathrm{U}_{\mathrm{Tot}}\right)$, taken to a maximum strain of 0.008 , can be viewed as the strain energy dissipated under the stress strain curve $\left(\mathrm{U}_{\mathrm{ssc}}\right)$, seen in Table 3.2, plus the strain energy dissipated due to cyclic loading $\left(\mathrm{U}_{\mathrm{cyc}}\right)$. The goal in investigating the strain energy was to 
compare the amount of energy dissipated in recycled aggregate concrete and natural aggregate concrete as a result of fatigue loading.

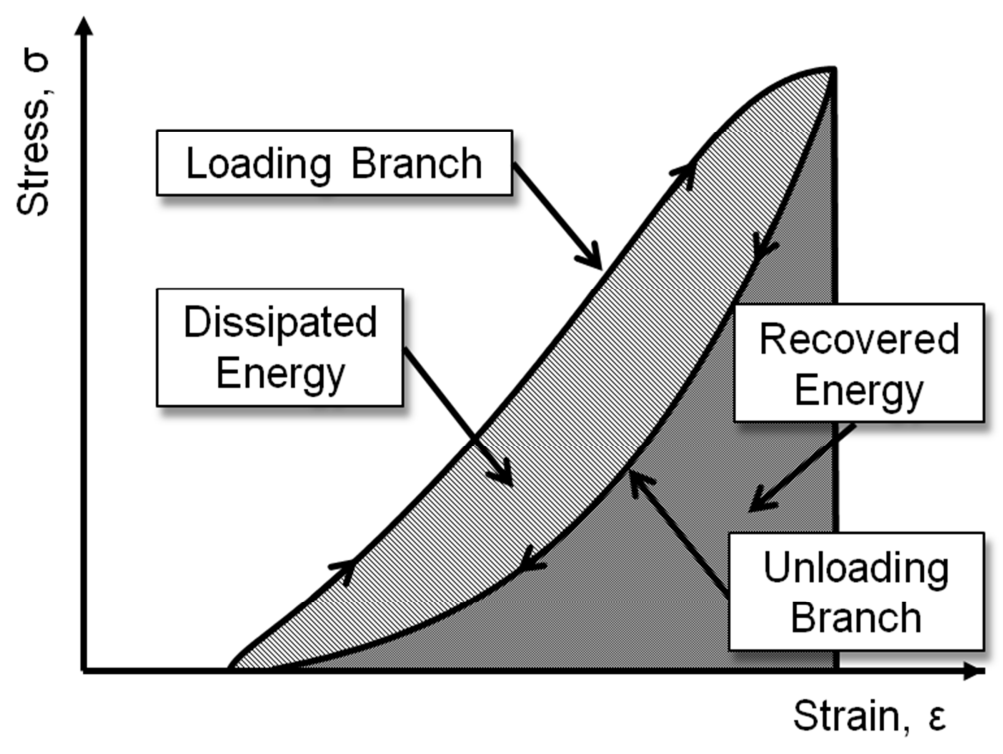

Figure 3.16 - Energy dissipation in one cycle

The total strain energy dissipated during a fatigue test was divided by the average strain energy dissipated during monotonic testing and called the strain energy ratio. This normalization gives the increase in strain energy dissipation due to cyclic loading as an increase in the strain energy ratio above one and is given by the following equation:

$$
\frac{U_{T o t}}{U_{s S c}}=1+\frac{U_{c y c}}{U_{s s c}}
$$

The total amount of energy dissipated during 10 cycles of fatigue loading to a specified unloading strain increases as the unloading strain increases. This increase in 
dissipated energy is the result of the unique loading and unloading paths creating hysteresis in the concrete with cyclic loading. The energy dissipation from hysteresis can be seen in Figure 3.17 where, as the strain ratio at cycling increases, the cycle strain energy ratio increases.

Table 3.2 - Dissipated strain energy from monotonic loading

\begin{tabular}{|c|c|c|c|c|c|}
\hline \multirow{3}{*}{$\begin{array}{c}\text { Water/ } \\
\text { Cement } \\
\text { Ratio }\end{array}$} & \multirow{3}{*}{$\begin{array}{c}\text { Recycled } \\
\text { Concrete } \\
\%\end{array}$} & \multicolumn{4}{|c|}{ 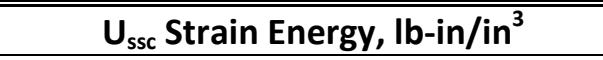 } \\
\hline & & \multicolumn{3}{|c|}{ Sample \# } & \multirow[b]{2}{*}{ Average } \\
\hline & & SSC-A & SSC-B & SSC-C & \\
\hline \multirow{2}{*}{0.39} & 0 & 27.3 & 26.5 & 25.9 & 26.6 \\
\hline & 100 & 26.1 & 23.7 & 23.9 & 24.5 \\
\hline \multirow{5}{*}{0.45} & 0 & 24.8 & 26.3 & 24.9 & 25.3 \\
\hline & 25 & 23.0 & 22.6 & 24.6 & 23.4 \\
\hline & 50 & 23.5 & 20.8 & 21.9 & 22.1 \\
\hline & 75 & 17.7 & 20.0 & 19.5 & 19.1 \\
\hline & 100 & 23.9 & 19.8 & 21.9 & 21.8 \\
\hline \multirow{3}{*}{0.60} & 0 & 20.1 & 17.3 & 19.0 & 18.8 \\
\hline & 50 & 20.3 & 18.9 & 18.8 & 19.4 \\
\hline & 100 & 20.0 & 19.3 & 19.4 & 19.6 \\
\hline
\end{tabular}

$1 \mathrm{psi}=6.895 \mathrm{kPa}$

In Figure $3.17 \mathrm{~A}$, the energy increase is plotted for natural aggregate concrete with all w/c ratios analyzed. Despite a considerable amount of scatter, batches with natural aggregates but different $\mathrm{w} / \mathrm{c}$ ratios have a similar increase in percent dissipated strain energy due to cycling. The same increase is seen in Figure 3.17 B and C which contain 50 and 100\% recycled aggregates respectively. 

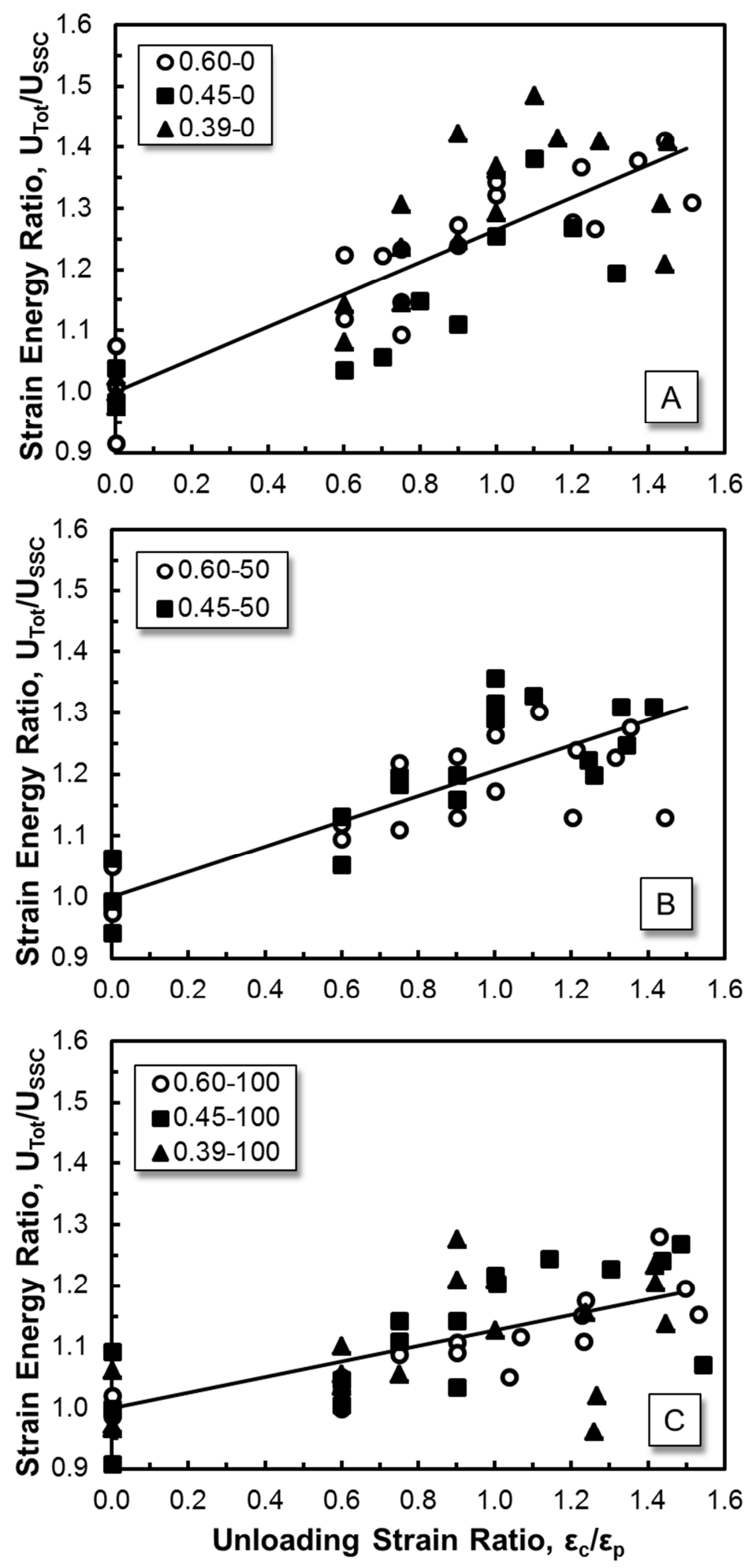

Figure 3.17 - Dissipated strain energy due to cycling: (A) natural aggregate, (B) $50 \%$ recycled concrete and $(C) \mathbf{1 0 0 \%}$ recycled concrete 
A comparison of the plots in Figure 3.17 shows that as the recycled aggregate content increases, the percent of strain energy dissipated due to cycling decreases. As a result, this recycled aggregate concrete has a diminished ability to dissipate energy during cyclic loading compared to the natural aggregate concrete. While this reduction in energy dissipation is significant at the material level, it may not significantly affect structural level performance. In a reinforced concrete structure the largest contribution to energy dissipation comes from the plastic deformation of its reinforcing steel, but as part of a moment couple, the concrete must continue to carry compression in order for the steel to be fully utilized.

Corinaldesi and Morinconi (2003) performed cyclic testing on beam column joints made with recycled aggregate concrete of equivalent strength to a reference natural aggregate concrete and recorded a slight decrease in the energy dissipated during cyclic testing as a percent of the input energy. This correlates well with the reduced cyclic energy dissipation capacity found for recycled aggregate concrete cylinders, and does show that the reduction in the recycled aggregate concrete's energy dissipation has a noticeable effect on a structural system.

\subsubsection{Post Fatigue}

The ability of concrete to withstand further loading after experiencing fatigue loading is quantified by looking at the stress strain curve out to a strain of 0.008 after cyclic fatigue has occurred. The energy dissipated and stresses at strains of 0.005 and 0.008 are normalized with respect to the average monotonic stress strain curve for each batch of concrete considered. 
Strain energy dissipated after cyclic loading, divided by the strain energy dissipated under the monotonic stress strain curve, each taken to a strain of 0.008 and seen in Table 3.2, decreases as the unloading strain increases, shown in Figure 3.18. The data from batches with zero and 100 percent recycled concrete aggregate replacements are shown, and it can be seen that, with increasing recycled aggregate content, no significant difference exists in the post-fatigue strain energy dissipation. One linear fit was used to describe the post fatigue energy dissipation capacity for all concrete batches and is given by the following equation which describes the line plotted in Figure 3.18:

$$
\frac{U_{\text {post }}}{U_{S S C}}=-0.386 \frac{\varepsilon_{c}}{\varepsilon_{p}}+1.19
$$

where $U_{\text {post }}$ is the energy dissipated after cyclic fatigue, $U_{\text {ssc }}$ is the energy dissipated under the monotonic stress strain curve, and $\varepsilon_{\mathrm{c}} / \varepsilon_{\mathrm{p}}$ is the unloading strain ratio.

Table 3.3 - Stresses at strains of 0.005 and 0.008 from monotonic testing

\begin{tabular}{|c|c|c|c|c|c|c|c|c|c|c|c|}
\hline \multirow{3}{*}{$\begin{array}{c}\text { Water/ } \\
\text { Cement } \\
\text { Ratio }\end{array}$} & \multirow{3}{*}{$\begin{array}{c}\text { Recycled } \\
\text { Concrete, } \\
\% \\
\end{array}$} & \multicolumn{10}{|c|}{ Stress, ksi } \\
\hline & & \multicolumn{5}{|c|}{$\varepsilon=0.005$} & \multicolumn{5}{|c|}{$\varepsilon=0.008$} \\
\hline & & A & B & $\mathrm{C}$ & AVG & STDV & A & B & $\mathrm{C}$ & AVG & STDV \\
\hline \multirow{2}{*}{0.39} & 0 & 2.50 & 1.91 & 2.26 & 2.23 & 0.30 & 1.00 & 0.61 & 0.83 & 0.81 & 0.19 \\
\hline & 100 & 2.66 & 2.16 & 2.29 & 2.37 & 0.26 & 1.13 & 1.27 & 0.80 & 1.07 & 0.24 \\
\hline \multirow{5}{*}{0.45} & 0 & 2.64 & 2.87 & 2.85 & 2.79 & 0.13 & 0.76 & 1.21 & 0.79 & 0.92 & 0.25 \\
\hline & 25 & 2.12 & 2.08 & 2.71 & 2.30 & 0.35 & 0.93 & 0.75 & 1.12 & 0.94 & 0.18 \\
\hline & 50 & 2.58 & 2.17 & 2.22 & 2.32 & 0.22 & 1.25 & 0.86 & 1.14 & 1.05 & 0.20 \\
\hline & 75 & 1.11 & 1.70 & 1.79 & 1.53 & 0.37 & 0.35 & 0.68 & 0.76 & 0.60 & 0.21 \\
\hline & 100 & 2.47 & 1.74 & 2.30 & 2.17 & 0.38 & 1.39 & 0.87 & 1.36 & 1.21 & 0.29 \\
\hline \multirow{3}{*}{0.6} & 0 & 2.29 & 1.66 & 2.04 & 2.00 & 0.32 & 1.17 & 0.49 & 1.16 & 0.94 & 0.39 \\
\hline & 50 & 2.44 & 2.22 & 2.13 & 2.26 & 0.16 & 1.34 & 0.96 & 1.01 & 1.10 & 0.21 \\
\hline & 100 & 2.42 & 2.39 & 2.30 & 2.37 & 0.07 & 1.66 & 1.48 & 1.19 & 1.44 & 0.23 \\
\hline
\end{tabular}

$1 \mathrm{ksi}=6.895 \mathrm{Mpa}$ 
The stresses at strains of 0.005 and 0.008 , taken from cyclic testing specimens, were divided by the stresses from the average monotonic stress strain curve at these same strains, seen in Table 3.3. The resulting stress ratio is shown in Figure 3.19 where the post cycling stress strain curve's stresses do not appear to be affected by the previous cyclic loading but remain close to the stresses seen in the monotonic stress strain curves. Results are heavily dependent on the stresses from the monotonic stress strain curve.

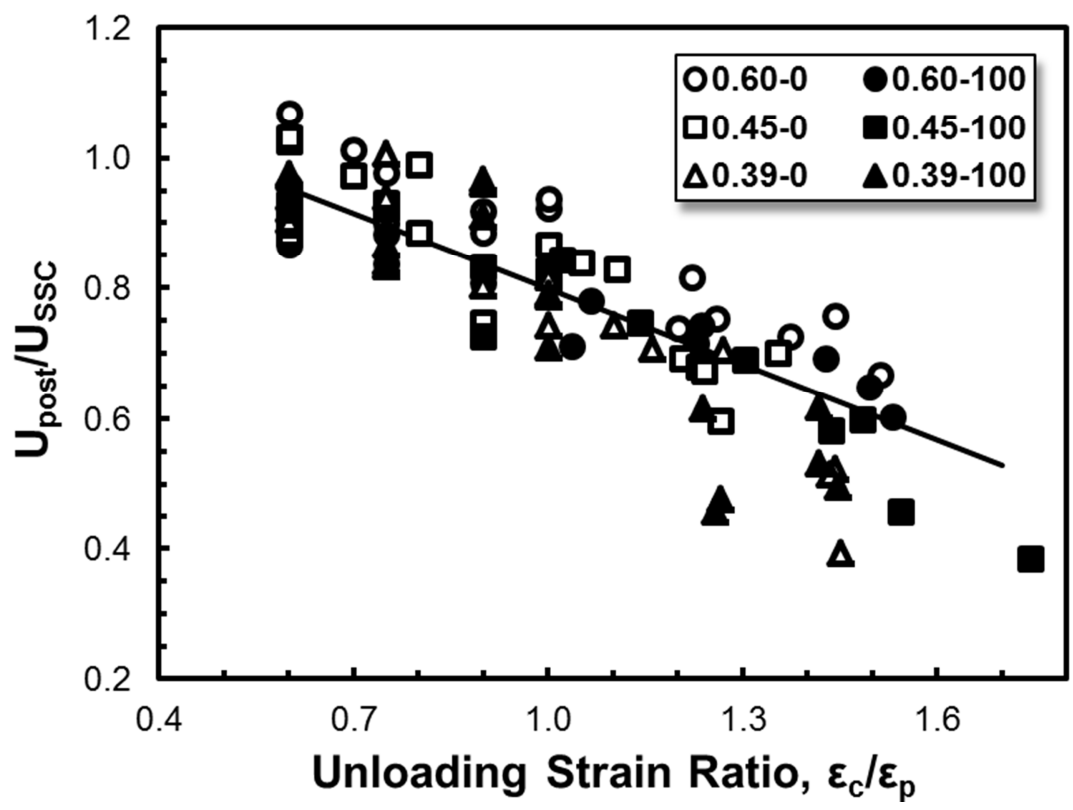

Figure 3.18 - Post cycling dissipated strain energy

Analysis of the stress strain response of concrete subjected to post cyclic loading indicates that when concrete is subjected to further loading after the cyclic loading has taken place, it behaves very similarly to concrete loaded monotonically. This would seem to indicate that concrete does not carry a memory of previous cyclic loading when loaded to strains significantly greater than those reached in previous loading. This may not be the case with different types of cyclic loading or for specimens cycled more than 10 times. 


$$
\underline{\varepsilon=0.005}
$$
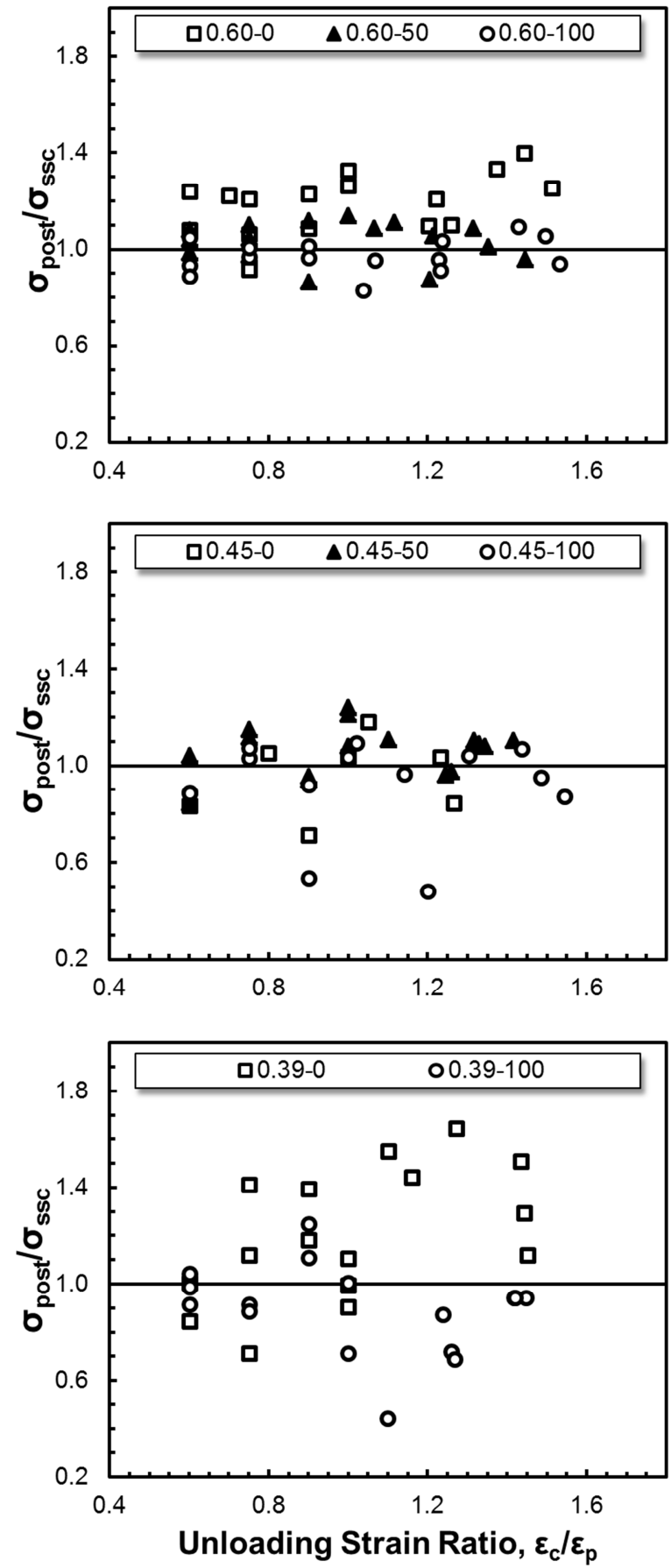

$\underline{\varepsilon=0.008}$
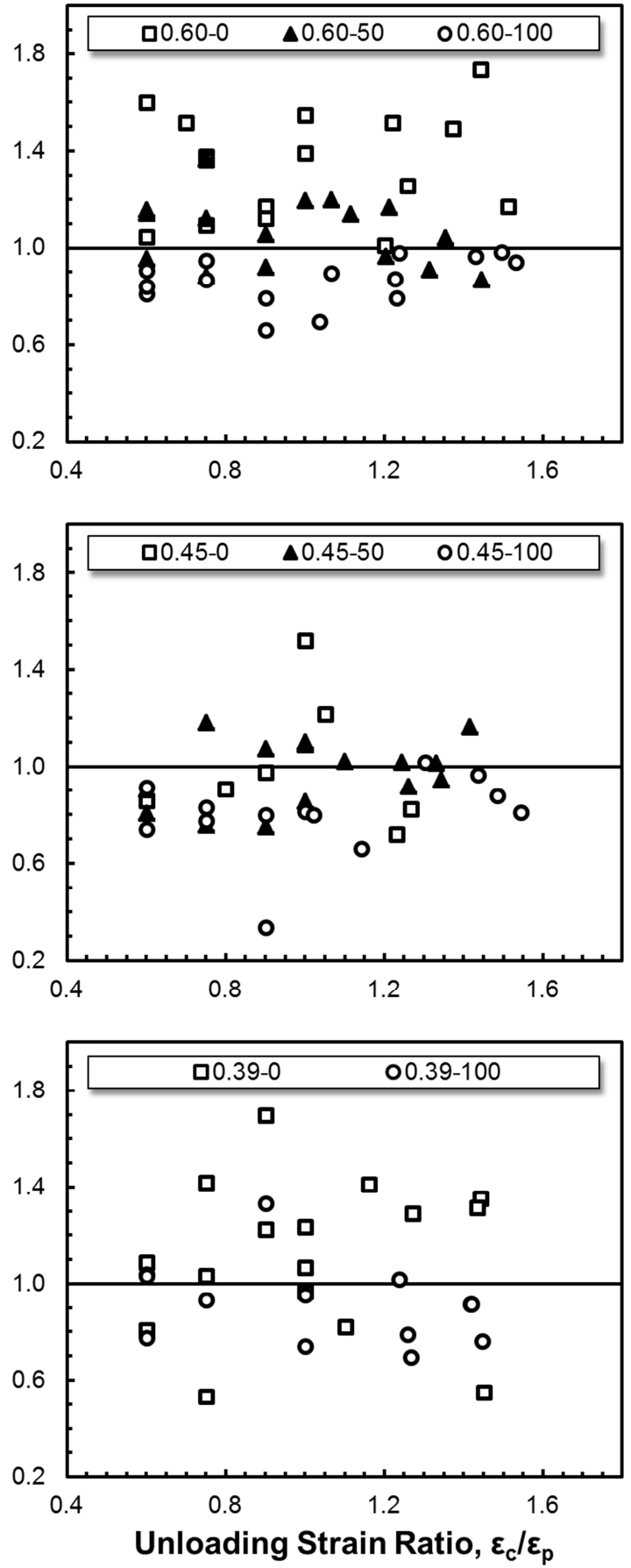

Figure 3.19 - Stresses at strains of 0.005 and 0.008 for 0,50 , and $100 \%$ recycled aggregate replacements 


\section{CHAPTER 4}

\section{Conclusions}

\subsection{Introduction}

This study compares the performance of concrete containing recycled concrete coarse aggregates to concrete containing crushed granite coarse aggregates when subjected to monotonic loading and 10 cycles of fatigue loading to a specified unloading strain. Results indicate that hardened concrete with the same w/c ratio and containing recycled concrete coarse aggregates experiences a reduction in mechanical properties. When the strength of recycled aggregate concrete and natural aggregate concrete is the same, the concrete containing recycled aggregates, subjected to fatigue, experiences a greater degradation of its stiffness and dissipates less energy.

Recycled concrete aggregates achieve the best utility when used in highly urbanized environments. In these settings, natural aggregates are often transported over long distances, and waste concrete disposal sites may not be readily available. The effective use of recycled concrete aggregate will provide substantial savings in aggregate acquisition and waste concrete disposal, but savings may be offset due to the increased cement content required to achieve equivalent strengths of concrete as compared to natural aggregate concrete. 
The commercially produced recycled concrete aggregates used in this study have a low water absorption capacity and high specific gravity compared to those typically found in literature. Sagoe-Crentsil et al. (2001) also found a reduction in the difference between the properties of recycled and natural aggregates when recycled concrete aggregates were commercially produced.

Concrete's performance was evaluated through monotonic and cyclic testing. The mechanical properties of recycled aggregate concrete subjected to monotonic loading are based on stress and strain controlled compressive testing. Fatigue testing involved 10 cycles of strain controlled compressive loading to a specified unloading strain then compression out to a strain of 0.008 .

\subsection{Conclusions}

\subsubsection{Monotonic Testing}

The conclusions derived from monotonic stress and strain controlled testing are as follows:

1. For concrete samples with identical w/c ratios, the compressive strength decreased from 1-15\% with increasing recycled concrete coarse aggregate content. The percent reduction in strength increased as the concrete's w/c ratio decreased. Larger nonlinear strength decreases occurred with greater recycled aggregate content.

2. The elastic modulus of recycled aggregate concrete can be higher than that of natural aggregate concrete depending on the properties of the recycled concrete 
aggregate's source concrete and the natural aggregate used for comparison. The elastic modulus is dependent on the stiffness of the natural aggregates and the w/c ratio of the recycled concrete aggregate's source concrete.

3. The strain at concrete's peak stress decreased with increasing recycled concrete coarse aggregate content. Previous research with recycled concrete aggregates suggests that the strain at peak stress increases with increasing recycled concrete coarse aggregate content. A change in the strain at peak stress appears to simply be the result of a change in concrete's strength and elastic modulus which is altered by the usage of recycled concrete aggregates.

\subsubsection{Fatigue Testing}

Conclusions based on strain controlled fatigue testing are as follows:

1. The percent reduction of the maximum stress in each cycle, with respect to $\sigma_{0}$, is not altered with the use of recycled concrete coarse aggregates. However, its behavior does vary between different $\mathrm{w} / \mathrm{c}$ ratios.

2. Residual strain, due to one cycle of loading to a specified strain, remains unchanged with changing aggregate and a constant w/c ratio. When concrete's w/c ratio increases, less elastic recovery or an increased residual deformation is seen for all unloading strains.

3. Concrete's stiffness experiences more rapid degradation due to cyclic loading with the use of recycled concrete coarse aggregates for all cycling strains considered. This decrease is slightly less when cycled at unloading strains in the post peak region of the stress strain curve. 
4. The energy dissipated during cycling, normalized by the energy dissipated with monotonic loading to a strain of 0.008 , stays the same for concrete containing identical aggregates no matter the $\mathrm{w} / \mathrm{c}$ ratio but decreases with increasing recycled concrete aggregate content.

5. Concrete behavior, after fatigue loading, does not change with increasing recycled concrete aggregate content. Although there is a considerable amount of scatter, the post fatigue stress strain curve does not consistently deviate from the monotonic stress strain curve at strains of 0.005 and 0.008 for cyclic loading at all unloading strains up to a strain of 0.003 .

\subsubsection{Common Correlations}

Conclusions for concrete containing 25\% recycled concrete aggregates and concrete with different aggregates but an equivalent strength are as follows:

1. Concrete with a w/c ratio of 0.45 and $25 \%$ recycled concrete aggregates exhibited the following properties in terms of the recycled aggregate concrete:

- A $1.4 \%$ reduction in the concrete's strength;

- A $1.3 \%$ increase in the elastic modulus;

- A $4.3 \%$ reduction in the strain at peak stress;

- An equivalent degradation of each cycle's maximum stress;

- An equivalent degradation of each cycle's stiffness;

- An equivalent energy dissipation resulting from cyclic loading.

For the tests completed, this concrete is virtually indistinguishable from natural aggregate concrete. 
2. Equivalent strength concrete (6.4 ksi (44 MPa)), one containing $100 \%$ natural aggregates and one with 100\% recycled concrete aggregates, exhibited the following properties in terms of the recycled aggregate concrete:

- A $15 \%$ increase in the elastic modulus;

- An $8 \%$ reduction in the strain at peak stress;

- Reduced resistance to degradation of the maximum strength in each cycle;

- Increased stiffness degradation for all specified cycling strains;

- A reduction in the energy dissipated during cycling for all strains with the reduction becoming greater as the concrete was cycled at higher strains. 


\section{References}

Abdelgadir, A., Gholamreza, F., Isgor, O. B., Razaqpur, A. G., Fournier, B., and Foo, S. (2007). Proposed method for determining the residual mortar content of recycled concrete aggregates. Journal of ASTM International, 5(1), 1-12.

Abrams, D.A. (1927). Water-cement ratio as a basis of concrete quality. American Concrete Institute Journal Proceedings, 23(2), 452-457.

Ajdukiewicz, A., and Kliszczewicz, A. (2002). Influence of recycled aggregates on mechanical properties of HS/HPC. Cement and Concrete Composites, 24(2), 269279.

Anderson, K. W., Uhlmeyer, J. S., and Russell, M. (2009). Use of recycled concrete aggregate in PCCP: literature search. (Report No. WA-RD 726.1). Olympia, WA: Washington State Department of Transportation Research Report.

ASTM (2007). Annual book of standards, concrete and aggregates, vol. 4.02. Philadelphia, $\mathrm{Pa}$.

Belén, G. F., Fernando, M. A., and Sindy, S. P. (2010). Stress-Strain Relationship in Axial Compression for Concrete Using Recycled Saturated Coarse Aggregate. Construction and Building Materials, 25(5), 2335-2342

Carrasquillo, P. M., and Carrasquillo, R. L. (1987). Effect of using unbounded capping systems on the compressive strength of concrete cylinders. ACI Materials Journal, 85(3), 141-147.

Chung, Y. S., Meyer, C., and Shinozuka, M. (1989). A damage model for reinforced concrete. Seismic Engineering: Research and Practice, Conference Article, 478487.

The Construction Materials Recycling Association (2011). Markets for recycled concrete aggregate. Retrieved May 8, 2011, from http://

concreterecycling.org/markets.html 
Corinaldesi, V., and Morinconi, G. (2003). Recycled aggregate concrete under cyclic loading. Role of Cement Science in Sustainable Development. London, UK: Thomas Telford Services Ltd, 509-518.

Etxeberria, M., Vázquez, E., Marí, A., and Barra, M. (2007). Influence of amount of recycled coarse aggregates and production process on properties of recycled aggregate concrete. Cement and Concrete Research, 37(5), 735-742.

Hansen, T. C., and Narud, H. (1983). Strength of recycled concrete made from crushed concrete coarse aggregate. Concrete International, 5(1), 79-83.

Hansen, T. C. (1986). Recycled aggregates and recycled aggregate concrete second stateof-the-art report developments 1945-1985. Materials and Structures, 19(3), 201246.

Hansen, T. C. (1992). Recycling of demolished concrete and masonry. London, UK: E and FN Spon.

Hsu, T. C. (1981) Fatigue of plain concrete. Journal of the American Concrete Institute, 78(4), 292-305.

Jansen, D. C., and Shah, S. P. (1997). Effect of length on compressive strain softening of concrete. Journal of Engineering Mechanics, 123(1), 25-35.

Katz, A. (2003). Properties of concrete made with recycled aggregate from partially hydrated old concrete. Cement and Concrete Research, 33(5), 703-711.

Koulouris, A., Limbachiya, M. C., Fried, A. N., and Roberts, J. J. (2004). Use of recycled aggregate in concrete application: Case studies. Proceedings of the International Conference on Sustainable Waste Management and Recycling: Construction Demolition Waste. London, UK: Thomas Telford Services LTD, 245-257.

Lee, M. K., and Barr, B. I. G., (2004). An overview of the fatigue behavior of plain and fibre reinforced concrete. Cement and Concrete Composites, 26(1), 299-305.

Limbachiya, M. C., Leelawat, T., and Dhir, R. K. (2000). Use of recycled concrete aggregate in high-strength concrete. Materials and Structures, 33(9), 574-580.

Maher, A., and Darwin, D. (1989). Mortar constituent of concrete in compression. Journal of the American Concrete Institute, 79(2), 100-109.

Milenkovic, A., and Pluis, M. (2000). Fatigue of normal weight concrete and lightweight concrete. (Document No. BE96-3942/R34). The European Union Brite EuRam III, Euro-LightCon. pp. 1-72. 
Mindess, S., Young, J. F., and Darwin, D. (2003). Concrete (2 ${ }^{\text {nd }}$ ed.). Upper Saddle River, NJ: Pearson Education Inc.

Mu, B., Subramaniam, K. V., and Shah, S. P. (2004). Failure mechanism of concrete under fatigue compressive load. Journal of Materials in Engineering, 16(6), 566572.

Nixon, P. J. (1978). Recycled concrete as an aggregate for concrete - a review. Materials and Structures, 11(65), 371-378.

Otter, D. E., and Naaman, A. E. (1988). Properties of steel fiber reinforced concrete under cyclic loading. ACI Materials Journal, 85(4), 254-261.

Paskova, T. and Meyer, C. (1997). Low-cycle fatigue of plain and fiber-reinforced concrete. ACI Materials Journal, 94(4), 273-285.

Rakshvir, M., and Barai, S.V. (2006). Studies on recycled aggregates-based concrete. Waste Management and Research, 24(3), 225-233.

Rao, A., Jha, K. N., and Misra, S. (2007). Use of aggregates from recycled construction and demolition waste in concrete. Resources, Conservation, and Recycling, 50(1), $71-81$.

Ross, A. C., Tedesco, J. W., and Kuennen, S. T. (1994). Effects of Strain Rate on Concrete Strength. ACI Materials Journal, 92(1), 37-47.

Sagoe-Crentsil, K., Brown, T., and Taylor, A. H. (2001). Performance of concrete made with commercially produced coarse recycled concrete aggregate. Cement and Concrete Research, 31(5), 707-712.

Sánchez de Juan, M., and Gutiérrez, P. A., (2009). Study on the influence of attached mortar content on the properties of recycled concrete aggregate. Construction and Building Materials, 23, 872-877.

Sandler, K. (2003). Analyzing what's Recyclable in C\&D Debris. Biocycle, 44(11), 51-54.

Shayan, A., and Xu, A. (2003). Performance and properties of structural concrete made with recycled concrete aggregate. ACI Materials Journal, 100(5), 371-380.

Sinha, B., Gerstle, K., and Leonard, G. (1964). Stress-strain relations for concrete under cyclic loading. ACI Journal Proceedings, 61(2), 195-212.

Tabsh, S. W., and Abdelfatah, A. S. (2009). Influence of recycled concrete aggregates on strength properties of concrete. Construction and Building Materials, 23(2), 1163 1167. 
Tavakoli, M., and Soroushian, P. (1996). Strengths of recycled aggregate concrete made using field-demolished concrete as aggregate. ACI Materials Journal, 93(2), 182190.

Topçu, I. B., and Guncan, N. F. (1995). Using waste concrete as aggregate. Cement and Concrete Research, 25(7), 1385-1390.

Topçu, I. B. (1997). Physical and mechanical properties of concretes produced with waste concrete. Cement and Concrete Research, 27(12), 1817-1823.

Topçu, I. B., and Sengel, S. (2004). Properties of concretes produced with waste concrete aggregate. Cement and Concrete Research, 34(8), 1307-1312.

Willett, J. C. (2009). Minerals Yearbook: Stone, Crushed. U.S. Geological Survey, 71.171.27 .

Xiao, J., Li, J., and Zhang, C. (2004). Mechanical properties of recycled aggregate concrete under uniaxial loading. Cement and Concrete Research, 35(6), 11871194.

Yang, K. H., Chung, H.S., and Ashour, A. F. (2008). Influence of type and replacement level of recycled aggregates on concrete properties. ACI Materials Journal, 105(3), 289-296.

Zega, C. J., Villagrán-Zaccardi, Y. A., and Di Maio, A. A. (2009). Effect of natural coarse aggregate type on the physical and mechanical properties of recycled coarse aggregates. Materials and Structures, 43(1-2), 195-202.

Zhou, F.P., Lydon, F.D., and Barr, B.I.G. (1995). Effect of coarse aggregate on elastic modulus and compressive strength of high performance concrete. Cement and Concrete Research, 25(1), 177-186. 


\section{Appendix A}

The following symbols are used in this manuscript:

$\boldsymbol{a}=$ coefficient describing a change in stiffness with cyclic loading. An increase in $\boldsymbol{a}$ represents an increased reduction in $\mathrm{E}_{\mathrm{i}}$ as a percent of $\mathrm{E}_{0}$;

$\boldsymbol{b}=$ coefficient describing a change in each cycle's maximum stress, $\sigma_{i}$. An increase in $\boldsymbol{b}$ represents and increased reduction in $\sigma_{\mathrm{i}}$ as a percent of $\sigma_{0}$;

$\mathrm{E}=$ elastic modulus of the initial loading branch. $\mathrm{E}$ was calculated as the slope of a line between points a and b, seen in Figure $2.4 \mathrm{~A}$;

$\mathrm{E}_{0}=$ stiffness of the initial loading branch. $\mathrm{E}_{0}$ was calculated as the slope between points a and b, seen in Figure 2.4 B;

$E_{i}=$ stiffness of cycle i. Seen in Figure $2.4 \mathrm{~B}, \mathrm{E}_{\mathrm{i}}$ for cycle one was calculated as the slope between points e and $\mathrm{f}$. $\mathrm{E}_{\mathrm{i}}$ was calculated in a similar manner for all cycles;

$\varepsilon_{0} / \varepsilon_{\mathrm{p}}=$ residual strain ratio

$\varepsilon_{\mathrm{c}}=$ unloading strain, strain at which cycling occurred;

$\varepsilon_{\mathrm{c}} / \varepsilon_{\mathrm{p}}=$ unloading strain ratio or cycling strain ratio

$\mathrm{f}_{\mathrm{c}}{ }_{\mathrm{c}}=$ maximum compressive stress found with load controlled testing;

$\mathrm{i}=$ cycle number, varies from $0-10$.

$\sigma_{0}=$ stress at initiation of cycling. Seen as point $\mathrm{d}$ in Figure $2.4 \mathrm{~B}$;

$\sigma_{\mathrm{i}}=$ maximum stress in cycle $\mathrm{i}$; 
$\sigma_{\mathrm{p}}, \varepsilon_{\mathrm{p}}=$ peak stress and strain at the maximum stress of concrete subjected to strain controlled monotonic compression. Seen as point c in Figure 2.4;

$\mathrm{U}_{\mathrm{cyc}}=$ hysteretic strain energy dissipated due to cyclic loading;

$\mathrm{U}_{\text {post }}=$ strain energy dissipated after cyclic loading to a strain of 0.008 ;

$\mathrm{U}_{\mathrm{ssc}}=$ strain energy dissipated under the monotonic stress strain curve, calculated to a strain of 0.008 ;

$\mathrm{U}_{\text {Tot }}=$ total strain energy dissipated in samples subjected to cyclic loading, calculated to a strain of 0.008 ;

$\mathrm{w} / \mathrm{c}=$ water to cement ratio of concrete 


\section{Appendix B Residual Mortar Content}

The residual mortar content was evaluated with six samples and calculated for the complete recycled concrete aggregate gradation.

Table B 1 - Residual mortar content - raw data

\begin{tabular}{lcccccccc}
\hline Sample & A & B & C & D & E & F & Average & St. Dev. \pm \\
\hline \hline Recycled Concrete, g & 3089 & 3134 & 3071 & 3285 & 3202 & 3263 & 3174 & 82 \\
Natural Aggregate, g & 1965 & 2057 & 2061 & 2223 & 2114 & 2165 & 2098 & 83 \\
RMC (\%) & $36.4 \%$ & $34.4 \%$ & $32.9 \%$ & $32.3 \%$ & $34.0 \%$ & $33.7 \%$ & $33.9 \%$ & $1.4 \%$ \\
\hline \hline
\end{tabular}

$1 \mathrm{~g}=0.002205 \mathrm{lbm}$ 


\section{Appendix C}

\section{Stiffness Degradation}

The following supplementary graphs show the change in concrete's stiffness when subjected to fatigue loading. See Section 3.2.3 for further information regarding stiffness degradation.
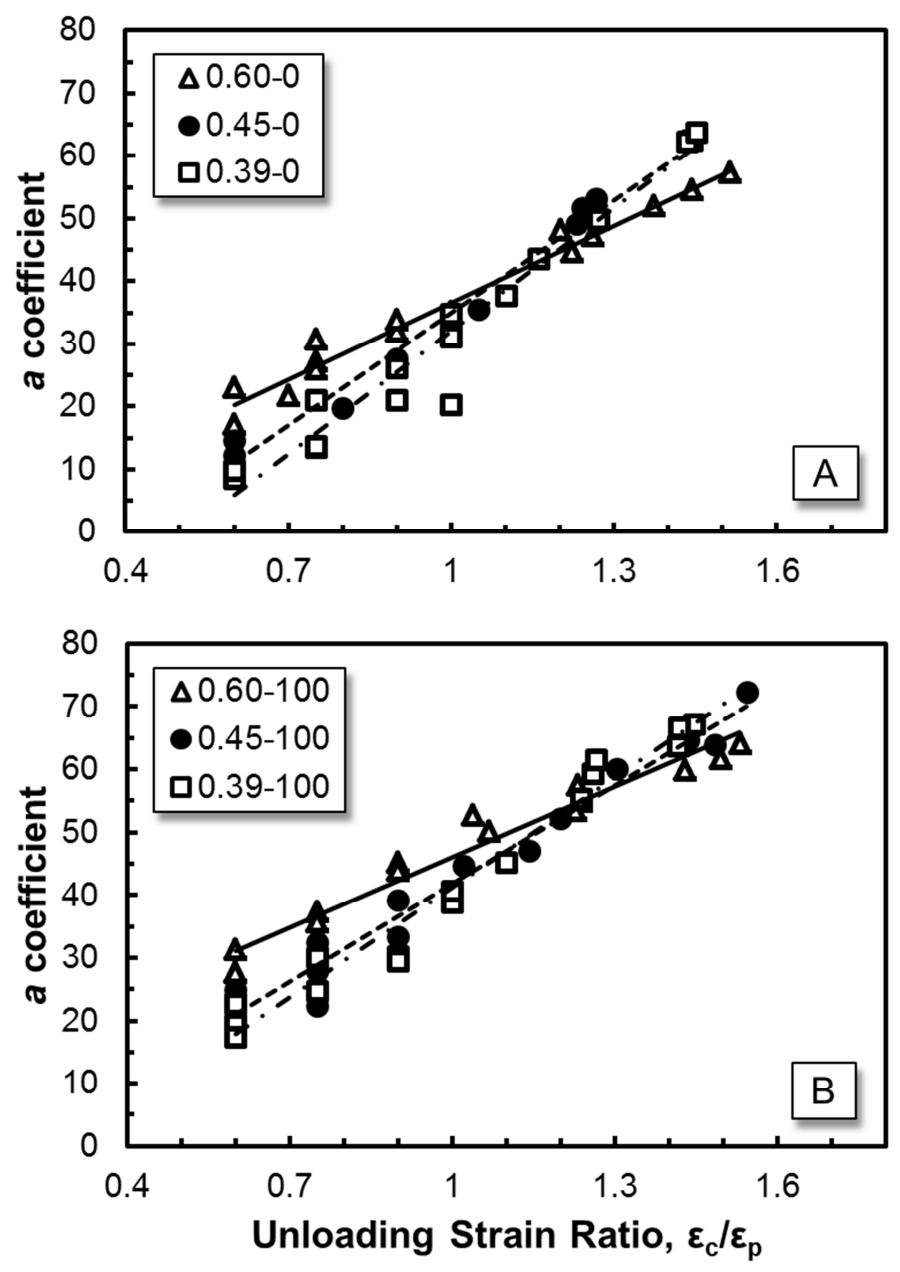

Figure C 1 - Comparison of stiffness degradation with varying w/c ratio: (A) natural aggregate and $(B)$ recycled concrete aggregate 

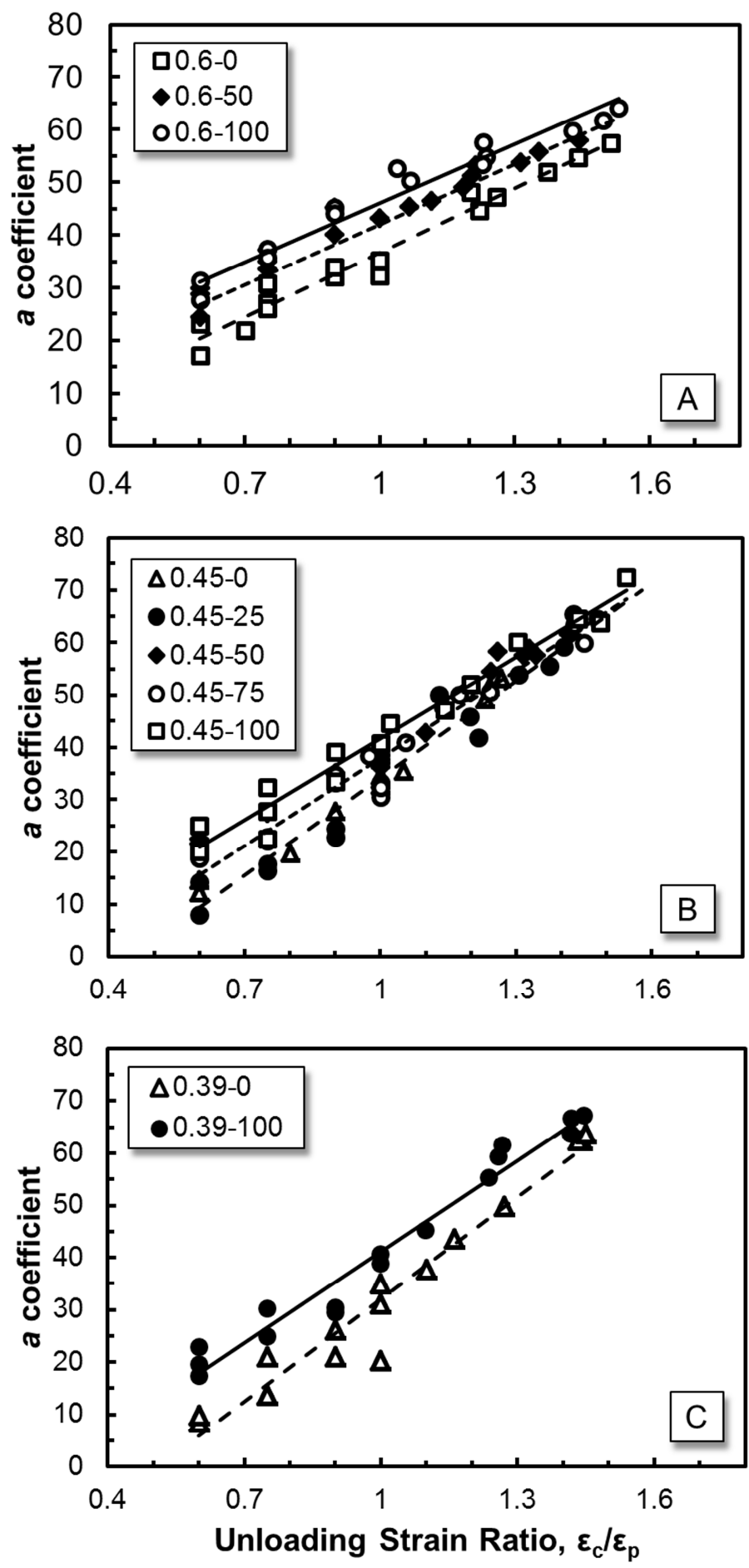

Figure $\mathbf{C} 2$ - Comparison of stiffness degradation with changing recycled concrete aggregate content. The w/c ratio remains the same within each graph. 


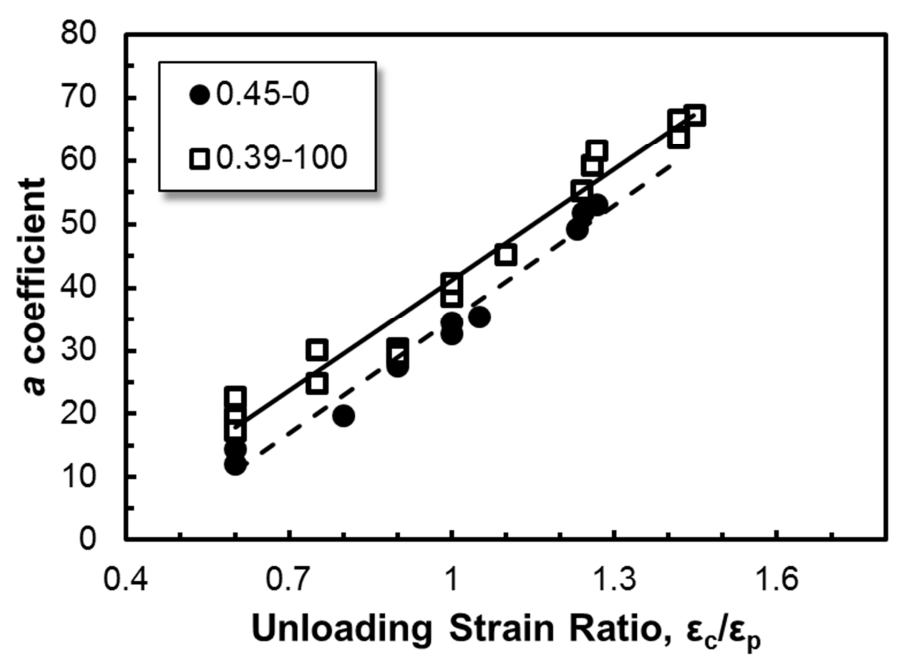

Figure C 3 - Stiffness degradation for concretes with the same strength but different aggregates. 


\section{Appendix D}

\section{Batch Records}

Batch records provide vital information regarding the properties of concrete and its constituents on the day of batching. Records are grouped by w/c ratio $(0.60,0.45$ and 0.39$)$ and, within each grouping, are listed consecutively from the batch containing the least recycled aggregate content to the batch with the most. Explanation of mixture designations can be found in section 2.2 . 


\begin{tabular}{|c|c|c|c|c|c|c|c|c|}
\hline Mix Designation: & $0.60-0$ & Cement & $12: 10$ & & & & & \\
\hline Date Cast: & 7/30/2010 & Time Cast: & 12:45 & & & & & \\
\hline & & & & & & Mixture $\mathrm{F}$ & portions & \\
\hline Material & Description & $\begin{array}{l}\text { Specific } \\
\text { Gravity }\end{array}$ & Absorption & $\begin{array}{c}\text { Moisture } \\
\text { Content }\end{array}$ & $\begin{array}{l}\text { Stock WTS } \\
\text { (lbs/batch) }\end{array}$ & $\begin{array}{c}\text { Stock WTS } \\
\left(\mathrm{lbs}^{\prime} / \mathrm{yd}^{3}\right)\end{array}$ & $\begin{array}{c}\text { SSD WTS } \\
\left(\mathrm{lbs} / \mathrm{yd}^{3}\right)\end{array}$ & $\begin{array}{c}\text { ABS Volume } \\
\left(\mathrm{ft}^{3} / \mathrm{yd}^{3}\right)\end{array}$ \\
\hline Cement & Portland Type II/V & 3.15 & $\mathrm{~N} / \mathrm{A}$ & $\mathrm{N} / \mathrm{A}$ & 52.0 & 532 & 532 & 2.707 \\
\hline Water & & 1.00 & $\mathrm{~N} / \mathrm{A}$ & $\mathrm{N} / \mathrm{A}$ & 30.6 & 313 & 319 & 5.115 \\
\hline Coarse Aggregates & Santa Margarita 1"x\#4 & 2.61 & $1.4 \%$ & $0.3 \%$ & 155.3 & 1589 & 1606 & 9.860 \\
\hline Recycled Concrete & San Diego & 2.47 & $4.9 \%$ & $0.0 \%$ & 0.0 & 0 & 0 & 0.000 \\
\hline Fine Aggregates & Sisquoc C33 Sand & 2.56 & $2.2 \%$ & $3.9 \%$ & 135.3 & 1384 & 1361 & 8.519 \\
\hline Air Content, Non-air- & trained (Entrapped) & $\mathrm{N} / \mathrm{A}$ & $\mathrm{N} / \mathrm{A}$ & $\mathrm{N} / \mathrm{A}$ & $\mathrm{N} / \mathrm{A}$ & $\mathrm{N} / \mathrm{A}$ & $\mathrm{N} / \mathrm{A}$ & 0.799 \\
\hline Total & & & & & 373 & 3818 & 3818 & 27.000 \\
\hline Superplasticizer & W.R. Grace ADVA 100 & & & & 25 & $\mathrm{ml} / \mathrm{batch}$ & 8.6 & $\mathrm{oz} / \mathrm{yd}^{3}$ \\
\hline Temperature $\left({ }^{\circ} \mathrm{F}\right)$ : & & 73.0 & & & & Moisture & ontents & \\
\hline Slump (inches): & & 6.000 & & & & Sant. Marg. & SD RCA & Sand \\
\hline Unit Weight $\left(\mathrm{lbs} / \mathrm{ft}^{3}\right)$ : & & 141.4 & & & Pan (g.) & 634.7 & 1 & 555.4 \\
\hline Air Content, Pressur & Method (\%): & $\mathrm{N} / \mathrm{A}$ & & & Pan+Stock (g.) & 4747.4 & 100 & 5203.4 \\
\hline Air Content, Volume & Method (\%): & $3.0 \%$ & & & Pan+OD (g.) & 4734.8 & 100 & 5027.7 \\
\hline Batch Size $\left(\mathrm{ft}^{3}\right)$ : & & 2.639 & & & M.C. (\%) & $0.3 \%$ & $0.0 \%$ & $3.9 \%$ \\
\hline
\end{tabular}




\begin{tabular}{|c|c|c|c|c|c|c|c|c|}
\hline Mix Designation: & $0.60-50$ & Cement & $10: 40$ & & & & & \\
\hline Date Cast: & $8 / 13 / 2010$ & Time Cast: & $11: 20$ & & & & & \\
\hline & & & & & \multicolumn{4}{|c|}{ Mixture Proportions } \\
\hline Material & Description & $\begin{array}{l}\text { Specific } \\
\text { Gravity }\end{array}$ & Absorption & $\begin{array}{c}\text { Moisture } \\
\text { Content } \\
\end{array}$ & $\begin{array}{l}\text { Stock WTS } \\
\text { (lbs/batch) }\end{array}$ & 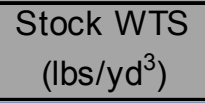 & $\begin{array}{c}\text { SSD WTS } \\
\left({\left.\mathrm{lbs} / \mathrm{yd}^{3}\right)}\right.\end{array}$ & $\begin{array}{c}\text { ABS Volume } \\
\left(\mathrm{ft}^{3} / \mathrm{yd}^{3}\right)\end{array}$ \\
\hline Cement & Portland Type II/V & 3.15 & $\mathrm{~N} / \mathrm{A}$ & $\mathrm{N} / \mathrm{A}$ & 34.0 & 541 & 541 & 2.753 \\
\hline Water & & 1.00 & $\mathrm{~N} / \mathrm{A}$ & $\mathrm{N} / \mathrm{A}$ & 20.0 & 318 & 325 & 5.203 \\
\hline Coarse Aggregates & Santa Margarita 1"x\#4 & 2.61 & $1.4 \%$ & $2.1 \%$ & 51.7 & 822 & 817 & 5.015 \\
\hline Recycled Concrete & San Diego & 2.47 & $4.9 \%$ & $1.6 \%$ & 47.0 & 748 & 773 & 5.015 \\
\hline Fine Aggregates & Sisquoc C33 Sand & 2.56 & $2.2 \%$ & $4.1 \%$ & 88.6 & 1410 & 1384 & 8.665 \\
\hline \multicolumn{2}{|c|}{ Air Content, Non-air-entrained (Entrapped) } & $\mathrm{N} / \mathrm{A}$ & $\mathrm{N} / \mathrm{A}$ & $\mathrm{N} / \mathrm{A}$ & $\mathrm{N} / \mathrm{A}$ & $\mathrm{N} / \mathrm{A}$ & $\mathrm{N} / \mathrm{A}$ & 0.349 \\
\hline Total & & & & & 241 & 3840 & 3840 & 27.000 \\
\hline Superplasticizer & W.R. Grace ADVA 100 & & & & \multicolumn{2}{|r|}{$\mathrm{ml} / \mathrm{batch}$} & \multicolumn{2}{|r|}{$\mathrm{oz} / \mathrm{yd}^{3}$} \\
\hline \multicolumn{2}{|l|}{ Temperature $\left({ }^{\circ} \mathrm{F}\right)$ : } & 66.0 & & & \multicolumn{4}{|c|}{ Moisture Contents } \\
\hline \multicolumn{2}{|l|}{ Slump (inches): } & 5.500 & & & & Sant. Marg. & SD RCA & Sand \\
\hline \multicolumn{2}{|l|}{ Unit Weight $\left(\mathrm{lbs} / \mathrm{ft}^{3}\right)$ : } & 142.2 & & & Pan (g.) & 634.7 & 555.1 & 636.6 \\
\hline \multicolumn{2}{|c|}{ Air Content, Pressure Method (\%): } & $\mathrm{N} / \mathrm{A}$ & & & Pan+Stock (g.) & 3715.1 & 4619.6 & 4706.6 \\
\hline \multicolumn{2}{|c|}{ Air Content, Volumetric Method (\%): } & $1.3 \%$ & & & Pan+OD (g.) & 3651.3 & 4556.5 & 4546.2 \\
\hline \multicolumn{2}{|l|}{ Batch Size $\left(\mathrm{ft}^{3}\right)$ : } & 1.696 & & & M.C. $(\%)$ & $2.1 \%$ & $1.6 \%$ & $4.1 \%$ \\
\hline
\end{tabular}




\begin{tabular}{|c|c|c|c|c|c|c|c|c|}
\hline Mix Designation: & $0.60-100$ & Cement & $9: 55$ & & & & & \\
\hline Date Cast: & 8/6/2010 & Time Cast: & 10:30 & & & & & \\
\hline & & & & & \multicolumn{4}{|c|}{ Mixture Proportions } \\
\hline Material & Description & $\begin{array}{l}\text { Specific } \\
\text { Gravity }\end{array}$ & Absorption & $\begin{array}{c}\text { Moisture } \\
\text { Content }\end{array}$ & $\begin{array}{l}\text { Stock WTS } \\
\text { (lbs/batch) }\end{array}$ & 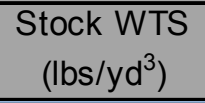 & $\begin{array}{c}\text { SSD WTS } \\
\left({\left.\mathrm{lbs} / \mathrm{yd}^{3}\right)}\right.\end{array}$ & $\begin{array}{c}\text { ABS Volume } \\
\left(\mathrm{ft}^{3} / \mathrm{yd}^{3}\right)\end{array}$ \\
\hline Cement & Portland Type II/V & 3.15 & $\mathrm{~N} / \mathrm{A}$ & $\mathrm{N} / \mathrm{A}$ & 52.0 & 539 & 539 & 2.744 \\
\hline Water & & 1.00 & $\mathrm{~N} / \mathrm{A}$ & $\mathrm{N} / \mathrm{A}$ & 33.2 & 345 & 324 & 5.186 \\
\hline Coarse Aggregates & Santa Margarita 1"x\#4 & 2.61 & $1.4 \%$ & $0.0 \%$ & 0.0 & 0 & 0 & 0.000 \\
\hline Recycled Concrete & San Diego & 2.47 & $4.9 \%$ & $1.9 \%$ & 144.3 & 1496 & 1541 & 9.996 \\
\hline Fine Aggregates & Sisquoc C33 Sand & 2.56 & $2.2 \%$ & $3.9 \%$ & 135.3 & 1403 & 1380 & 8.637 \\
\hline \multicolumn{2}{|c|}{ Air Content, Non-air-entrained (Entrapped) } & $\mathrm{N} / \mathrm{A}$ & $\mathrm{N} / \mathrm{A}$ & $\mathrm{N} / \mathrm{A}$ & $\mathrm{N} / \mathrm{A}$ & $\mathrm{N} / \mathrm{A}$ & $\mathrm{N} / \mathrm{A}$ & 0.438 \\
\hline Total & & & & & 365 & 3783 & 3783 & 27.000 \\
\hline Superplasticizer & W.R. Grace ADVA 100 & & & & \multicolumn{2}{|r|}{$\mathrm{ml} / \mathrm{batch}$} & \multicolumn{2}{|r|}{$\mathrm{oz} / \mathrm{yd}^{3}$} \\
\hline \multicolumn{2}{|l|}{ Temperature $\left({ }^{\circ} \mathrm{F}\right)$ : } & 63.3 & & & \multicolumn{4}{|c|}{ Moisture Contents } \\
\hline \multicolumn{2}{|l|}{ Slump (inches): } & 7.250 & & & & Sant. Marg. & SD RCA & Sand \\
\hline \multicolumn{2}{|l|}{ Unit Weight $\left(\mathrm{lbs} / \mathrm{ft}^{3}\right)$ : } & 140.1 & & & Pan (g.) & 0 & 555.4 & 634.7 \\
\hline \multicolumn{2}{|c|}{ Air Content, Pressure Method (\%): } & $\mathrm{N} / \mathrm{A}$ & & & Pan+Stock (g.) & 1 & 5722.9 & 3204.5 \\
\hline \multicolumn{2}{|c|}{ Air Content, Volumetric Method (\%): } & $1.6 \%$ & & & Pan+OD (g.) & 1 & 5627.1 & 3107.4 \\
\hline \multicolumn{2}{|l|}{ Batch Size $\left(\mathrm{ft}^{3}\right)$ : } & 2.603 & & & M.C. $(\%)$ & $0.0 \%$ & $1.9 \%$ & $3.9 \%$ \\
\hline
\end{tabular}




\begin{tabular}{|c|c|c|c|c|c|c|c|c|}
\hline Mix Designation: & $0.45-0$ & Cement & $11: 30$ & & & & & \\
\hline Date Cast: & 6/22/2010 & Time Cast: & $12: 30$ & & & & & \\
\hline & & & & & \multicolumn{4}{|c|}{ Mixture Proportions } \\
\hline Material & Description & $\begin{array}{l}\text { Specific } \\
\text { Gravity }\end{array}$ & Absorption & $\begin{array}{c}\text { Moisture } \\
\text { Content }\end{array}$ & $\begin{array}{l}\text { Stock WTS } \\
\text { (lbs/batch) }\end{array}$ & 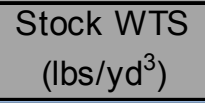 & $\begin{array}{c}\text { SSD WTS } \\
\left({\left.\mathrm{lbs} / \mathrm{yd}^{3}\right)}\right.\end{array}$ & $\begin{array}{c}\text { ABS Volume } \\
\left(\mathrm{ft}^{3} / \mathrm{yd}^{3}\right)\end{array}$ \\
\hline Cement & Colton Type II/V & 3.15 & $\mathrm{~N} / \mathrm{A}$ & $\mathrm{N} / \mathrm{A}$ & 80.0 & 717 & 717 & 3.647 \\
\hline Water & & 1.00 & $\mathrm{~N} / \mathrm{A}$ & $\mathrm{N} / \mathrm{A}$ & 32.9 & 295 & 323 & 5.175 \\
\hline Coarse Aggregates & Santa Margarita 1"x\#4 & 2.61 & $1.4 \%$ & $0.3 \%$ & 179.2 & 1606 & 1623 & 9.966 \\
\hline Recycled Concrete & San Diego & 2.47 & $4.9 \%$ & $0.0 \%$ & 0.0 & 0 & 0 & 0.000 \\
\hline Fine Aggregates & Sisquoc C33 Sand & 2.56 & $2.2 \%$ & $6.0 \%$ & 142.3 & 1275 & 1230 & 7.699 \\
\hline \multicolumn{2}{|c|}{ Air Content, Non-air-entrained (Entrapped) } & $\mathrm{N} / \mathrm{A}$ & $\mathrm{N} / \mathrm{A}$ & $\mathrm{N} / \mathrm{A}$ & $\mathrm{N} / \mathrm{A}$ & $\mathrm{N} / \mathrm{A}$ & $\mathrm{N} / \mathrm{A}$ & 0.513 \\
\hline Total & & & & & 434 & 3893 & 3893 & 27.000 \\
\hline Superplasticizer & W.R. Grace ADVA 100 & & & & \multicolumn{2}{|r|}{$\mathrm{ml} / \mathrm{batch}$} & \multicolumn{2}{|r|}{$\mathrm{oz} / \mathrm{yd}^{3}$} \\
\hline \multicolumn{2}{|l|}{ Temperature $\left({ }^{\circ} \mathrm{F}\right)$ : } & 70.0 & & & \multicolumn{4}{|c|}{ Moisture Contents } \\
\hline \multicolumn{2}{|l|}{ Slump (inches): } & 6.500 & & & & Sant. Marg. & SD RCA & Sand \\
\hline \multicolumn{2}{|l|}{ Unit Weight $\left(\mathrm{lbs} / \mathrm{ft}^{3}\right)$ : } & 144.2 & & & Pan (g.) & 639 & 0 & 633 \\
\hline \multicolumn{2}{|c|}{ Air Content, Pressure Method (\%): } & $\mathrm{N} / \mathrm{A}$ & & & Pan+Stock (g.) & 4352 & 100 & 3688 \\
\hline \multicolumn{2}{|c|}{ Air Content, Volumetric Method (\%): } & $1.9 \%$ & & & Pan+OD (g.) & 4340 & 100 & 3516 \\
\hline \multicolumn{2}{|l|}{ Batch Size $\left(\mathrm{ft}^{3}\right)$ : } & 3.013 & & & M.C. $(\%)$ & $0.3 \%$ & $0.0 \%$ & $6.0 \%$ \\
\hline
\end{tabular}




\begin{tabular}{|c|c|c|c|c|c|c|c|c|}
\hline Mix Designation: & $0.45-25$ & Cement & - & & & & & \\
\hline Date Cast: & | $7 / 2 / 2010$ & Time Cast: & $10: 45$ & & & & & \\
\hline & & & & & \multicolumn{4}{|c|}{ Mixture Proportions } \\
\hline Material & Description & $\begin{array}{l}\text { Specific } \\
\text { Gravity }\end{array}$ & Absorption & $\begin{array}{c}\text { Moisture } \\
\text { Content }\end{array}$ & $\begin{array}{l}\text { Stock WTS } \\
\text { (lbs/batch) }\end{array}$ & $\begin{array}{c}\text { Stock WTS } \\
\left({ }^{\prime l b s} / \mathrm{yd}^{3}\right)\end{array}$ & $\begin{array}{c}\text { SSD WTS } \\
\left(\mathrm{lbs} / \mathrm{yd}^{3}\right)\end{array}$ & $\begin{array}{c}\text { ABS Volume } \\
\left(\mathrm{ft}^{3} / \mathrm{yd}^{3}\right)\end{array}$ \\
\hline Cement & Colton Type II/V & 3.15 & N/A & $\mathrm{N} / \mathrm{A}$ & 42.7 & 724 & 724 & 3.682 \\
\hline Water & & 1.00 & N/A & $\mathrm{N} / \mathrm{A}$ & 18.8 & 318 & 326 & 5.219 \\
\hline Coarse Aggregates & Santa Margarita 1"x\#4 & 2.61 & $1.4 \%$ & $0.3 \%$ & 71.7 & 1215 & 1229 & 7.544 \\
\hline Recycled Concrete & San Diego & 2.47 & $4.9 \%$ & $2.4 \%$ & 22.3 & 378 & 388 & 2.515 \\
\hline Fine Aggregates & Sisquoc C33 Sand & 2.56 & $2.2 \%$ & $4.7 \%$ & 75.0 & 1271 & 1241 & 7.771 \\
\hline \multicolumn{2}{|c|}{ Air Content, Non-air-entrained (Entrapped) } & $\mathrm{N} / \mathrm{A}$ & $\mathrm{N} / \mathrm{A}$ & $\mathrm{N} / \mathrm{A}$ & N/A & $\mathrm{N} / \mathrm{A}$ & N/A & 0.270 \\
\hline Total & & & & & 230 & 3907 & 3907 & 27.000 \\
\hline Superplasticizer & W.R. Grace ADVA 100 & & & & \multicolumn{2}{|r|}{$\mathrm{ml} / \mathrm{batch}$} & \multicolumn{2}{|r|}{$\mathrm{oz} / \mathrm{yd} \mathrm{d}^{3}$} \\
\hline \multicolumn{2}{|l|}{ Temperature $\left({ }^{\circ} \mathrm{F}\right)$ : } & 66.0 & & & \multicolumn{4}{|c|}{ Moisture Contents } \\
\hline \multicolumn{2}{|l|}{ Slump (inches): } & 6.250 & & & & Sant. Marg. & SD RCA & Sand \\
\hline \multicolumn{2}{|l|}{ Unit Weight $\left(\mathrm{lbs} / \mathrm{ft}^{3}\right)$ : } & 144.7 & & & Pan (g.) & 633.4 & 636 & 633.5 \\
\hline \multicolumn{2}{|c|}{ Air Content, Pressure Method (\%): } & $\mathrm{N} / \mathrm{A}$ & & & Pan+Stock (g.) & 5462.8 & 3325.8 & 4803.7 \\
\hline \multicolumn{2}{|c|}{ Air Content, Volumetric Method (\%): } & $1.0 \%$ & & & Pan+OD (g.) & 5448.6 & 3262.7 & 4617.7 \\
\hline \multicolumn{2}{|l|}{ Batch Size $\left(\mathrm{ft}^{3}\right)$ : } & 1.592 & & & M.C. $(\%)$ & $0.3 \%$ & $2.4 \%$ & $4.7 \%$ \\
\hline
\end{tabular}




\begin{tabular}{|c|c|c|c|c|c|c|c|c|}
\hline Mix Designation: & $0.45-50$ & Cement & 10:10 & & & & & \\
\hline Date Cast: & |7/9/2010 & Time Cast: & 10:40 & & & & & \\
\hline & & & & & \multicolumn{4}{|c|}{ Mixture Proportions } \\
\hline Material & Description & $\begin{array}{l}\text { Specific } \\
\text { Gravity }\end{array}$ & Absorption & $\begin{array}{c}\text { Moisture } \\
\text { Content } \\
\end{array}$ & $\begin{array}{l}\text { Stock WTS } \\
\text { (lbs/batch) }\end{array}$ & 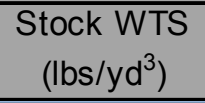 & $\begin{array}{c}\text { SSD WTS } \\
\left({\left.\mathrm{lbs} / \mathrm{yd}^{3}\right)}\right.\end{array}$ & $\begin{array}{c}\text { ABS Volume } \\
\left(\mathrm{ft}^{3} / \mathrm{yd}^{3}\right)\end{array}$ \\
\hline Cement & Colton Type II/V & 3.15 & $\mathrm{~N} / \mathrm{A}$ & $\mathrm{N} / \mathrm{A}$ & 80.0 & 713 & 713 & 3.629 \\
\hline Water & & 1.00 & $\mathrm{~N} / \mathrm{A}$ & $\mathrm{N} / \mathrm{A}$ & 37.0 & 330 & 321 & 5.145 \\
\hline Coarse Aggregates & Santa Margarita 1"x\#4 & 2.61 & $1.4 \%$ & $0.3 \%$ & 89.6 & 799 & 808 & 4.958 \\
\hline Recycled Concrete & San Diego & 2.47 & $4.9 \%$ & $1.8 \%$ & 83.2 & 742 & 764 & 4.958 \\
\hline Fine Aggregates & Sisquoc C33 Sand & 2.56 & $2.2 \%$ & $4.0 \%$ & 139.7 & 1246 & 1224 & 7.660 \\
\hline \multicolumn{2}{|c|}{ Air Content, Non-air-entrained (Entrapped) } & $\mathrm{N} / \mathrm{A}$ & $\mathrm{N} / \mathrm{A}$ & $\mathrm{N} / \mathrm{A}$ & $\mathrm{N} / \mathrm{A}$ & $\mathrm{N} / \mathrm{A}$ & $\mathrm{N} / \mathrm{A}$ & 0.649 \\
\hline Total & & & & & 429 & 3830 & 3830 & 27.000 \\
\hline Superplasticizer & W.R. Grace ADVA 100 & & & & \multicolumn{2}{|r|}{$\mathrm{ml} / \mathrm{batch}$} & \multicolumn{2}{|r|}{$\mathrm{oz} / \mathrm{yd}^{3}$} \\
\hline \multicolumn{2}{|l|}{ Temperature $\left({ }^{\circ} \mathrm{F}\right)$ : } & 64.0 & & & \multicolumn{4}{|c|}{ Moisture Contents } \\
\hline \multicolumn{2}{|l|}{ Slump (inches): } & 8.000 & & & & Sant. Marg. & SD RCA & Sand \\
\hline \multicolumn{2}{|l|}{ Unit Weight $\left(\mathrm{lbs} / \mathrm{ft}^{3}\right)$ : } & 141.8 & & & Pan (g.) & 632 & 633.6 & 633.4 \\
\hline \multicolumn{2}{|c|}{ Air Content, Pressure Method (\%): } & $\mathrm{N} / \mathrm{A}$ & & & Pan+Stock (g.) & 5204.4 & 3993.8 & 4617.5 \\
\hline \multicolumn{2}{|c|}{ Air Content, Volumetric Method (\%): } & $2.4 \%$ & & & Pan+OD (g.) & 5191.3 & 3933 & 4463.2 \\
\hline \multicolumn{2}{|l|}{ Batch Size $\left(\mathrm{ft}^{3}\right)$ : } & 3.028 & & & M.C. $(\%)$ & $0.3 \%$ & $1.8 \%$ & $4.0 \%$ \\
\hline
\end{tabular}




\begin{tabular}{|c|c|c|c|c|c|c|c|c|}
\hline Mix Designation: & $0.45-75$ & Cement & 10:10 & & & & & \\
\hline Date Cast: & |7/23/2010 & Time Cast: & 10:40 & & & & & \\
\hline & & & & & \multicolumn{4}{|c|}{ Mixture Proportions } \\
\hline Material & Description & $\begin{array}{l}\text { Specific } \\
\text { Gravity }\end{array}$ & Absorption & $\begin{array}{c}\text { Moisture } \\
\text { Content } \\
\end{array}$ & $\begin{array}{l}\text { Stock WTS } \\
\text { (lbs/batch) }\end{array}$ & 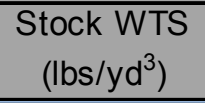 & $\begin{array}{c}\text { SSD WTS } \\
\left({\left.\mathrm{lbs} / \mathrm{yd}^{3}\right)}\right.\end{array}$ & $\begin{array}{c}\text { ABS Volume } \\
\left(\mathrm{ft}^{3} / \mathrm{yd}^{3}\right)\end{array}$ \\
\hline Cement & Portland Type II/V & 3.15 & $\mathrm{~N} / \mathrm{A}$ & $\mathrm{N} / \mathrm{A}$ & 45.3 & 720 & 720 & 3.665 \\
\hline Water & & 1.00 & $\mathrm{~N} / \mathrm{A}$ & $\mathrm{N} / \mathrm{A}$ & 20.9 & 331 & 324 & 5.194 \\
\hline Coarse Aggregates & Santa Margarita 1"x\#4 & 2.61 & $1.4 \%$ & $0.3 \%$ & 25.4 & 403 & 408 & 2.503 \\
\hline Recycled Concrete & San Diego & 2.47 & $4.9 \%$ & $2.1 \%$ & 70.9 & 1127 & 1157 & 7.509 \\
\hline Fine Aggregates & Sisquoc C33 Sand & 2.56 & $2.2 \%$ & $4.5 \%$ & 79.5 & 1263 & 1236 & 7.735 \\
\hline \multicolumn{2}{|c|}{ Air Content, Non-air-entrained (Entrapped) } & $\mathrm{N} / \mathrm{A}$ & $\mathrm{N} / \mathrm{A}$ & $\mathrm{N} / \mathrm{A}$ & $\mathrm{N} / \mathrm{A}$ & $\mathrm{N} / \mathrm{A}$ & $\mathrm{N} / \mathrm{A}$ & 0.394 \\
\hline Total & & & & & 242 & 3845 & 3845 & 27.000 \\
\hline Superplasticizer & W.R. Grace ADVA 100 & & & & \multicolumn{2}{|r|}{$\mathrm{ml} / \mathrm{batch}$} & \multicolumn{2}{|r|}{$\mathrm{oz} / \mathrm{yd}^{3}$} \\
\hline \multicolumn{2}{|l|}{ Temperature $\left({ }^{\circ} \mathrm{F}\right)$ : } & 66.0 & & & \multicolumn{4}{|c|}{ Moisture Contents } \\
\hline \multicolumn{2}{|l|}{ Slump (inches): } & 6.000 & & & & Sant. Marg. & SD RCA & Sand \\
\hline \multicolumn{2}{|l|}{ Unit Weight $\left(\mathrm{lbs} / \mathrm{ft}^{3}\right)$ : } & 142.4 & & & Pan (g.) & 634.7 & 634.3 & 555.4 \\
\hline \multicolumn{2}{|c|}{ Air Content, Pressure Method (\%): } & $\mathrm{N} / \mathrm{A}$ & & & Pan+Stock (g.) & 4280.5 & 3591.5 & 3152.3 \\
\hline \multicolumn{2}{|c|}{ Air Content, Volumetric Method (\%): } & $1.5 \%$ & & & Pan+OD (g.) & 4269.1 & 3530 & 3040.7 \\
\hline \multicolumn{2}{|l|}{ Batch Size $\left(\mathrm{ft}^{3}\right)$ : } & 1.699 & & & M.C. $(\%)$ & $0.3 \%$ & $2.1 \%$ & $4.5 \%$ \\
\hline
\end{tabular}




\begin{tabular}{|c|c|c|c|c|c|c|c|c|}
\hline Mix Designation: & $0.45-100$ & Cement & $10: 45$ & & & & & \\
\hline Date Cast: & |7/16/2010 & Time Cast: & 11:45 & & & & & \\
\hline & & & & & \multicolumn{4}{|c|}{ Mixture Proportions } \\
\hline Material & Description & $\begin{array}{l}\text { Specific } \\
\text { Gravity }\end{array}$ & Absorption & $\begin{array}{c}\text { Moisture } \\
\text { Content }\end{array}$ & $\begin{array}{l}\text { Stock WTS } \\
\text { (lbs/batch) }\end{array}$ & $\begin{array}{c}\text { Stock WTS } \\
\left({\left.\mathrm{lbs} / \mathrm{yd} \mathrm{d}^{3}\right)}\right.\end{array}$ & 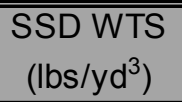 & $\begin{array}{c}\text { ABS Volume } \\
\left(\mathrm{ft}^{3} / \mathrm{yd}^{3}\right)\end{array}$ \\
\hline Cement & Portland Type II/V & 3.15 & $\mathrm{~N} / \mathrm{A}$ & $\mathrm{N} / \mathrm{A}$ & 69.3 & 718 & 718 & 3.654 \\
\hline Water & & 1.00 & $\mathrm{~N} / \mathrm{A}$ & $\mathrm{N} / \mathrm{A}$ & 33.1 & 343 & 323 & 5.180 \\
\hline Coarse Aggregates & Santa Margarita 1"x\#4 & 2.61 & $1.4 \%$ & $0.3 \%$ & 0.0 & 0 & 0 & 0.000 \\
\hline Recycled Concrete & San Diego & 2.47 & $4.9 \%$ & $2.1 \%$ & 144.5 & 1497 & 1539 & 9.985 \\
\hline Fine Aggregates & Sisquoc C33 Sand & 2.56 & $2.2 \%$ & $4.0 \%$ & 121.0 & 1254 & 1232 & 7.713 \\
\hline \multicolumn{2}{|c|}{ Air Content, Non-air-entrained (Entrapped) } & $\mathrm{N} / \mathrm{A}$ & $\mathrm{N} / \mathrm{A}$ & $\mathrm{N} / \mathrm{A}$ & $\mathrm{N} / \mathrm{A}$ & $\mathrm{N} / \mathrm{A}$ & $\mathrm{N} / \mathrm{A}$ & 0.468 \\
\hline Total & & & & & 368 & 3813 & 3813 & 27.000 \\
\hline Superplasticizer & W.R. Grace ADVA 100 & & & & \multicolumn{2}{|r|}{$\mathrm{ml} / \mathrm{batch}$} & \multicolumn{2}{|r|}{$\mathrm{oz} / \mathrm{yd} \mathrm{d}^{3}$} \\
\hline \multicolumn{2}{|l|}{ Temperature $\left({ }^{\circ} \mathrm{F}\right)$ : } & 64.5 & & & \multicolumn{4}{|c|}{ Moisture Contents } \\
\hline \multicolumn{2}{|l|}{ Slump (inches): } & 6.000 & & & & Sant. Marg. & SD RCA & Sand \\
\hline \multicolumn{2}{|l|}{ Unit Weight $\left(\mathrm{lbs} / \mathrm{ft}^{3}\right)$ : } & 141.2 & & & Pan (g.) & 632 & 555.3 & 634.7 \\
\hline \multicolumn{2}{|c|}{ Air Content, Pressure Method (\%): } & $\mathrm{N} / \mathrm{A}$ & & & Pan+Stock (g.) & 5204.4 & 4203.7 & 3181.2 \\
\hline \multicolumn{2}{|c|}{ Air Content, Volumetric Method (\%): } & $1.7 \%$ & & & Pan+OD (g.) & 5191.3 & 4129.9 & 3083.1 \\
\hline \multicolumn{2}{|l|}{ Batch Size $\left(\mathrm{ft}^{3}\right)$ : } & 2.606 & & & M.C. $(\%)$ & $0.3 \%$ & $2.1 \%$ & $4.0 \%$ \\
\hline
\end{tabular}




\begin{tabular}{|c|c|c|c|c|c|c|c|c|}
\hline Mix Designation: & $0.39-0$ & Cement & $9: 28$ & & & & & \\
\hline Date Cast: & $11 / 22 / 2010$ & Time Cast: & 10:05 & & & & & \\
\hline & & & & & & Mixture & portions & \\
\hline Material & Description & $\begin{array}{l}\text { Specific } \\
\text { Gravity }\end{array}$ & Absorption & $\begin{array}{l}\text { Moisture } \\
\text { Content }\end{array}$ & $\begin{array}{l}\text { Stock WTS } \\
\text { (lbs/batch) }\end{array}$ & 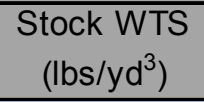 & $\begin{array}{c}\text { SSD WTS } \\
\left(\mathrm{lbs} / \mathrm{yd}^{3}\right)\end{array}$ & $\begin{array}{c}\text { ABS Volume } \\
\left(\mathrm{ft}^{3} / \mathrm{yd}^{3}\right)\end{array}$ \\
\hline Cement & Portland Type II/V & 3.15 & $\mathrm{~N} / \mathrm{A}$ & $\mathrm{N} / \mathrm{A}$ & 52.3 & 833 & 833 & 4.236 \\
\hline Water & & 1.00 & $\mathrm{~N} / \mathrm{A}$ & N/A & 15.0 & 239 & 325 & 5.204 \\
\hline Coarse Aggregates & Santa Margarita 1"x\#4 & 2.61 & $1.4 \%$ & $2.4 \%$ & 103.6 & 1650 & 1634 & 10.030 \\
\hline Recycled Concrete & San Diego & 2.47 & $4.9 \%$ & $0.0 \%$ & 0.0 & 0 & 0 & 0.000 \\
\hline Fine Aggregates & Sisquoc C33 Sand & 2.56 & $2.2 \%$ & $8.4 \%$ & 76.5 & 1217 & 1147 & 7.183 \\
\hline Air Content, Non-air- & rained (Entrapped) & $\mathrm{N} / \mathrm{A}$ & $\mathrm{N} / \mathrm{A}$ & $\mathrm{N} / \mathrm{A}$ & $\mathrm{N} / \mathrm{A}$ & $\mathrm{N} / \mathrm{A}$ & $\mathrm{N} / \mathrm{A}$ & 0.347 \\
\hline Total & & & & & 247 & 3938 & 3938 & 27.000 \\
\hline Superplasticizer & W.R. Grace ADVA 100 & & & & 77 & $\mathrm{ml} / \mathrm{batch}$ & 41.4 & $\mathrm{oz} / \mathrm{yd}^{3}$ \\
\hline Temperature $\left({ }^{\circ} \mathrm{F}\right)$ : & & 56.0 & & & & Moistur & ontents & \\
\hline Slump (inches): & & 8.250 & & & & Sant. Marg. & SD RCA & Sand \\
\hline Unit Weight $\left(\mathrm{lbs} / \mathrm{ft}^{3}\right)$ : & & 145.9 & & & Pan (g.) & 693.7 & 1 & 631.8 \\
\hline Air Content, Pressur & Method (\%): & $\mathrm{N} / \mathrm{A}$ & & & Pan+Stock (g.) & 5855.2 & 100 & 3484.8 \\
\hline Air Content, Volumet & Method (\%): & $1.3 \%$ & & & Pan+OD (g.) & 5733.9 & 100 & 3263.8 \\
\hline Batch Size $\left(\mathrm{ft}^{3}\right)$ : & & 1.696 & & & M.C. (\%) & $2.4 \%$ & $0.0 \%$ & $8.4 \%$ \\
\hline
\end{tabular}




\begin{tabular}{|c|c|c|c|c|c|c|c|c|}
\hline Mix Designation: & $0.39-100$ & Cement & $8: 30$ & & & & & \\
\hline Date Cast: & $1 / 10 / 2011$ & Time Cast: & $9: 15$ & & & & & \\
\hline & & & & & \multicolumn{4}{|c|}{ Mixture Proportions } \\
\hline Material & Description & $\begin{array}{l}\text { Specific } \\
\text { Gravity }\end{array}$ & Absorption & $\begin{array}{c}\text { Moisture } \\
\text { Content }\end{array}$ & $\begin{array}{l}\text { Stock WTS } \\
\text { (lbs/batch) }\end{array}$ & $\begin{array}{c}\text { Stock WTS } \\
\left(\mathrm{lbs} / \mathrm{yd}^{3}\right)\end{array}$ & 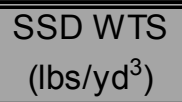 & $\begin{array}{c}\text { ABS Volume } \\
\left(\mathrm{ft}^{3} / \mathrm{yd}^{3}\right)\end{array}$ \\
\hline Cement & Portland Type II/V & 3.15 & $\mathrm{~N} / \mathrm{A}$ & $\mathrm{N} / \mathrm{A}$ & 52.3 & 832 & 832 & 4.234 \\
\hline Water & & 1.00 & $\mathrm{~N} / \mathrm{A}$ & $\mathrm{N} / \mathrm{A}$ & 20.2 & 322 & 325 & 5.202 \\
\hline Coarse Aggregates & Santa Margarita 1"x\#4 & 2.61 & $1.4 \%$ & $0.0 \%$ & 0.0 & 0 & 0 & 0.000 \\
\hline Recycled Concrete & San Diego & 2.47 & $4.9 \%$ & $1.4 \%$ & 93.9 & 1494 & 1545 & 10.027 \\
\hline Fine Aggregates & Sisquoc C33 Sand & 2.56 & $2.2 \%$ & $7.0 \%$ & 75.5 & 1201 & 1147 & 7.181 \\
\hline \multicolumn{2}{|c|}{ Air Content, Non-air-entrained (Entrapped) } & $\mathrm{N} / \mathrm{A}$ & $\mathrm{N} / \mathrm{A}$ & $\mathrm{N} / \mathrm{A}$ & $\mathrm{N} / \mathrm{A}$ & $\mathrm{N} / \mathrm{A}$ & $\mathrm{N} / \mathrm{A}$ & 0.356 \\
\hline Total & & & & & 242 & 3849 & 3849 & 27.000 \\
\hline Superplasticizer & W.R. Grace ADVA 100 & & & & \multicolumn{2}{|r|}{$\mathrm{ml} / \mathrm{batch}$} & \multicolumn{2}{|r|}{$\mathrm{oz} / \mathrm{yd}^{3}$} \\
\hline \multicolumn{2}{|l|}{ Temperature $\left({ }^{\circ} \mathrm{F}\right)$ : } & 49.0 & & & \multicolumn{4}{|c|}{ Moisture Contents } \\
\hline \multicolumn{2}{|l|}{ Slump (inches): } & 7.875 & & & & Sant. Marg. & SD RCA & Sand \\
\hline \multicolumn{2}{|l|}{ Unit Weight $\left(\mathrm{lbs} / \mathrm{ft}^{3}\right)$ : } & 142.6 & & & Pan (g.) & 0 & 630.4 & 693.7 \\
\hline \multicolumn{2}{|c|}{ Air Content, Pressure Method (\%): } & $\mathrm{N} / \mathrm{A}$ & & & Pan+Stock (g.) & 100 & 5353.9 & 4867.7 \\
\hline \multicolumn{2}{|c|}{ Air Content, Volumetric Method (\%): } & $1.3 \%$ & & & $\mathrm{Pan}+\mathrm{OD}$ (g.) & 100 & 5287.2 & 4595.3 \\
\hline \multicolumn{2}{|l|}{ Batch Size $\left(\mathrm{ft}^{3}\right)$ : } & 1.697 & & & M.C. $(\%)$ & $0.0 \%$ & $1.4 \%$ & $7.0 \%$ \\
\hline
\end{tabular}

